\title{
GIVE, AND IT SHALL BE GIVEN UNTO YOU? \\ THE EFFECTS OF CORPORATE PHILANTHROPY ON REPUTATION FOLLOWING NATURAL DISASTERS
}

BY

GUY BENNETT-LONGLEY

A thesis

submitted to the Victoria University of Wellington

in fulfilment of the requirements for the degree of

Master of Commerce

Victoria University of Wellington

2019 


\begin{abstract}
Conventional logic suggests that businesses should look inwards following natural disasters to ensure employee welfare, and minimise disruptions to operations. However, disasters afford the opportunity to administer corporate philanthropy to affected communities, providing a nonreciprocal gift of money or in-kind services. Philanthropic aid results in commercial benefits for firms, including strengthened financial performance, employee motivation, and reputation. While businesses are increasingly cognisant of their moral responsibilities, few studies examine consumer reactions to corporate philanthropy during a disaster. This research aims to address gaps in extant knowledge, examining the impact of non-reciprocal giving on consumer perceptions of corporate reputation. Further, it seeks to better understand the effect of consumer scepticism and ethnocentrism on evaluations of giving. Three studies were employed to satisfy the research objectives, utilising a between-subjects experimental design.
\end{abstract}

Study 1A manipulates types of corporate responses after the 2016 Kaikōura 7.8-magnitude earthquake (monetary, voluntary time, forgoing giving to recover internally), and measures consumer scepticism. The results demonstrate that monetary and employee time donations have an equivalent positive impact on perceptions of reputation. Forgoing philanthropy is viewed significantly worse, leading to negative evaluations of reputation. Low scepticism consumers assess reputation more positively than those suspicious of the corporate motives for giving. Focusing on employee voluntary time, Study 1B shows that philanthropy administered by companies suffering adverse impacts to operations garner more positive evaluations of reputation than uninterrupted organisations. Study 2 compares domestic (2016 Kaikōura earthquake) and overseas relief (2018 New Caledonia earthquake), measuring the impact of ethnocentrism on preferences for giving. Interestingly, there are no differences in evaluations between high and low ethnocentrism consumers in each geographic context.

The overall findings suggest that companies should look beyond their own interests following disasters, administering non-reciprocal giving to generate reputational benefits. Moreover, firms suffering direct adverse impacts are uniquely positioned to generate the strongest reputation gains from giving, fostering moral capital through selfless offerings. Although, sceptical consumer predispositions dilute such benefits, suggesting that businesses cannot simply rely on giving as a panacea to reputational concerns. A natural disaster context also suspends the influence of ethnocentrism on geographic preferences for philanthropy, meaning managers should assess the perceived needs of benefactors when determining where to give. 


\section{ACKNOWLEDGEMENTS}

To my supervisor, Associate Professor Daniel Laufer, thank you for your invaluable support and feedback throughout the past 18 months. Your expertise and ongoing guidance has provided the backbone for my research. With your help, I have learnt so much.

To my friends and co-workers outside of University, thank you for your encouragement and emotional backing throughout my research. Whether it be occasional coffee catch-ups, a quick gym distraction, or many (many) glasses of wine, you've kept me sane and able to stick at this.

To my Masters companion, Brittany, thank you for diving into this with me! Your humour, light-heartedness, and mutual self-deprecation have been a source of constant relief. I'm excited to enter the real-world with you now and track your long list of future successes.

To the Honours Class of 2018, thank you for beginning this research journey with me! The Questionable Quality of Mind Club will always live on.

Thank you to the lecturers and administration staff in the School of Marketing \& International Business for helping to shape my academic perspective. Your advice has always been exceptional. I've also greatly appreciated the opportunity to de-tangle my mind through tutoring each week.

To my family; Mum, Dad, Julian, Joyce (and Couscous), this wholly would not have been possible without your support. Thank you for providing me with the opportunity to study in Wellington over the past 5 and a half years, and always encouraging me to do, and be, my best. Oh, and mum - you're not so superior now!

Finally, to Grandma, this is for you. 


\section{Table of Contents}

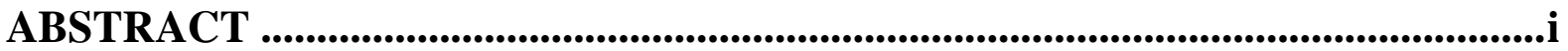

ACKNOWLEDGEMENTS ..................................................................................

List of Figures n............................................................................................................

List of Tables ........................................................................................................................vi

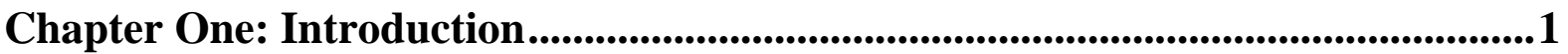

1.1. Research Background .................................................................................................2

1.2. Research Gaps ............................................................................................................4

1.3. Research Purpose \& Questions....................................................................................5

1.4. Significance \& Contribution of Research ....................................................................6

1.5. Structure of the Thesis .........................................................................................

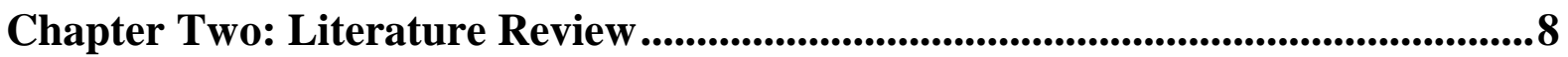

2.1. Corporate Philanthropy \& Cause-related Marketing .....................................................8

2.1.1. Perceived Benefits of Corporate Philanthropy …………………………………......11

2.1.2. Corporate Philanthropy as a Disaster Response ……………………………….....13

2.2. Corporate Reputation ........................................................................................................15

2.2.1. Corporate Reputation \& Philanthropic Giving .....................................................17

2.3. Corporate Social Responsibility.................................................................................19

2.3.1. Consumer Scepticism to CSR ......................................................................21

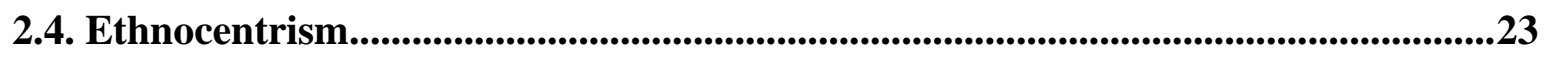

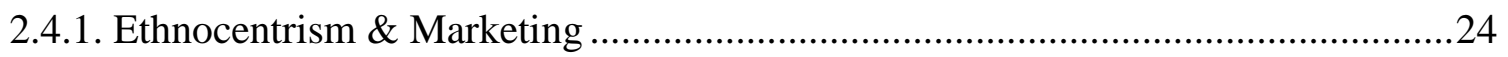

2.5. Research Gaps .................................................................................................................26

Chapter Three: Conceptual Development ......................................................................29

3.1. Research Problem \& Objectives ......................................................................................29

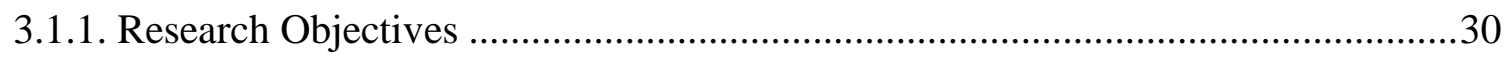

3.2. Study 1A .............................................................................................................31

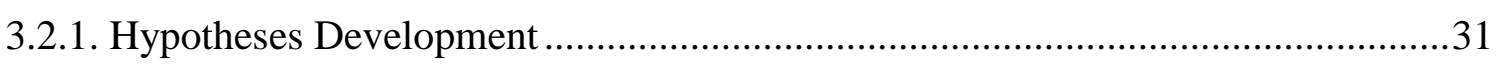

3.3. Study 1B ......................................................................................................................34

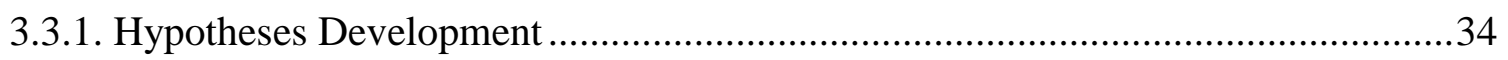

3.4. Study 2 ....................................................................................................................................36

3.4.1. Hypotheses Development ………………………………………………….......36 
Chapter Four: Methodology ................................................................................................38

4.1. Research Approach ..................................................................................................................38

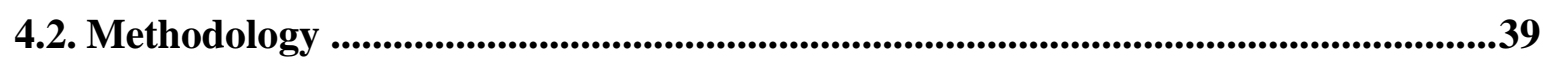

4.3. Research Design................................................................................................40

4.4. Experimental Procedure .........................................................................................42

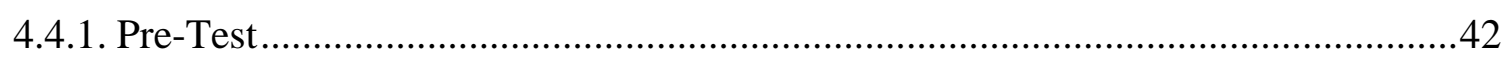

4.4.2. Design and Measures ....................................................................................4

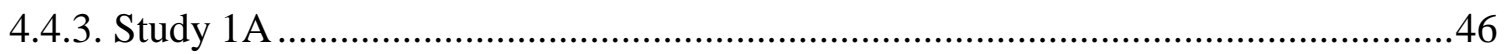

4.4.3.1. Experimental Scenario Conditions.......................................................................... 46

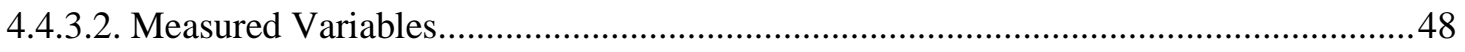

4.4.3.3. Manipulation Checks ……………………………………………………………... 49

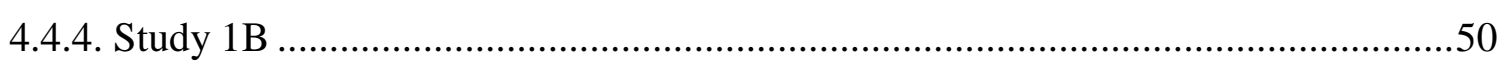

4.4.4.1. Experimental Scenario Conditions.........................................................................50

4.4.4.2. Measured Variables..................................................................................................

4.4.4.3. Manipulation Checks ............................................................................................... 51

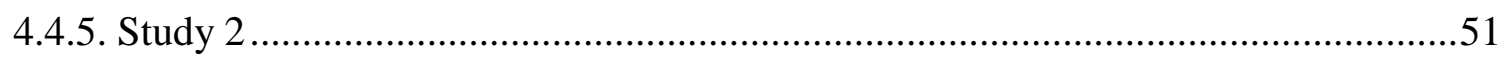

4.4.5.1. Experimental Scenario Conditions....................................................................... 51

4.4.5.2. Measured Variables............................................................................................

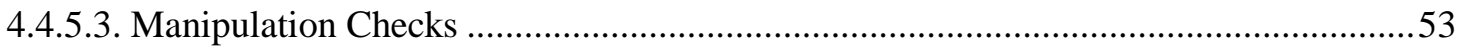

4.5. Research Sample ..................................................................................................................53

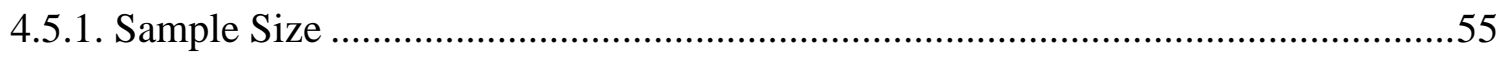

4.6. Data Analysis Strategy ................................................................................................55

4.7. Ethics Approval ...................................................................................................55

Chapter Five: Results ...............................................................................................................56

5.1. Validity \& Reliability ..........................................................................................................56

5.2. Study 1A .................................................................................................................................57

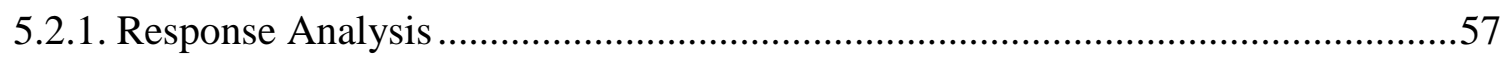

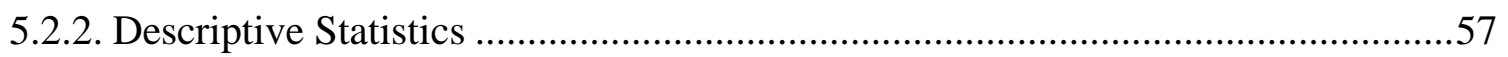

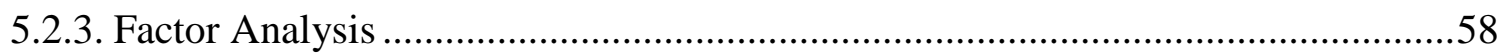

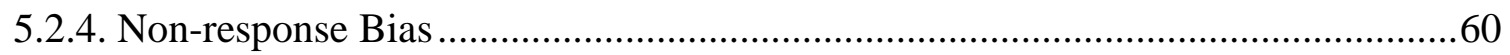

5.2.5. Assumptions of One-Way ANOVA …………………………………………....6

5.2.6. Hypothesis Testing: Corporate Philanthropy \& Reputation......................................61

5.2.7. Hypothesis Testing: Corporate Philanthropy \& Consumer Scepticism ..................63

5.3. Study 1B ...................................................................................................................................64

5.3.1. Response Analysis .............................................................................................64 
5.3.2. Descriptive Statistics

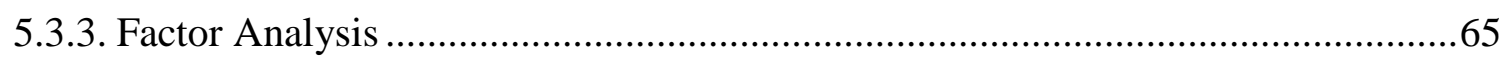

5.3.4. Hypotheses Testing: Adverse Operational Impacts...........................................66

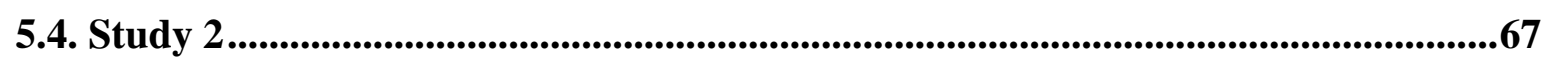

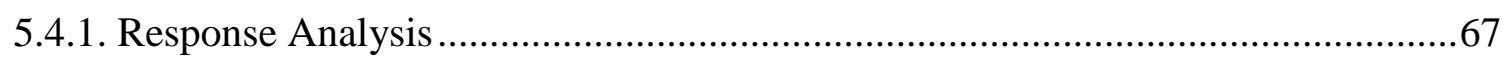

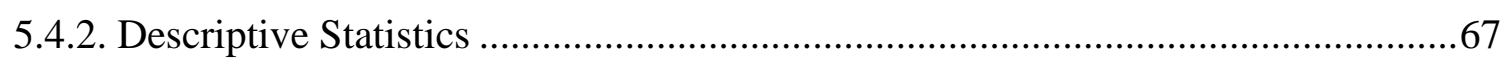

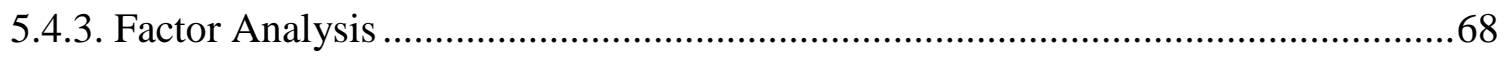

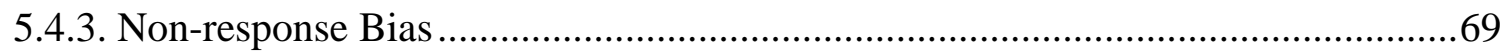

5.4.4. Assumptions for Independent Samples $t$ Test ....................................................70

5.4.5. Hypothesis Testing: Domestic Giving \& Ethnocentrism ...................................... 70

5.4.6. Hypothesis Testing: Global Giving \& Ethnocentrism........................................... 71

Chapter Six: Discussion ........................................................................................................... 74

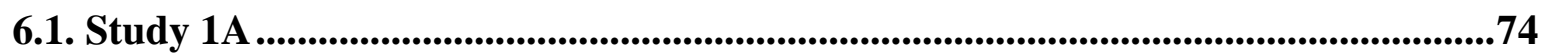

6.1.1. Corporate Philanthropy \& Giving Type .......................................................... 74

6.1.2. Corporate Philanthropy \& Consumer Scepticism ............................................... 76

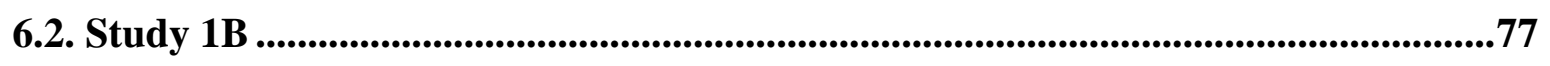

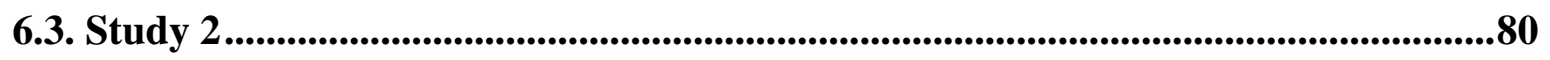

Chapter Seven: Conclusions \& Implications ..........................................................83

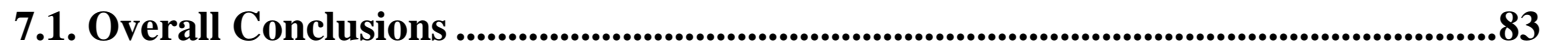

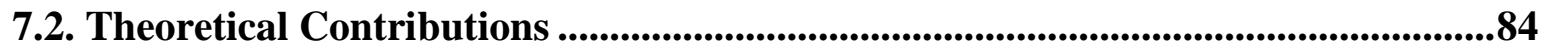

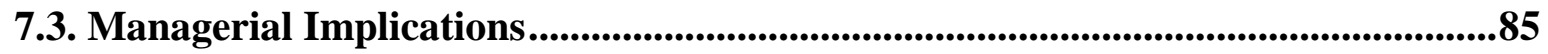

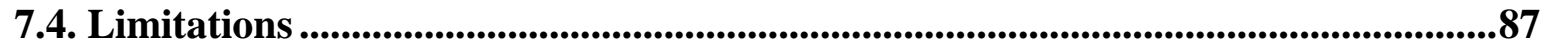

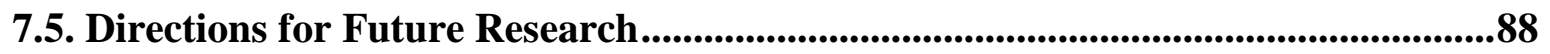

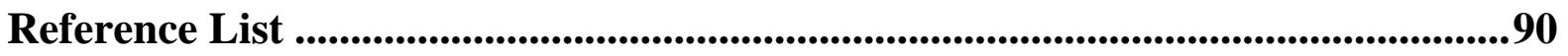

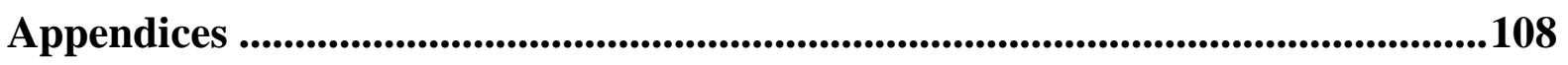

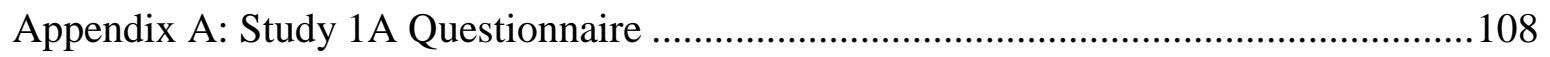

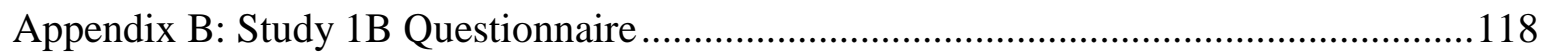

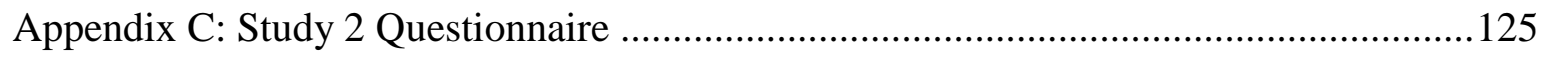

Appendix D: Pre-Test Reliability Results ................................................................ 135

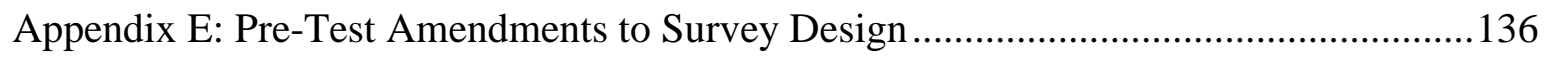

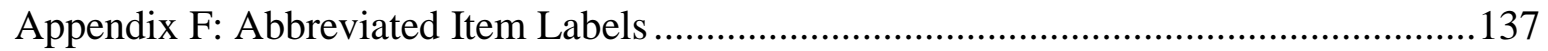

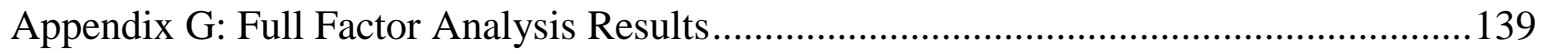




\section{List of Figures}

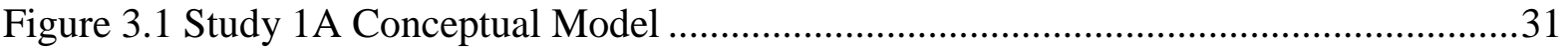

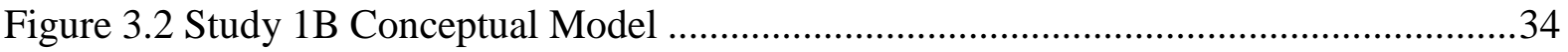

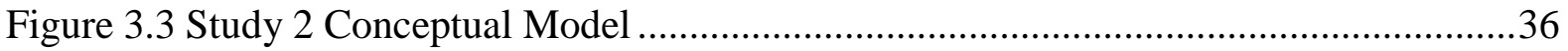

\section{List of Tables}

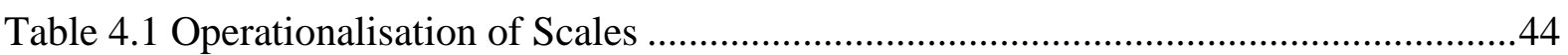

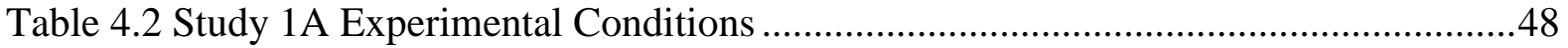

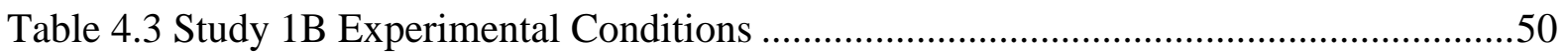

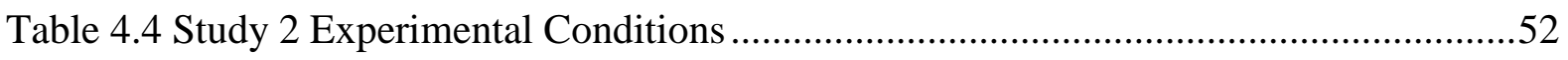

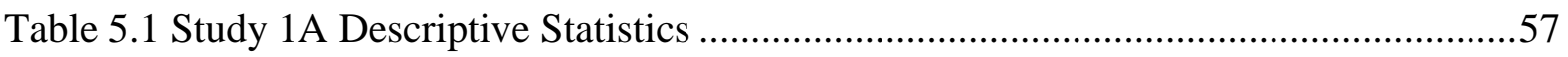

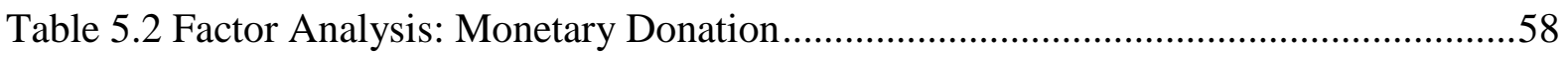

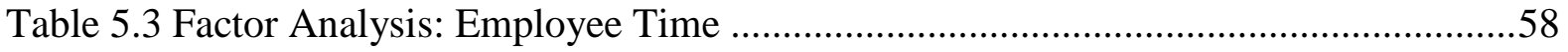

Table 5.4 Factor Analysis: Minimising Internal Disruptions .............................................59

Table 5.5 Factor Analysis: Consumer Scepticism ..............................................................59

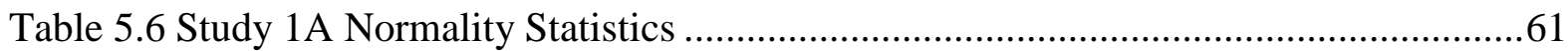

Table 5.7 One-Way ANOVA: Corporate Philanthropy \& Reputation ...................................62

Table 5.8 Post Hoc Analyses: Corporate Philanthropy \& Reputation ...................................62

Table 5.9 Independent samples $t$ test: Corporate Philanthropy \& Consumer Scepticism .......63

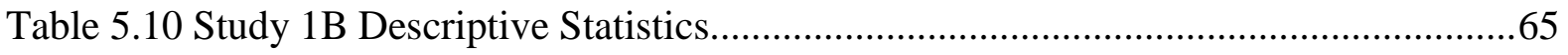

Table 5.11 Factor Analysis: Operations Impacted …..........................................................65

Table 5.12 Factor Analysis: Operations Not Impacted .........................................................66

Table 5.13 Independent samples $t$ test: Adverse Operational Impacts .................................67

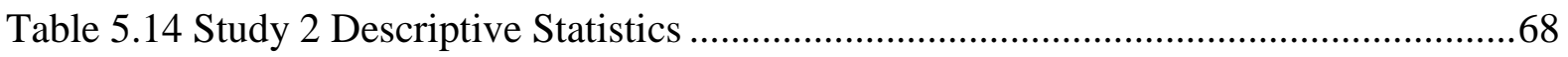

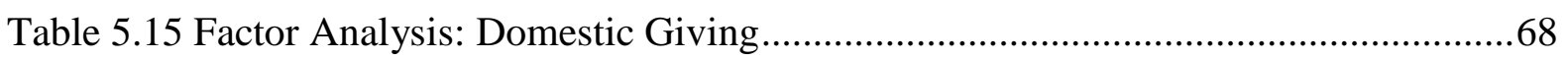

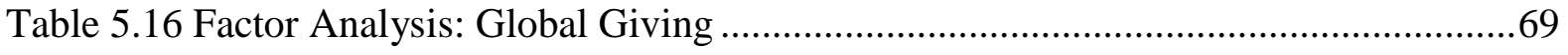

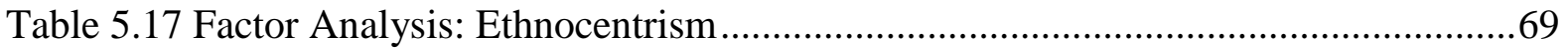

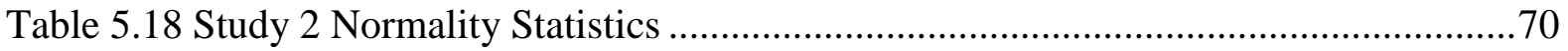

Table 5.19 Independent samples $t$ test: Domestic Giving \& Ethnocentrism ..........................71

Table 5.20 Independent samples $t$ test: Global Giving \& Ethnocentrism...............................72

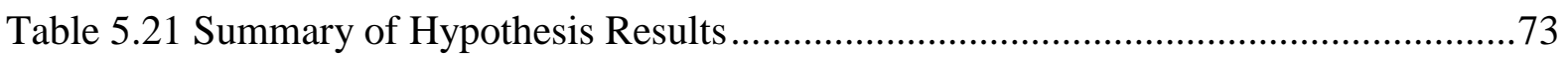




\section{Chapter One: Introduction}

The importance of corporate philanthropy (CP) is clearly on the minds of companies, with the world's largest businesses increasing non-reciprocal giving by 15\% between 2015 and 2017 (Committee Encouraging Corporate Philanthropy [CECP], 2018). Emboldened by strategic reviews into corporate social responsibility (CSR), philanthropy has emerged as an indispensable commercial tool that fosters positive stakeholder perceptions and improves financial performance (Brammer \& Millington, 2005; Mithani, 2017). Corporate philanthropy refers to the unconditional transfer of company resources for public aid (Financial Accounting Standards Board [FASB], 1993). Philanthropic practice has permeated small and mediumsized enterprises (SMEs) and multinationals alike, as companies jostle to achieve differentiation in the market (Porter \& Kramer, 2002). Proponents of philanthropy praise its ability to foster competitive advantages through a dual convergence of business and social interests (Porter \& Kramer, 2002; Seifert, Morris \& Bartkus, 2004). Corporate philanthropy equips companies with the ability to demonstrate social responsiveness to the communities in which they operate, fostering consumer goodwill (Brammer \& Millington, 2005). Academic literature also reflects the burgeoning importance of $\mathrm{CP}$, with recent research tracing its theoretical development and developing future areas of study (Gautier \& Pache, 2015; Vveinhardt \& Zygmantaite, 2015).

New Zealand remains one of the most generous countries globally, ranked fourth in the Charities Aid Foundation's (CAF) (2017) aggregate giving index. In the most recently available information, Philanthropy New Zealand (2014) estimated a total of $\$ 2.788$ billion was given to charitable causes within the country in 2014. Only 3\% of philanthropy, approximately $\$ 77.2$ million, is attributable to businesses, compared to $42 \%$ from foundations, and 55\% in personal giving (Philanthropy NZ, 2014). However, the establishment of philanthropic foundations is an increasingly popular avenue for companies to administer nonreciprocal giving (Seifert et al., 2004). Corporate philanthropy is highly elastic to exogenous shocks, as evidenced by a $22 \%$ rise in donations following the 2011 Christchurch series of earthquakes (Philanthropy NZ, 2014). CECP (2018) identify disaster relief as the catalyst for increases in giving across both cash donations and matched initiatives. Moreover, in an international context, corporate donations in the United States rose 8\% from 2016 to 2017, bolstered by $\$ 405$ million in contributions to disaster relief (Giving USA, 2018). As a result, 
disaster-related philanthropy is an important area for future empirical research, further contextualising drivers behind giving, and equipping managers with actionable insights to assist CP decision-making.

Corporate philanthropy is inextricably tied to corporate reputation (Brammer \& Millington, 2005; Gardberg, Zyglidopoulos, Symeou \& Schepers, 2017), as a dependent measure of philanthropic success to impress customers. Reputation management is seen as the key to corporate communication (Doorley \& Garcia, 2015), and the new face of public relations (Hutton, Goodman, Alexander \& Genest, 2001). A favourable corporate reputation is muchvaunted, with Schwaiger, Raithel, Rinkenburger and Schloderer (2011, p. 62) viewing perceptions of reputation as "the ultimate determinant of competitiveness". Positive customer sentiment to reputation also has spillover effects on relational outcomes, such as trust and purchase intention (Walsh, Beatty \& Shiu, 2009). Therefore, fostering goodwill and reputation becomes essential in order to maximise profits and strengthen a firm's competitive positioning (Gautier \& Pache, 2015).

\subsection{Research Background}

Companies adversely impacted by disasters tend to look inwards, minimising internal disruptions to operations to promote trustworthiness for investors (Muller \& Kräussl, 2011a). An internal posture means impacted businesses sacrifice engaging in philanthropy, as disasters decrease aggregate giving; in particular, following large-scale events with loss of life (Muller \& Kräussl, 2011a; Tilcsik \& Marquis, 2013). However, fraught contexts offer the opportunity for firms to look beyond company-centric needs and engage in philanthropic activity, adopting an outward focus that can have positive impacts on community resilience (McKnight \& Linnenluecke, 2016). The widespread devastation of the 2016 Kaikōura and 2011 Christchurch earthquakes highlights the pertinence, and immediacy with which New Zealand companies must consider robust social responsibility strategies during a disaster (Greater Christchurch Group, 2017).

Empirical research suggests that corporate philanthropy is beneficial across many commercial measures, including financial returns (Wang, Choi \& Li, 2008), employee commitment (Block, 
Glavas, Mannor \& Erskine, 2017), shareholder value (Gao, Faff \& Navissi, 2012), and corporate reputation (Brammer \& Millington, 2005; Ma \& Zhan, 2016). As an expression of wider CSR strategy, non-reciprocal giving can also work as an inoculation against damaging internal and external crises (Gardberg et al., 2017; Sen \& Bhattacharya, 2001). A "reservoir of goodwill" (Jones, Jones \& Little, 2000, p. 21) buffers companies from financial and competitive decline in times of uncertainty and economic concern, underscoring the importance of managing reputation during disasters.

Contextual and moderating factors influence the efficacy of philanthropy (Godfrey, 2005; Hildebrand, DeMotto, Sen \& Valenzuela, 2017). Few normative guidelines explicate consumer reactions to post-disaster giving; yet, organisations with a presence near stricken regions are significantly more likely to provide immediate aid than those geographically removed (Crampton \& Patten, 2008; Muller \& Whiteman, 2009). Moreover, giving that is viewed as altruistic helps to minimise perceptions of philanthropy as an attempt of ingratiation towards stakeholders (Godfrey, 2005). At an individual level, giving that comes from greater sacrifice and opportunity cost is also viewed more positively by consumers (Bracha \& Vesterlund, 2017; Dees, 2012). Therefore, firms that absorb financial risk and choose to give may be rewarded with positive perceptions that augment moral capital (Ellen, Mohr, \& Webb, 2000; Godfrey, 2005).

Consumer scepticism toward the motives of social responsibility is a moderating factor, shaping the effectiveness of non-reciprocal activities (Peterson, 2018). High scepticism reduces the value of CSR (Skarmeas \& Leonidou, 2013), imbuing negative associations toward the participating company, such as a desire to promote brand image and maximise product sales (Becker-Olsen, Cudmore \& Hill, 2006). Firms offering monetary support are particularly vulnerable to suspicion, whereas voluntary, non-transactional offerings nurture consumer trust (Cui, Trent, Sullivan \& Matiru, 2003). In short, when consumers question the veracity of causerelated initiatives, they are less likely to develop positive company associations and purchase products (Ellen et al., 2000; Elving, 2013). As Skarmeas and Leonidou (2013, p. 1831) succinctly posit: "When consumers doubt, watch out!" 
Operating in an increasingly globalised marketplace, managers are forced to exercise prudence when determining benefactors of giving. Businesses are willing to administer philanthropy for causes abroad (Lieber, 2015; Muller \& Whiteman, 2016), with multinational enterprises grasping the strategic opportunity to foster an international profile for CSR (Brammer, Pavelin \& Porter, 2009). In a non-disaster setting, consumers exhibit little preference toward the location for corporate giving, varying based on the relevance of product category (Auger, Devinney, Louviere, \& Burke, 2010), and the perceived need of benefactors (Schons, Cadogan, Tsakona, 2017). As firms negotiate where to focus finite philanthropic resources, ethnocentrism helps to explain preferences for giving. In essence, ethnocentrism reflects the extent to which people evaluate other cultures with reference to their own communities and customs (Sharma, Shimp \& Shin, 1995; Sumner, 1906). Ethnocentrism links to perceptions of cross-national giving (Szöcs, 2013), with highly ethnocentric consumers likely to prefer localised philanthropy that is more personally relevant to domestic citizens (Russell \& Russell, 2010). Conversely, less ethnocentric consumers perceive global giving positively, more willing to support causes abroad (Szöcs, 2013).

\subsection{Research Gaps}

Extant literature fails to examine the drivers behind corporate philanthropy, with a paucity of empirical studies considering giving across different contexts, and failing to integrate relevant moderating variables (Gautier \& Pache, 2015). As disaster relief is a catalyst for donations (CECP, 2018), further inquiry is needed to delineate the minutiae of post-disaster giving. Marketers' knowledge of stakeholder responses to CSR is also limited (Peloza \& Shang, 2011), necessitating closer examination of consumer reactions to donations that go beyond well-worn financial means.

While previous studies focus on the amount of monetary donation administered (Brammer \& Millington, 2006; Gao \& Hafsi, 2015), few scholars have directly compared typologies of giving from a firm in the midst of a disaster (Hildebrand et al., 2017). As managers attempt to minimise organisational disruptions following disasters (Tilcsik \& Marquis, 2013), research should also evaluate consumer perceptions toward wholly forgoing philanthropy. Moreover, the likely diffuse circumstances of businesses operating amid disaster have been scarcely modelled (Parker \& Steenkamp, 2012). Impacted organisations are likely to have diminished 
capacities for giving (Tilcsik \& Marquis, 2013), although may have non-monetary resources at their disposal, such as employee idle time (Morris, 2018). The benefits afforded through post-disaster philanthropic aid are of great community value (McKnight \& Linnenluecke, 2016), and could offer reputational value as consumers assign altruistic associations that foster moral capital (Ellen et al., 2000; Godfrey, 2005).

It is also essential to consider untested exogenous variables that moderate the efficacy of giving. Consumer scepticism influences perceived financial and reputational benefits of CSR (Skarmeas \& Leonidou, 2013), with suspicion also weakening attitudes toward the donating company (Bae \& Cameron, 2006; Elving, 2013). The impact of a sceptical predisposition is not known, elucidating whether crisis conditions suspend the influence of scepticism (Ellen et al., 2000), or if short-term assistance continues to promote distrust (Vanhamme \& Grobben, 2009). Further, Szöcs' (2013) identification of ethnocentrism as a relevant philanthropyreputation moderator should be tested concerning disaster-based giving, in which companies must decide where to direct geographic support (Schons et al., 2017).

By filling these research gaps, this study aims to advance understanding of corporate giving, situating the relationship between philanthropy and reputation in a disaster context, and integrating moderating variables to develop more complete understandings of company giving.

\subsection{Research Purpose \& Questions}

As acknowledged above, the purpose of this paper is to examine consumer perceptions of corporate philanthropy in a disaster context. Further, it aims to test variables and situating factors that moderate the effectiveness of $\mathrm{CP}$ on reputation, including consumer scepticism, degree of organisational disruption, and ethnocentrism. In fulfilling its purpose, this research will extend the link between philanthropy and reputation, introducing salient contextual factors that determine the efficacy of donations. Through a detailed investigation of previous literature, gaps in knowledge are identified that underpin the following research questions: 
1) Do consumers prefer companies to donate money or employee voluntary time during a disaster?

2) Is external corporate philanthropy viewed more positively than minimising internal disruptions to operations following a disaster?

3) To what extent does consumer scepticism to the motives behind philanthropy influence evaluations of corporate reputation?

4) Is philanthropy perceived more positively when administered by adversely impacted companies, compared to those uninterrupted?

5) How does ethnocentrism influence perceptions of companies that donate to domestic disasters?

6) How does ethnocentrism influence perceptions of companies that donate to overseas disasters?

\subsection{Significance \& Contribution of Research}

The following research contributes to the body of knowledge that highlights conditions under which philanthropy adds to firm value (Brammer \& Millington, 2008; Muller \& Kräussl, 2011a). From an academic standing, this paper responds to Gautier and Pache's (2015) call for greater integrative CP studies, examining moderating effects of consumer scepticism and ethnocentrism in the relationship between philanthropy and reputation. Shifting the focus of philanthropic scholarship from financial and employee-based measures, consumer evaluations of reputation provide a demand-side view of goodwill fostered through giving. By broadening the CSR canon to consider relief gifts, this research hopes to embolden future inquiry in the corporate disaster aid domain. Further, the identified variables provide a unique interdisciplinary contribution, spanning marketing, public relations, management, and business ethics, establishing rich insights for researchers across a range of industries.

From a managerial perspective, preferred types of giving during a disaster are identified. The importance of developing robust contingency plans for adversely impacted companies is unscored by New Zealand's recent ranking as high-risk for almost every possible natural disaster (Satherley, 2017). Further, the importance of consumer scepticism is addressed, determining whether suspicion toward CSR motives should attempt to be minimised by marketers when providing philanthropic aid. Practitioners met with the strategic impasse of 
donating to domestic or international initiatives are also equipped with unique insights involving ethnocentrism, identifying consumers' in-versus-out group posture in evaluations of giving. Overall, this study hopes to subvert conventional thinking of an inward focus during adverse circumstances, challenging executives to consider the distinct reputational opportunities afforded when disaster strikes.

\subsection{Structure of the Thesis}

The following thesis is separated into seven chapters. Following the introduction outlined above, Chapter Two provides a rich exploration of present literature surrounding corporate philanthropy, corporate reputation, and proposed moderating variables, synthesising research to advance apparent gaps in knowledge. Next, Chapter Three develops a conceptual approach, constructing models and hypotheses to be examined across three studies that fulfil proposed research objectives. Chapter Four illustrates the methodological approach employed, characterising the research paradigm, method of data collection, sampling, experimental design, and data analysis strategy. The subsequent results garnered by online questionnaires are then detailed in Chapter Five, before Chapter Six formally interprets and discusses findings, situating insights in relation to current knowledge. Chapter Seven concludes this thesis by outlining key conclusions, alongside managerial and theoretical implications, limitations, and avenues for future consideration. 


\section{Chapter Two: Literature Review}

The study of corporate philanthropy during a disaster represents a nascent field, limiting the amount of extant literature to draw upon when identifying a specific research gap. The following review is diffused into related areas of interest across philanthropy, reputation, and proposed moderating factors. Synthesising key findings across each topic will provide a clear and unique gap of research to examine further.

\subsection{Corporate Philanthropy \& Cause-related Marketing}

A technical definition for corporate philanthropy is the "unconditional transfer of cash or other assets to an entity [...] in a voluntary, non-reciprocal transfer by another entity" (FASB, 1993, p. 2). Philanthropy New Zealand (NZ) (2014, p. 4) provides a more operational characterisation as, "the act of giving financial resources to a cause that is intended to improve general human well-being, and where the giver expects no direct reciprocation". Collins (1993, p. 46) emphasises this altruistic element, highlighting that global giving efforts eclipse acting as a "good corporate citizen"; rather, involving an action that goes "beyond the call of duty". Philanthropic literature is scarce compared to the more established, overlapping field of causerelated marketing (CRM). Although, it is important to provide a demarcation of the two concepts, as philanthropy is distinct for marketers in its non-reciprocal nature.

In their seminal piece, Varadarajan and Menon (1988, p. 60) advanced a definition for CRM as "[...] the process of formulating and implementing marketing activities that are characterised by an offer from the firm to contribute a specified amount to a designated cause when customers engage in revenue-providing exchanges [...]". CRM takes a familiar role to traditional philanthropy; however, is organised around marketing objectives that aim to trigger increased product sales (DiNitto, 1989; File \& Prince, 1998). Therein, CRM works through a synergistic and mutually beneficial exchange relationship between firm and charity stakeholders, accepted by scholars as an established component of the contemporary marketing mix (Adkins, 1999; Simon, 1995). The partnership between Auckland's Starship Hospital and Wallace Cotton is a local example of CRM, with sales of 'Ruby's Tea Towels for Starship' being chiefly donated back to the children's hospital (Starship, 2019). Conversely, philanthropy emphasises a transfer with no expectation of reciprocation (FASB, 1993; 
Philanthropy NZ, 2014). For instance, Google's matched giving program sees employee donations and fundraising efforts matched by the company at a 1:1 ratio, most recently benefiting Puerto Rico and Florida following Hurricane Irma (Double the Donation, 2019; Solinger, 2017).

From a theoretical perspective, Kotler (1972) first argued for a societal marketing posture that goes beyond serving customers in an exchange relationship (Kotler \& Levy, 1969), but also the well-being of society as a whole. Collins (1993) traced a historical apathy to corporate philanthropy, as both an area of academia, and as a relevant activity within the marketing programme. Devoid of explicit customer targeting to generate financial returns, some questioned whether philanthropy was a congruent fit within the traditional marketing zeitgeist as a non-reciprocal activity (Galaskiewicz, 1989). As marketing seeks to generate revenues for stakeholders, an impasse exists between achieving financial gains and administering wholly altruistic giving (Galaskiewicz, 1989). Gautier and Pache (2015) argued that the presence of philanthropy in marketing discourse continues to punctuate its effectiveness, residing alongside sponsorship and CRM as other forms of corporate giving in a kaleidoscope of charitable avenues.

As a decision underpinned by both business management and ethics (Vardarajan \& Menon, 1988; Wulfson, 2001), CP crosses disciplinary bounds. While non-reciprocal in nature, it is myopic to exclude philanthropy from the contemporary marketing field, which shifts away from monetary exchanges to a more conceptual and value-based exchange philosophy (Sheth \& Uslay, 2007). Collins (1993) argued that philanthropy represents a product that must be offered to the public in a structured manner to address needs, rather than an ill-planned response mechanism. Integrating philanthropy into marketing strategy allows targeting groups and delivering innovative gestures that foster goodwill and improve corporate image (Collins, 1993; Gautier \& Pache, 2015). Corporate giving can result in unintended spillover benefits and financial returns (Patten, 2008; Wang \& Qian, 2011), suggesting a greater congruence in marketing thought than Galaskiewicz (1989) first contended. In short, philanthropy has evolved from consignment "under the corporate bushel basket" (Mescon \& Tilson, 1987, p. 59) to a practice that helps to answer Kotler and Levy's (1969) clarion call for a broadened 
marketing discipline, as businesses are more eager to enact giving with strategic intent (Gautier \& Pache, 2015).

Corporate philanthropy has since been popularised as an expression of CSR, providing the opportunity to demonstrate social responsibility and corporate citizenship (Brammer \& Millington, 2005; Carroll, 1979). As a cornerstone aspect of CSR, non-reciprocal giving spans help aimed at education, culture, arts, healthcare, minority communities, and natural disaster relief (Godfrey, 2005; Seifert et al., 2004; Wang et al., 2008). Carroll (1979) argued that philanthropic responsibilities sit at the apex of the CSR paradigm, expressly desired, rather than expected, by society to address social ills. Visser (2011) also demarcated CSR and corporate philanthropy by characterising philanthropy as the driving stimulus behind charitable activities, with a recognised benefactor (Seifert et al., 2004). Comparatively, integrated forms of CSR are not always considered philanthropic, driven by promotional objectives, such as advertised eco-friendly business practices (Orlitzky, Siegel \& Waldman, 2011; Visser, 2011).

Philanthropy is primarily exercised through monetary donations, but can also materialise in the form of volunteering, sponsorship, and in-kind giving (Philanthropy NZ, 2014; Porter \& Kramer, 2002). Cash involves a monetary transaction, whereas voluntary time relates to the phenomenon of corporate volunteering, defined as the "formal sponsoring and subsidising of employees' community service and outreach activities on company time" (Muller, Pfarrer \& Little, 2014, p. 12). Employee time is also characterised as a pro bono service; that is, noncash-based giving in which employee skills are donated and valued at a fair market rate (CECP, 2018). In New Zealand, other forms of giving dwarf purely cash-based philanthropy. For every $\$ 1$ donated by business enterprise, \$1.43 is contributed to sponsorship, and \$3.27 worth of inkind goods and services (Philanthropy NZ, 2014). It is difficult to precisely characterise the range of in-kind goods and services elicited through philanthropy; however, legal aid, education, and technology training are acknowledged as alternate avenues for giving (Jamali, 2007; Philanthropy NZ, 2014). Recent empirical research highlights a steady increase in global philanthropy, with total corporate giving in the United States reaching $\$ 23.8$ billion in 2017, representing a 15 per cent rise over the past three years (CECP, 2018). Companies continue to exhibit greater cognisance of social responsibility efforts and disaster relief behind gifted gestures (CECP, 2018). 


\subsubsection{Perceived Benefits of Corporate Philanthropy}

A range of constructs reflect the impact of philanthropy, including shareholder value (Gao et al., 2012; Muller \& Kräussl, 2011a), corporate reputation (Brammer \& Millington, 2005; Morris, Bartkus, Glassman \& Rhiel, 2013), and financial performance (O’Hare, 1991; Wang et al., 2008). Shareholder value is frequently examined, examining market performance following giving (Muller \& Kräussl, 2011a; Muller \& Whiteman, 2009), supplemented with investor interviews to understand stakeholder perceptions (Jamali, 2007).

Wang et al. (2008) suggested that corporate philanthropy is valuable for firm financial wellbeing, precipitating greater control over stakeholder resources, and increased consumer purchase intention. Several scholars also find positive effects on financial performance (see O’Hare, 1991; Patten, 2008; Su \& He, 2010; Wang \& Qian, 2011), yet hesitate to conclude a causal relationship. Instead, Seifert et al. (2004) determined no significant relationship between philanthropic contributions and aggregate financial performance, although the researchers fail to model for in-kind, non-monetary gifts. The link between $\mathrm{CP}$ and revenue also risks diminishing returns, with higher philanthropic contributions becoming outpaced by agency costs and direct costs (Masulis, \& Reza, 2015; Wang et al., 2008). Agency costs begin to accelerate as shareholders become concerned about the misuse of corporate resources, while direct costs rise as philanthropy is facilitated and administered in more copious amounts (Masulis \& Reza, 2015; Wang et al., 2008). A lack of robust consensus across the literature is symptomatic of a failure to examine philanthropy with greater nuance, overlooking antecedent and contextual factors to elucidate insights. Profitability measures saturate philanthropic study (Gautier \& Pache, 2015), leaving room for future research beyond financial measures.

Corporate reputation is widely observed by researchers to detail the benefits of giving (Gardberg et al., 2017; Peterson, 2018). Reputation is a proxy for market competitiveness, and the ability of a company to foster goodwill among consumers (Schwaiger et al., 2011). Engaging in corporate philanthropy is roundly considered beneficial to reputation (see Brammer \& Millington, 2005; Gardberg et al., 2017; Lii \& Lee, 2012; Morris et al., 2013; Peterson, 2018). Cash donations typically generate more significant benefits on reputation than employee volunteering, or product donations (Brammer \& Millington, 2005), and are most likely to be communicated to stakeholders and customers (Chalmeta \& Viinikka, 2017). 
Multinational firms are more likely to engage in cash-based donations, whereas in-kind giving is favoured by local companies, due to strengthened social networks and greater market knowledge (Bin \& Edwards, 2009).

While monetary giving is perceived most positively, disaster response philanthropy shifts preferred giving type. Shareholders display more positive reactions to post-disaster donations that involve employees, rather than purely cash-based transactions (Muller \& Kräussl, 2011b). Corporate volunteering has emerged as a means through which to administer disaster response philanthropy (Whittaker, McLennan \& Handmer, 2015). Firms adversely impacted by a natural disaster may have non-monetary resources at their disposal, such as employees with idle time due to business disruptions, who can assist in volunteering (Morris, 2018; Muller et al., 2014). Employee involvement offers a sense-giving effect that sends positive signals to shareholders, helping a "firm's ability to bounce back from the disaster's adverse effects" (Muller \& Kräussl, 2011b, p. 203). Hildebrand et al. (2017) also acknowledge that in-kind contributions are perceived more positively by consumers to issues deemed uncontrollable, whereas monetary giving assists more strongly in response to controllable circumstances. Market participants continue to react positively to monetary donations following a disaster (Gao et al., 2012; Hildebrand et al., 2017); however, stock returns and brand image are more favourable toward in-kind gifts. In addition to the sense-giving effect identified by Muller and Kräussl (2011b), consumers perceive in-kind offerings as a higher level of participation to cultivate genuine, hands-on stakeholder relations (Gao et al., 2012; Twigg, 2001).

The type of cause supported is also linked to CP attitudes, with non-customers forming perceptions of philanthropy through cause-related means (Szöcs, Schlegelmilch, Rusch \& Shamma, 2016). The attitudes of non-customers have similar importance to customers, as noncustomers outnumber patrons of a business, and can significantly impact the aggregate consumer sentiment towards an entity (Shamma \& Hassan, 2009; Szöcs et al., 2016). Moreover, the impact of philanthropy on reputational evaluations is highly specific to its audience, as cultural backgrounds and socio-economic standing influence consumer perceptions toward CRM (Brønn \& Vrioni, 2001) and philanthropy (Szöcs et al., 2016). Corporate stakeholders from individualistic countries, such as New Zealand, tend to perceive philanthropy more positively than in collectivist cultures, in which greater corporate 
involvement is expected (Szöcs et al., 2016). Therefore, researchers should be hesitant to generalise the positive effects of giving on reputation without developing a greater sensibility of cultural and geographical influences (Szöcs et al., 2016).

\subsubsection{Corporate Philanthropy as a Disaster Response}

Mayner and Arbon (2015, p. 21) typify disasters as "the widespread disruption and damage to a community that exceeds its ability to cope and overwhelms its resources". The United Nations (UN) General Assembly (2016, p. 13) offers an analogous interpretation, emphasising "a serious disruption of the functioning of a community or a society $[\ldots]$ leading to $[\ldots]$ human, material, economic, and environmental losses". This paper draws upon the shared understanding of disasters as a wholly disruptive phenomenon; in particular, through the lens of large-scale disasters that necessitate national or international assistance (UN General Assembly, 2016).

The deficiency of research surrounding corporate philanthropy during a disaster affords the opportunity to expand on knowledge in this domain. Giving during a disaster is also commonly referred to as both humanitarian aid and disaster relief, which are defined separately to philanthropy in the literature (CECP, 2018; Day, Melnyk, Larson, Davis \& Whybark, 2012; Wang et al., 2008). Thomas and Mizushima (2005, p. 60) focused on the tangible aspect of disaster relief as a planned and controlled "flow and storage of goods and materials", rather than a prospective cash-based offering. Instead, CECP (2018, p. 48) define disaster relief as "contributions that support preparedness, relief, recovery, and/or rebuilding efforts in the wake of a natural or civil disaster [...]". Given the non-reciprocal nature of philanthropy that crystallises around different forms of giving, CECP's (2018) relief characterisation most appropriately fits the objectives of this study.

Within scholarly publications, consistent findings emerge that adverse economic conditions incited by a disaster decrease levels of corporate giving (Muller \& Kräussl, 2011a; Tilcsik \& Marquis, 2013). Further, Tilcsik and Marquis (2013) uncovered that the largest drop in corporate donations follows major disasters. Minor disasters, without loss of human life, tend to prompt increased expenditure, as company resources are less adversely impacted (Tilcsik \& 
Marquis, 2013). Companies actively involved in local social networks are also highly likely to provide disaster relief to serve community interests (Bin \& Edwards, 2009; Gautier \& Pache, 2015). In the United States, disaster relief has increased by $306 \%$ over the past three years (CECP, 2018). Further, 10\% of all international corporate giving is spent on disaster recovery, highlighting the managerial importance of giving across borders during times of significant damage (CECP, 2018). Although, empirical trends in relief giving are influenced by the magnitude and incidence of disasters (Philanthropy NZ, 2014), suggesting that aggregate patterns are not wholly representative of long-term philanthropic commitments.

As overall corporate giving declines following large-scale disasters (Mayner \& Arbon, 2015), it is important to better understand the consequences of administering philanthropy in highly fraught contexts. Mithani (2017) identified the commercial opportunity afforded by disaster; in particular, for multinational enterprises (MNEs) to strengthen local connections, and appeal to both domestic and international audiences (Collins, 1993). Further, social responsibility efforts are a unique mechanism through which to strengthen corporate engagement with affected communities, helping to build resilience in employee teams (Van der Vegt, Essens, Wahlstrom \& George, 2015). Interestingly, MNE philanthropy during a disaster may be perceived as less self-promotional than contributions by domestic firms, resulting in stronger post-disaster financial performance for donors (Mithani, 2017). A crisis context provides the impetus for social investment by well-resourced multinationals, whereas negative evaluations threaten less generous domestic firms (Mithani, 2017). As such, MNEs may view disaster relief as a strategic opportunity to overcome liability of foreignness, referring to the higher financial and social costs faced compared to local counterparts (Denk, Kaufmann \& Roesch, 2012).

From a consumer perspective, philanthropic responses to disasters are an opportunity to examine whether companies are ephemeral in their giving commitments (Wang, Tong, Takeuchi \& George, 2016). The underlying motives for philanthropy are paramount to garner positive stakeholder perceptions and reputational benefits (Godfrey, 2005; Patten, 2008; Wang et al., 2016). Godfrey (2005, p. 784) emphasised that relief must be interpreted as, "a genuine manifestation of the firm's underlying intention, vision and character", rather than an activity to ingratiate the firm among an impacted community. The uncontrollable nature of natural disasters means consumers are less likely to assign personal responsibility to suffering 
individuals, issuing noble associations toward those impacted (Ellen et al., 2000). Yoon, Gürhan-Canliand and Schwarz (2006) also acknowledged the importance of consumer attributions to motives for giving, with trustworthiness and sincerity augmenting company evaluations when CSR stems from an ethical responsibility (Skarmeas \& Leonidou, 2013). Empirical evidence from the 2004 Southeast Asia tsunami bares out these contentions. Firms that announced monetary disaster relief of exactly $\$ 1$ million did not garner significant changes to stock market returns, perceived as calculated and disingenuous displays of social responsiveness to ingratiate businesses alongside customers (Patten, 2008). Conversely, donation amounts higher or lower than $\$ 1$ million resulted in stronger market returns, particularly for those donating well above $\$ 1$ million (Patten, 2008). There is value in more closely examining consumer reactions toward philanthropy (Peloza \& Shang, 2011), and the extent to which motive suspicion may shift post-disaster evaluations (Vanhamme \& Grobben, 2009).

\subsection{Corporate Reputation}

Corporate reputation is defined uniquely across disciplines, spanning psychology, sociology, marketing, and management (Fombrun, 1996). A synthesis of research uncovers five critical attributes of reputation. Fombrun's (1996) formative conceptualisation highlights three characteristics: reputation is based on perceptions; is the aggregate view of many stakeholders; and, is relative to competitors (Walker, 2010; Wartick, 2002). Further, reputation can likely be positive or negative (Mahon, 2002), and is relatively stable (Rindova, 1997). While perceptions of reputation can shift in the short-term, the standing of a firm is less fluid than related phenomena, such as company image (Fombrun, 1996; Walker, 2010). Overall, Walker (2010, p. 370) advanced Fombrun's (1996) definition for corporate reputation as, "a relatively stable, issue-specific, aggregative perceptual representation of a company's past actions and future prospects, compared against some standard".

Gotsi and Wilson (2001) traced the historical shift of corporate reputation, which began as an analogous school of thought, synonymous with customer-centric perceptions of company image (Walker, 2010; Whetten, 1997). Reputation has become differentiated from superficial image-based characterisations that are prone to manipulation and management, failing to capture a company's actual reality (Bernstein, 1984; Gotsi \& Wilson, 2001). Comparatively, 
organisational identity focuses on internal stakeholder perceptions about company positioning (Walker, 2010). In essence, corporate reputation represents a dynamic and bilateral phenomenon, encompassing the actual perceptions from both internal and external stakeholders (Gotsi \& Wilson, 2001). In a succinct summation, Balmer and Greyser (2006, p. 735) posited that firms considering reputation must ask themselves, "What are we seen to be?" in the eyes of consumers and internal stakeholders.

Reputational measures have shifted to the eye of the consumer, first typified by Walsh and Beatty (2007) who noted a heavy focus on shareholders, employees, and competitors, at the expense of customer-centricity. Walker (2010) echoed this sentiment, arguing that corporate reputation focused too heavily on a distillation of stakeholder perspectives, implicitly assuming that all relevant parties hold similar perceptions and value systems. As a result, traditional measures of reputation may lack insight due to a reliance and overrepresentation of high-level managers and financial performance (Fombrun, Gardberg \& Sever, 2000), failing to wholly capture the "[...] perceptual representation of a company [...]" (Walker, 2010, p. 370).

Consumer-led views of corporate reputation are also distinct from much of the literature considering the internal benefits of philanthropic activities on employee motivation and attitudes. Block et al. (2017) note the positive impacts of giving on employee attitudes, as donating voluntary time or money results in favourable implications for commitment, performance, and overall morale (Muller and Kräuss1, 2011b). The value of measuring external corporate reputation is its ability to foster a sustained competitive advantage for firms (Porter \& Kramer, 2002). As a result, it is important to consider reputation through a consumer-led lens, representing an attitude-like evaluative judgment of firms that is an extension of traditional customer satisfaction (Fournier \& Mick, 1999; Walsh \& Beatty, 2007). The distinction between customer views and disparate stakeholder perspectives means corporate reputation is most accurately defined as an affective construct with many elements, rather than one stringent measure that attempts to distil multiple perspectives (Fombrun, 1996). The shift of exchange-based marketing to customer-centricity (Sheth \& Uslay, 2007) underscores the need to focus on customer-held views of reputation, undiluted by the interests of other stakeholders. 
Walsh and Beatty's (2007, p. 130) view of corporate reputation is a multidimensional customer-based attitude that "explicitly considers customers' personal experiences with, and perceptions about, a firm". Customer-based corporate reputation (CBR) encompasses "the customer's overall assessment of a firm based on his or her reactions to the firm's goods, services, communication activities, interactions with the firm [...] and/or known corporate activities" (Walsh \& Beatty, 2007, p. 129). Evaluations of reputation also encompass any reputation-relevant information received about a firm through both direct and indirect interactions (Coombs, 2007), making it a comprehensive measure through which to consider customer sentiment (Walsh et al., 2009). Moreover, CBR is positively correlated with vital relational outcome variables, such as trust and re-patronage (Walsh et al., 2009), reinforcing the importance of customer-based reputation as a measure during fraught and unstable contexts, such as a disaster.

The specific dimensions of CBR have been ameliorated in recent years to better reflect the digitalisation of services (Wepener \& Boshoff, 2015). Stemming from marketing services literature, $\mathrm{CBR}$ encompasses five dimensions: emotional appeal, social engagement, corporate performance, good employer, and service points (digital) (Wepener \& Boshoff, 2015). Crucially, CBR is distinguished from brand equity; instead, encompassing overall company evaluations beyond the perceived value of singular brands. Moreover, much of the consumerbased brand equity literature focuses on loyalty, perceived quality, awareness, and willingness to buy; however, does not include CSR, through which reputation can be formed (Lii \& Lee, 2012). As CSR incorporates philanthropic giving, it is prudent to examine reputation from a wider perspective than simple associations, contributing to a broadened understanding toward the implications of philanthropy.

\subsubsection{Corporate Reputation \& Philanthropic Giving}

Empirical studies demonstrate that firms engaging in philanthropic activities can garner lasting reputational benefits, fostering moral capital to improve consumer perceptions, profitability, and inoculate reputation against damaging potential crises (Gardberg et al., 2017; Porter \& Kramer, 2002). Williams and Barrett (2000) also characterised the powerful ability of giving to foster reputation in light of crises, partially restoring the reputation of companies that have violated commercial regulations. Moreover, some consider altruistic philanthropy as the sole 
means through which to improve status and goodwill in the eye of the consumer (Collins, 1993), with ethical manufacturing no longer a differentiating commercial feature (Visser, 2011). However, the benefits of philanthropy are not necessarily direct, and may be altered by external factors before being positively attributed to reputation (Ellen et al., 2000; Park, Lee \& Kim, 2014). These findings begin to suggest that exogenous variables could also impact the relationship between philanthropy and CBR, whereby consumed-led evaluations of reputation must acknowledge a range of moderating factors that are less relevant for internal reputation measures.

More recent analysis advances contextual elements that impact reputation following philanthropy. In a multinational context, consumers in developed countries exhibit a positive association between philanthropy and all dimensions of CBR considered by Walsh and Beatty (2007) (Szöcs et al., 2016). Empirical research from South Korea reinforces the nuance of philanthropy in a cross-culture setting, with local consumers viewing ethical and philanthropic efforts as the most impactful areas of CSR on reputation (Park et al., 2014). The ingrained culture of Confucian ideology, whereby consumers hold high moral standards of corporate behaviours, means philanthropic practices are highly relevant in shaping business perceptions (Park et al., 2014). In medium-developing countries, however, such as Egypt, only the social and environmental responsibility dimension of CBR is positively associated with philanthropic efforts (Szöcs et al., 2016). This correlation may be partially attributable to Egyptian culture following the 2011 revolution (Avina, 2013), in which CSR activities have become a priority for companies to match heightened public expectations of advancing domestic wellbeing (Szöcs et al., 2016). The month of Ramadan also sees philanthropy and social responsibility as core tenets of domestic livelihood (Singer, 2013), promoting this attribute of CBR above others (Szöcs et al., 2016). As a result, the bounds of linking positive reputation and philanthropy should be understood with further inquiry to improve generalisability across contexts.

Similar to the risk of diminishing financial returns (Wang et al., 2008), scholars highlight that integration of philanthropy into marketing strategy may also have detrimental impacts on reputation. Communicating good deeds and the effectiveness of philanthropy can result in a backfire effect, engendering accusations of commercialism and hypocrisy (La Cour \& Kromann, 2011; Spence \& Thomson, 2009). Brammer and Millington (2005) identified that 
the reputational benefits garnered by corporate philanthropy are likely to be industry-specific, having a significantly more positive effect on industries with negative externalities, such as alcohol and tobacco. Conversely, this effect does not materialise in environmentally sensitive industries, suggesting that businesses must be wary of varied reputational benefits (Brammer \& Millington, 2005). Ultimately, the literature surrounding the impacts of CP on reputation is discordant. Symptomatic of the difficulties that managers face when exercising CP is the fact that a firm's portfolio of giving activities is often more predictive of future philanthropy than consumer responses towards donations (Gardberg et al., 2017). Ham and Kim (2017) explicitly identify the dearth of research considering consumer-held views of corporate philanthropy, particularly when deployed as a disaster response. Liket and Simaens (2015) also emphasise a failure to consider the impact of CP from a person-centric approach. Response strategies have little influence on reputation when consumers attribute crisis responsibility to a business; therefore, firms must develop strengthened understandings of consumer perceptions toward giving in different contexts (Ma \& Zhan, 2016).

\subsection{Corporate Social Responsibility}

Corporate social responsibility refers to the practice of companies integrating "social and environmental concerns in their business operations and in their interactions with their stakeholders, on a voluntary basis" (Commission of the European Communities, 2001, p. 7). While scholars have advanced contrasting definitions, content analyses illustrate five dimensions agreed upon as formulating the basis of CSR: environmental, social, economic, stakeholder, and voluntariness (Dahlsrud, 2008). For the purpose of this paper, CSR is considered centrally through its economic and social dimensions, "including describing CSR in terms of a business operation", alongside the integration of "social concerns in their business operations" (Dahlsrud, 2008, p. 4). This interpretation aligns with the focus of corporate philanthropy, which, as noted previously, centrally considers monetary donations and gifting of paid employee time to assist social concerns (Muller et al., 2014; Philanthropy NZ, 2014).

CSR continues to gain recognition as core business praxis, in which companies integrate social responsibility efforts into everyday operations and strategic planning (Galbreath, 2010; Porter \& Kramer, 2002). Businesses have been increasingly transparent about reporting CSR endeavours, with the underlying reporting rate, albeit abstract, rising to 75 per cent globally 
(KPMG, 2017). New Zealand has seen a particularly pronounced increase from 52 per cent to 69 per cent of companies reporting CSR efforts (KPMG, 2017). Empirical research underpins the positive correlation between CSR and financial performance (Bosch-Badia, MontlorSerrats \& Tarrazon, 2013). This relationship has shifted from the findings of earlier literature, in which little correlation between CSR and financial performance could be established (Beurden \& Gossling, 2008). A lag previously existed between the implementation of CSR initiatives and value creation, as financial markets were not aware of the prospective fiscal gains borne out of CSR (Bosch-Badia et al., 2013). Social responsibility efforts are now recognised as central to sustainable corporate financial wellbeing (Roberts \& Dowling, 2002; Shank, Manullang \& Hill, 2005). General CSR has also been shown to have a positive impact on reputation, ultimately influencing purchase intention (Elving, 2013; Sen \& Bhattacharya, 2001).

The traditional narrow perspective of CSR in business practice is steeped in economic scholarship, contending the relevance of social responsibility (Schwartz \& Saiia, 2012). Friedman (1970. p. 6) posited that firms engaging in CSR programs reveal a "suicidal impulse". For Friedman (1970), businesses merely hold artificial social responsibilities to the public, with CSR endeavours resembling a short-sighted view to garner public plaudits, perpetuating the view that profit-driven companies are inherently immoral. Contemporary literature characterises superficial responsibility activities as promotional CSR, used primarily by companies as a public relations activity to enhance organisational image (Visser, 2011). Prasad and Holzinger (2013) extend an uncertain rhetoric toward CSR, employing Zizek's (1989) false consciousness ideology to deconstruct the prevailing view of CSR. Through this philosophy, Prasad and Holzinger (2013, p. 1918) suggest that businesses engaged in selfless endeavours are shrouded by "unscrupulous political projects that altogether belies altruistic, and even philanthropic, motives". Therefore, a tension exists between fostering positive consumer sentiment through CSR and proliferating profit-driven associations, which should be further examined through empirical study.

Contemporary trends dispel much of Friedman's (1970) formative argument, as promotion of CSR efforts grows. A slew of high profile MNEs have elected to explicitly prioritise CSR initiatives in strategic planning (Strauss, 2017). More than 9,500 companies have signed the 
United Nation's Global Compact (2018) that aligns operations alongside cornerstones of social responsibility, with $80 \%$ of signatories taking recognised action. This approach represents broad CSR, which stipulates that business objectives should transcend financial measures to meet ethical and philanthropic obligations (Schwartz \& Saiia, 2012), such as the vaunted "triple bottom line" (Elkington, 1998, p. 37) metric of business success. A widened perspective of CSR is also referred to as systemic CSR, attempting to combat unsustainable practices through more innovative multinational business models and processes (Visser, 2011). Indeed, BoschBadia et al. (2013) acknowledge the synergistic relationship between CSR and wider value creation, in which CSR has moved from a business expense to a strategic investment that facilitates wide-ranging corporate benefits.

\subsubsection{Consumer Scepticism to CSR}

The perspective of Friedman (1970), and later Prasad and Holzinger (2013), which dispels CSR efforts considered as altruistic, is supported by the discourse of consumer scepticism. Scepticism refers to a person's tendency to express doubt and disbelief (Elving, 2013; Obermiller \& Spangenberg, 1998). Mohr, Eroglu and Ellen (1998) argued that scepticism and cynicism aid in explaining people's reactions to marketing communications. Cynicism is an enduring and stable personality trait that assumes people act based on selfish motives (Mohr et al., 1998). On the other hand, scepticism is not always present, and constitutes a situational and ephemeral impact on consumer evaluations (Brønn \& Vrioni, 2000; Mohr et al., 1998). The role of scepticism in CSR is increasingly significant in normative social practices, as millennial consumers seek out brands with greater transparency that integrate moral practices (Eveland, Crutchfield \& Rynarzewska, 2018). More than $90 \%$ of millennial consumers have claimed to switch brands to those associated with ethical causes, making personal sacrifices for issues they care about (Cone Communications, 2015).

Within previous literature, scepticism to the motives for giving is a pertinent moderating variable that influences the reputational and financial benefits of CSR (Peterson, 2018; Sankar \& Bhattacharya, 2001). Through the lens of attribution theory, consumers make causal inferences about intentions surrounding philanthropic behaviours (Ellen et al., 2000). Perceptions of reputation are more favourable if philanthropy is perceived to be altruistic, rather than a calculated move to influence revenue (Peterson, 2018). Similarly, a long-standing 
reputation for CSR is a significant determinant in consumer-based evaluations of an overall company image, providing "partial buffering" (Gardberg et al., 2017, p. 3) against external shocks, such as disasters. Conversely, short-term involvement in CSR is a cue for consumer scepticism (Vanhamme \& Grobben, 2009), demonstrating the importance of fostering a reputation for social activity, rather than engaging in initiatives solely following significant events.

A conditional form of CSR is cause-related marketing. As previously noted, CRM includes companies forming mutually-beneficial commercial partnerships with charities to market a product (Nan \& Heo, 2007; Vardarajan \& Menon, 1988). Sheikh and Beise-Zee (2011, p. 28) explicate the distinction between CSR and CRM, theorising that "CRM is not a synonym, but a manifestation of CSR", similar to the view of philanthropy as an expression of broader CSR. Conditional CSR risks consumer criticism, perceived as a promotional effort of businesses acting in their best interests, rather than helping to advance social purposes (Dean, 2003; Webb $\&$ Mohr, 1998). Comparatively, integrated forms of CSR that permeate across all policies and stakeholders of an organisation, and are long-term in nature, result in lower levels of consumer scepticism (Elving, 2013).

Communication also plays an essential role in maintaining CSR efficacy. Companies seeking to limit scepticism should ensure no inconsistencies lie between expectations of responsibility efforts and communication tools, therefore limiting criticism levelled toward company motives (Elving, 2013). Skarmeas and Leonidou (2013) noted that motives perceived as egotistic and stakeholder-driven elicit consumer scepticism towards CSR, while values-driven attributions reduce scepticism. Values-driven motives refer to the belief that a company engages in social responsibility efforts because of its moral and ethical duties, acting out of authentic concern for societal problems (Ellen et al., 2000). Becker-Olsen et al. (2006) also found that incongruent messaging in CSR initiatives increases scepticism, and profit-motivated CSR negatively impacts brand attitudes. Evidence of uncertainty surrounding financial transparency is also an indicator for mistrust, as scepticism increases when external donations are not verifiable to a recognised benefactor (Kim \& Lee, 2009). Lower levels of CSR scepticism are apparent when a company's reputation is already viewed positively by consumers, and when there is a harmonious fit between the company and CSR activity (Elving, 2013). The body of scepticism literature emphasises the plurality of contextual factors at play when deploying CSR 
strategies, whereby a failure to acknowledge situating elements may fulfil Friedman's (1970, p. 6) prophesied "suicidal impulse".

Ultimately, prolonged scepticism may result in entrenched cynicism towards a company, detrimentally impacting perceptions of reputation (Kim \& Lee, 2009; Mohr et al., 1998). Heightened CSR scepticism is also likely to have a negative influence on consumers' purchase intention, which can be minimised by improved congruence between CSR activity and the focal company (Elving, 2013). As consumers become increasingly cynical toward the influence of marketing in CSR initiatives (Vanhamme \& Grobben, 2009), it is germane for companies to also consider the moderating influence of scepticism on benefits afforded from philanthropic initiatives. It is unclear whether marketers must become even more strategic and calculated in donation practices as some scholars suggest (see Becker-Olsen et al., 2006; Friedman, 1970; Park et al., 2014), or ensure giving is altruistic and undiluted by politics or financial gains (Galaskiewicz, 1989). By failing to develop an established reputation for giving, short-term involvement is a cue for consumer scepticism (Vanhamme \& Grobben, 2009). Exogenous shocks that incite such short-term CSR responses are less detailed in present studies, therefore contribute to a more comprehensive understanding of consumer scepticism. Extending Peterson's (2018) integration of motive scepticism in the philanthropy-reputation relationship with further circumstantial factors would help to address current gaps in the literature, and situate the relevance of Friedman (1970) in contemporary practices.

\subsection{Ethnocentrism}

Ethnocentrism stems from psychological discourse, referring to a universal tendency of people to favour their group, or community, over others (Sharma et al., 1995; Sumner, 1906; Szöcs, 2013). Evaluations of another culture are influenced by the understanding of one's group, with reference to behaviours, language, and social mores (Booth, 1979; Shimp \& Sharma, 1987). Highly ethnocentric consumers tend to reject people and values that are culturally dissimilar and appear foreign (Herche, 1994). Sumner (1906, p. 13) developed a formative definition for ethnocentrism as, “[...] the view of things in which one's own group is the centre of everything, and all others are scaled and rated with reference to it. Each group nourishes its own pride [...] exalts its own divinities, and looks with contempt on outsiders". The result of such nourishment can lead to consumer perceptions of in-groups and out-groups within society; a concept 
crystallised through social identity theory (Tajfel, 1982). The symbols and values of in-groups garner feelings of pride and sincere attachment, meeting other groups with disdain (Shimp \& Sharma, 1987).

High ethnocentric tendencies are typical for an in-group, relative to an out-group, accepting those who share similar cultural and social values, and rejecting those that are different (Netemeyer, Durvasula \& Lichtenstein, 1991; Shimp \& Sharma, 1987). Cultural relativism represents an antithesis perspective to ethnocentrism, evaluating a person's beliefs, values and practices based on a unique cultural context (Donnelly, 1984). Instead of viewing the world through a universal lens, cultural relativism stipulates a greater understanding of the idiosyncrasies across world views, examined through the cultural context in which people learn (Baghramian \& Adam, 2018). Some contend the historical foundations of ethnocentrism attributed to Sumner (1906), noting its previous existence in classical foreign language publications (Bizumic, 2014). Gumplowicz (1879) advanced ethnocentrism as a similar phenomenon of group centrality, with the belief that one's ethnic persuasion is superior to any others. These reflections, however, critique academic contemporaries that hold ethnocentric tendencies, failing to reflect an objective social science (Bizumic, 2014; Gumplowicz, 1879). As an established author, Sumner (1906) acted as the catalyst that popularised ethnocentrism scholarship across Western social science disciplines. Much of the formative literature surrounding ethnocentrism in social sciences relies on Sumner's (1906) conceptualisation, including Neuliep and McCroskey (1997), Brewer (1999), LeVine and Campbell (1972), and Tajfel (1982).

\subsubsection{Ethnocentrism \& Marketing}

Shimp and Sharma (1987) introduced ethnocentrism thought to marketing, germane to the understanding of consumer behaviour in cross-national settings. From a consumption perspective, consumer ethnocentrism influences perceptions "about the appropriateness, indeed morality, of purchasing foreign-made products" (Shimp \& Sharma, 1987, p. 280). In short, general attitudes toward foreign-made products, compared to domestically-produced goods, are negatively correlated with ethnocentric tendencies. Highly ethnocentric consumers tend to purchase locally-made goods over imported products, perceiving overseas transactions as detrimental to the domestic economy, therefore rejecting 'out-groups' of which foreign 
products are symbolic (Shimp \& Sharma, 1987; Tseng, Balabanis, \& Liu, 2018). A weaker ethnocentric posture sees products evaluated on functional merits and benefits, with little consideration of manufacturing origin (Shimp \& Sharma, 1987). Ethnocentrism represents an important heuristic for consumers to foster feelings of belonging to an in-group social faction, ultimately influencing purchase decisions and behaviour (Aziz, Bahadur, Sarwar, Farooq \& Arshad, 2014; Shankarmahesh, 2006).

Ethnocentric tendencies are also identifiable at the community level, particularly surrounding support of economic health, and local group identity of the place in which consumers live (Lantz \& Loeb, 1998). Szöcs (2013) recognised the salience of community group identity in stimulating ethnocentric tendencies, which then impacts on evaluations of corporate philanthropy. A strengthened local identity augments support for localised giving, compared to assisting in countries abroad (Szöcs, 2013). In a similar vein, CSR literature highlights the prevalence of an egocentric bias when administering social responsibility. CSR activities focused locally, and more personally relevant to consumers, results in stronger reciprocal patronage and future purchase intention, compared to global efforts (Russell \& Russell, 2010). Consumers identifying as global citizens display weakened egocentric biases, actively approving CSR endeavours directed to a foreign country (Russell \& Russell, 2010). Although, reciprocity to CSR only materialises for activities conducted locally, and not by self-identified global citizens. This pattern demonstrates the strength of in-group identification to influence consumer behaviour (Diekmann, 1997; Russell \& Russell, 2010), which should be directly tested in terms of ethnocentrism to facilitate more constructive findings.

More recently, ethnocentrism has been introduced to the relationship between corporate philanthropy and reputation, moderating the effectiveness of philanthropic initiatives (Szöcs, 2013). After engaging in global giving, low ethnocentrism results in more positive evaluations of reputation than for highly ethnocentric consumers (Szöcs, 2013). In an increasingly globalised economy, some evidence suggests that companies elect to amplify philanthropy abroad, with fewer favouring local donations (Lieber, 2015). However, firms tend to still concentrate short-term relief efforts, such as those following a disaster, in areas of commercial operation (Muller \& Whiteman, 2009). 
Evidence from recent disasters illustrates far more significant contributions from firms operating near disaster-impacted areas, opposed to geographically removed businesses (Crampton \& Patten, 2008; Muller \& Whiteman, 2009; Muller \& Whiteman, 2016). Referring to the structural pressures experienced by businesses to participate in their communities of operation, these findings exemplify the principle of place embeddedness (Tilcsik \& Marquis, 2013). Nevertheless, organisations can be equally willing to administer philanthropy in locations not directly tied to their business presence (Tilcsik \& Marquis, 2013), contingent on perceived needs of a benefactor (Schons et al., 2017).

Businesses may also be incentivised to give abroad to augment their international profile, and tie philanthropy to countries with pressing political and civil rights concerns (Brammer et al., 2009). For example, Coca-Cola's international philanthropic foundation focuses on empowering women to achieve equality in developing countries through the ' 5 by 20 ' campaign (Tornhill, 2016), while simultaneously working abroad through the Replenish Africa Initiative to increase access to safe drinking water (The Coca-Cola Company, 2016). Perhaps indicative of contrasting evidence between where countries prefer to give, Szöcs et al. (2016) found high correlations between domestic and global philanthropic efforts, indicating that the geographical focus of philanthropy may not as relevant to stakeholders as previously thought in a nondisaster setting. While few scholarly guidelines inform the burgeoning study of ethnocentrism and philanthropy, previous comparative work also fails to consider highly fraught contexts, such as those following a disaster (Russell \& Russell, 2010; Schons et al., 2017; Szöcs et al., 2016). Therefore, it is of interest to extend Shimp and Sharma's (1987) examination of product preferences into the CSR philanthropic domain to consider whether uncontrollable circumstances and ethnocentrism influence preferences of giving.

\subsection{Research Gaps}

Extant corporate philanthropy research historically demonstrates the strategic importance of giving as a cornerstone element of CSR, fostering market differentiation and consumer goodwill (Carroll, 1979; Collins, 1993). Non-reciprocal giving showcases corporate citizenship and a willingness to provide support for local communities (Brammer \& Millington, 2005). Strengthened financial performance ( $\mathrm{Su} \& \mathrm{He}$, 2010; Wang \& Qian, 2011), employee 
motivation (Block et al., 2017), and reputation (Peterson, 2018) are linked to philanthropy. The body of literature has crystallised around profitability indices as the paragon of philanthropic success (Crampton \& Patten, 2008; Gautier \& Pache, 2015). While widely examined in the literature, corporate reputation measures focus firmly on internal stakeholders (Godfrey, 2005), and aggregate third-party reputation measures (Peterson, 2018). As a result, research fails to effectively integrate first-hand consumer perceptions toward giving (Ham \& Kim, 2017; Liket \& Simaens, 2015).

As a catalyst for philanthropy, research focusing on reactions to disaster relief are minimal. Established findings tend to focus on the amount of money donated, rather than typologies of giving (Brammer \& Millington, 2006; Gao \& Hafsi, 2015). As philanthropy is expressed through both monetary and non-monetary means, it is unclear whether cash donations garner more positive stakeholder evaluations than in-kind voluntary offerings, explicated by inconsistent conclusions across controllable and uncontrollable circumstances (see Brammer \& Millington, 2005; Gao \& Hafsi, 2015; Hildebrand et al., 2017; Muller \& Kräussl, 2011b). Given diminished capacities for giving following natural disasters (Tilcsik \& Marquis, 2013), the impact of entirely forgoing philanthropy would also enrichen present findings.

Moreover, studies typically consider philanthropy administered by uninterrupted firms (Gao \& Hafsi, 2015; Lii \& Lee, 2012), failing to consider reactions of giving by companies adversely impacted in natural disasters. The extent to which companies are disrupted is also likely to be highly varied following natural disasters (Parker \& Steenkamp, 2012), and adversely impacted firms may have surplus employee idle time at their disposable to administer for humanitarian relief (Morris, 2018). Comparing reactions to philanthropy between firms with a different degree of operational disruption has not been reported in the literature, helping to identify whether motives for giving are viewed more positively for suffering firms, thereby fostering moral capital (Godfrey, 2005).

Exogenous variables can also determine the effectiveness of CSR initiatives, with philanthropic discourse requiring more integrative studies that introduce moderating effects (Gautier \& Pache, 2015). Consumer scepticism reduces the effectiveness of CSR initiatives (Skarmeas \& 
Leonidou, 2013), and influences evaluations of companies (Elving, 2013). Examining the impact of scepticism on philanthropic assessments contributes further specificity to present findings in the CSR domain (Kim \& Lee, 2009). Moreover, the extent to which a disaster context suspends suspicion, and promotes altruistic views of giving, is unique to consider. Findings in this area will help to address the contention that short-term CSR is always a prompt for scepticism (Seifert et al., 2004; Vanhamme \& Grobben, 2009), introducing different contexts for philanthropy.

The interaction of ethnocentrism and corporate giving has also been scarcely considered by researchers, yet is necessary to address as companies determine the allocation of philanthropic resources between local and overseas benefactors (Lieber, 2015; Schons et al., 2017). It is unclear whether local giving is most appropriate to match heightened expectations of domestic wellbeing following crisis conditions (Szöcs et al., 2016), or whether consumer desires to give back to international communities overrides local needs (Schons et al., 2017). Szöcs (2013) typifies the moderating effect of ethnocentrism on philanthropic evaluations across geographic benefactors. As a factor in disaster relief giving, ethnocentrism should be addressed to expand contextual insights of philanthropy, equipping managers with more detailed consumer preference knowledge (Park et al., 2014; Szöcs et al., 2016). Extending consumer ethnocentrism from a proxy for goods-based preferences, to a predictor of philanthropic preferences, also helps to address gaps in normative ethnocentrism knowledge. 


\section{Chapter Three: Conceptual Development}

This chapter identifies core research problems and objectives across three studies, which have stemmed from gaps in present knowledge. The underpinning conceptual models and constructs are also detailed, before proposing relationships that each study examines.

\subsection{Research Problem \& Objectives}

The core relationship between corporate philanthropy and reputation is first investigated; in particular, the impact of different philanthropic strategies on customer-based corporate reputation. The body of literature establishes that corporate philanthropy is advantageous to corporate reputation (see Brammer \& Millington, 2005; Gardberg et al., 2017; Lii \& Lee, 2012; Morris et al., 2013; Peterson, 2018). However, little empirical work has considered the relationship between philanthropy and reputation in a disaster-based context; instead, focusing on philanthropy as a broad CSR tool at the disposal of firms (Avina, 2013; Hildebrand et al., 2017; Lii \& Lee, 2012; Schwartz \& Saiia, 2012). Further, the delineation of corporate giving across different approaches (monetary, employee time, forgoing to minimise internal disruptions) directly informs marketers of consumer preferences toward relief strategies.

The moderating role of consumer scepticism towards CSR is assessed in the philanthropyreputation relationship, acknowledging complication of the main effect through exogenous variables. Empirical work shows that scepticism influences perceptions of a firm's CSR initiatives and purchase intention (see Elving, 2013; Kim \& Lee, 2009; Peterson, 2018; Sankar \& Bhattacharya, 2001). As philanthropy represents a component of CSR (Wang \& Qian, 2011), there is evidence suggesting that scepticism also impacts on perceptions of reputation following corporate disaster relief giving (Peterson, 2018) (see Figure 3.1).

Given the paucity of disaster-based reputational research, the nuances of giving during these uncontrollable circumstances should be better understood. Companies that exhibit short-term profitability elect to give more when operating near the geographic location of a disaster (Crampton \& Patten, 2008; Muller \& Whiteman, 2009). However, it remains unclear whether adopting an outward, society-focused posture is perceived more positively by consumers when 
companies are also adversely affected. It is useful to assess the extent to which operational disruptions impact upon reputational perceptions of corporate giving. These findings help to elucidate whether suffering businesses should risk philanthropic practice during times of distress to foster reputation, or whether consumers perceive uninterrupted businesses as more appropriate to assist.

Finally, the moderating impact of ethnocentrism on the relationship between philanthropy and corporate reputation is analysed, further addressing Gautier and Pache's (2015) appeal for more complex and integrative $\mathrm{CP}$ studies. Ethnocentrism influences consumer perceptions about the morality and likelihood of purchasing foreign-made products (Shimp \& Sharma, 1987), and evaluations of corporate philanthropy at a community-based level (Szöcs, 2013). While postdisaster analysis finds that firms are willing to engage in giving overseas to augment their international profile (Brammer et al., 2009), studies fail to consider whether ethnocentrism impacts the efficacy of cross-national disaster philanthropy. Comparatively, the effects of domestic giving on reputation, following a disaster, have not been examined with respect to ethnocentrism. As consumers negotiate local or global citizenship and cause involvement (Russell \& Russell, 2010), researchers should consider whether ethnocentrism is a significant moderator in reactions to philanthropy across domestic and overseas aid.

\subsubsection{Research Objectives}

In light of the gaps in relevant literature across corporate philanthropy, reputation, scepticism, and ethnocentrism, the following research objectives are proposed:

1) Determine whether monetary donations or voluntary employee time have a stronger effect on customer-based corporate reputation, following a disaster.

2) Establish whether external disaster relief philanthropy is more beneficial to customerbased corporate reputation than forgoing giving entirely.

3) Determine the extent to which benefits of philanthropic aid on corporate reputation are moderated by consumer scepticism towards motives for giving.

4) Compare the reputational impacts of philanthropy for a company with its operations adversely impacted by a disaster, and a company with operations uninterrupted.

5) Determine the extent to which ethnocentrism influences perceptions of corporate reputation for a company giving locally, and those giving overseas. 


\subsection{Study 1A}

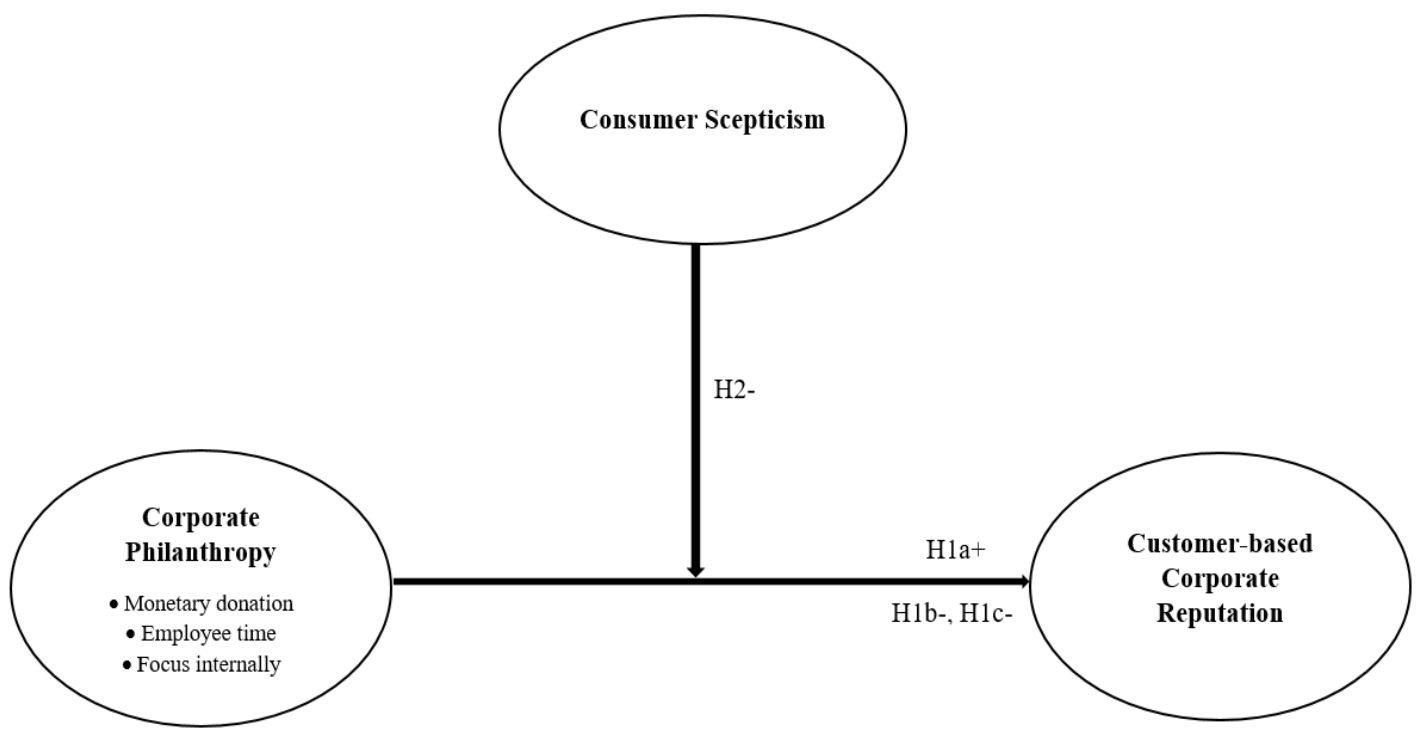

Figure 3.1 Study 1A Conceptual Model

\subsubsection{Hypotheses Development}

As previously acknowledged, several studies have considered the impact of corporate philanthropy on reputation (Brammer \& Millington, 2005; Ma \& Zhan, 2016; Morris et al., 2013). However, little is known about contextual factors that can impact the efficacy of giving, such as disaster-based settings. Further, a dearth of empirical inquiry compares the reputational value of different philanthropic practices (Hildebrand et al., 2017), more likely to analyse amounts given (Gao \& Hafsi, 2015). Study 1A seeks to better understand the reputational impact of CP during disasters; in particular, donating money and employee time.

In a non-disaster context, Brammer and Millington (2005) found that cash donations resulted in stronger benefits to reputation than in-kind giving, while Gao et al. (2012) posited that market participants react more positively to monetary donations. However, amid circumstances deemed uncontrollable, in-kind contributions may garner similarly positive reactions from consumers (Hildebrand et al., 2017). Moreover, attempts to foster long-term positive perceptions through employee involvement are viewed more positively than short-term injections of cash (Muller \& Kräussl, 2011b; Twigg, 2001). These findings indicate that the 
preferred type of philanthropic response may be subverted following a disaster, away from pure cash donations. However, previous studies situated in uncontrollable crises rarely consider corporate volunteering as the comparative response mechanism (Hildebrand et al., 2017). There is also reason to believe that consumers may hold weaker preferences for giving during a disaster (Ellen et al., 2000), focused on addressing basic human needs, such as access to power and water (Baker, 2009). Given the conflicting reasoning of preferred typology in a disaster context, the following hypothesis is proposed:

Hla: Monetary donations and employee time will have a commensurate positive impact on customer-based corporate reputation.

In addition to monetary giving and voluntary employee time, the final philanthropic condition focuses on forgoing giving entirely, allowing the impacted company to focus on minimising disruptions to its internal operations. Relevant literature does not directly consider companies focusing inward during a disaster, lauding the benefits of engaging in external giving (Brammer \& Millington, 2005; Gardberg et al., 2017; Lii \& Lee, 2012; Morris et al., 2013; Peterson, 2018). Interestingly, stakeholder-driven measures of corporate reputation widely acknowledge the importance of including a service or product quality dimension (Fombrun et al., 2000; Helm, 2007; Schwaiger, 2004; Walsh et al., 2009). Businesses may risk weakening the quality of their value delivery when prioritising external assistance, grappling with significant and costly disruptions (McKnight \& Linnenluecke, 2016). Consequently, it is useful to examine firms that bypass philanthropy to focus on internal operations, given the practical difficulty of simultaneously administering giving, and preserving service delivery. As in Ellen et al. (2000), consumers may perceive the failure to give as a company promoting self-interest, rather than making community-based sacrifices, therein undermining reputation. Hence, the proposed hypotheses state:

H1b: Forgoing philanthropy to minimise internal disruptions will be less beneficial to reputation than donating money.

H1c: Forgoing philanthropy to minimise internal disruptions will be less beneficial to reputation than donating employee time. 
Scepticism influences consumer evaluations of CSR initiatives, whereby high levels of scepticism reduce the efficacy of social responsibility (Peterson, 2018; Sankar \& Bhattacharya, 2001). From a philanthropic standpoint, short-term giving is a cue for high levels of scepticism (Vanhamme \& Grobben, 2009), suggesting that post-disaster aid could incite sceptics to question underlying motives for donations. Consumers will not view a firm positively if they perceive motives as selfish to solely augment brand image and sell products (Becker-Olsen et al., 2006; Cui et al., 2003; Gao \& Hafsi, 2015; Skarmeas \& Leonidou, 2013). High CSR scepticism can also weaken consumer purchase intention and company evaluations (Elving, 2013; Kim \& Lee, 2009; Peterson, 2018). Therefore, it is of interest to understand whether scepticism moderates the relationship between $\mathrm{CP}$ and reputation following a disaster, in which consumers have less reasonable opportunity to assess giving (Ellen et al., 2000). Hence, the proposed hypothesis states:

H2: Consumers less sceptical about the CSR motives of a company will perceive corporate philanthropy more positively than highly sceptical consumers. 


\subsection{Study 1B}

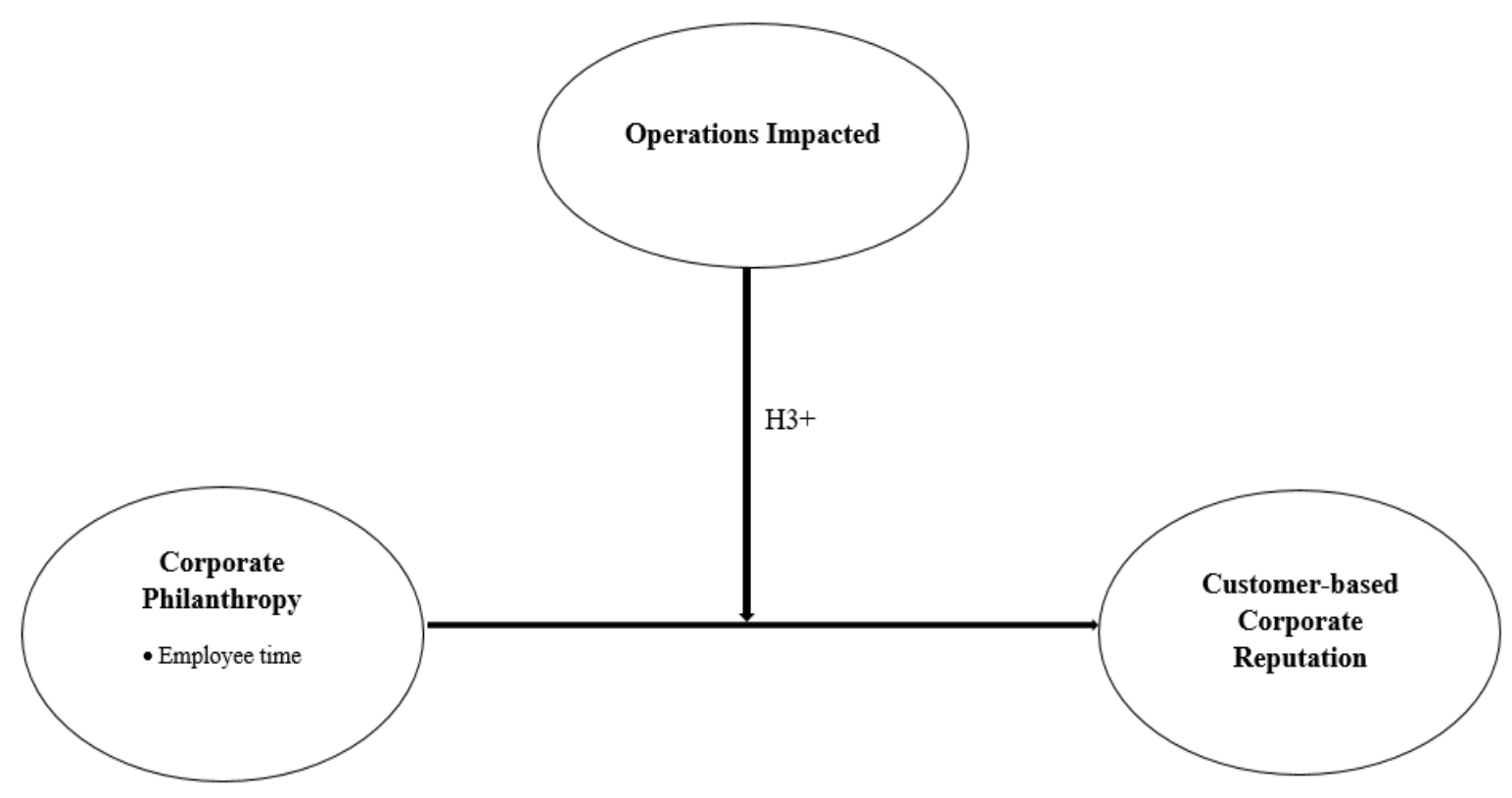

Figure 3.2 Study 1B Conceptual Model

\subsubsection{Hypotheses Development}

For the purposes of this study, $\mathrm{CP}$ is based solely on employee voluntary time, which refers to the formal sponsorship and subsidisation of employee community outreach activities on company time (Muller et al., 2014), such as disaster recovery clean-up (Whittaker et al., 2015). Corporate volunteering offers a personal and active form of involvement following a disaster, compared to monetary giving (Twigg, 2001). Employee time is also a relevant archetype of CP to compare reputational perceptions of disrupted operations, as employee involvement offers a sense-giving effect that sends positive signals to the marketplace about the value of philanthropy, promoting buy-in from stakeholders (Muller \& Kräussl, 2011b). During a disaster, particularly when operations are disrupted, companies are best equipped to offer employee time to assist in recovery efforts (Morris, 2018; Whittaker et al., 2015), hence the relevance of employee volunteering in a disaster setting.

Profitable firms operating in disaster-impacted areas are likely to give more significant philanthropic contributions than those operating abroad (Crampton \& Patten, 2008; Muller \& Whiteman, 2009). Moreover, companies closely linked to disasters experience local pressures to assist, drawing upon intimate civic knowledge to promote domestic well-being (Tilcsik \& 
Marquis, 2013; Szöcs et al., 2016). However, it is not clear if these pressures result in reputational benefits for businesses also suffering ill effects of disasters. The direct comparative impact on reputation for a firm not impacted is also unknown, yet provides a striking contrast to understand whether disrupted operations impact consumer evaluations of giving. The 2011 series of Christchurch earthquakes illustrates that disaster damage can be disproportionate in different geographical areas of a city, with Eastern suburbs impacted to a much greater extent than businesses in the West (Parker \& Steenkamp, 2012). The realism of this eventuality in a post-disaster setting is apparent; as such, businesses should assess whether disrupted operations affect reactions to giving.

Companies donating while in the midst of a disaster may enjoy stronger reputational benefits, advancing the interests of the impacted community above their own (Godfrey, 2005) (see Figure 3.2). Moreover, giving during a disaster is likely to promote altruistic and sincere associations (Yoon et al., 2006), especially when a firm is suffering itself (Ellen et al., 2000). Comparatively, calculated giving by companies not directly adversely impacted can be viewed as ingratiating and disingenuous (Patten, 2008). Therefore, the hypothesis of Study 1B states:

H3: Donating employee time following adverse impacts to operations will have a more positive effect on reputation, than when companies are not adversely affected. 


\subsection{Study 2}

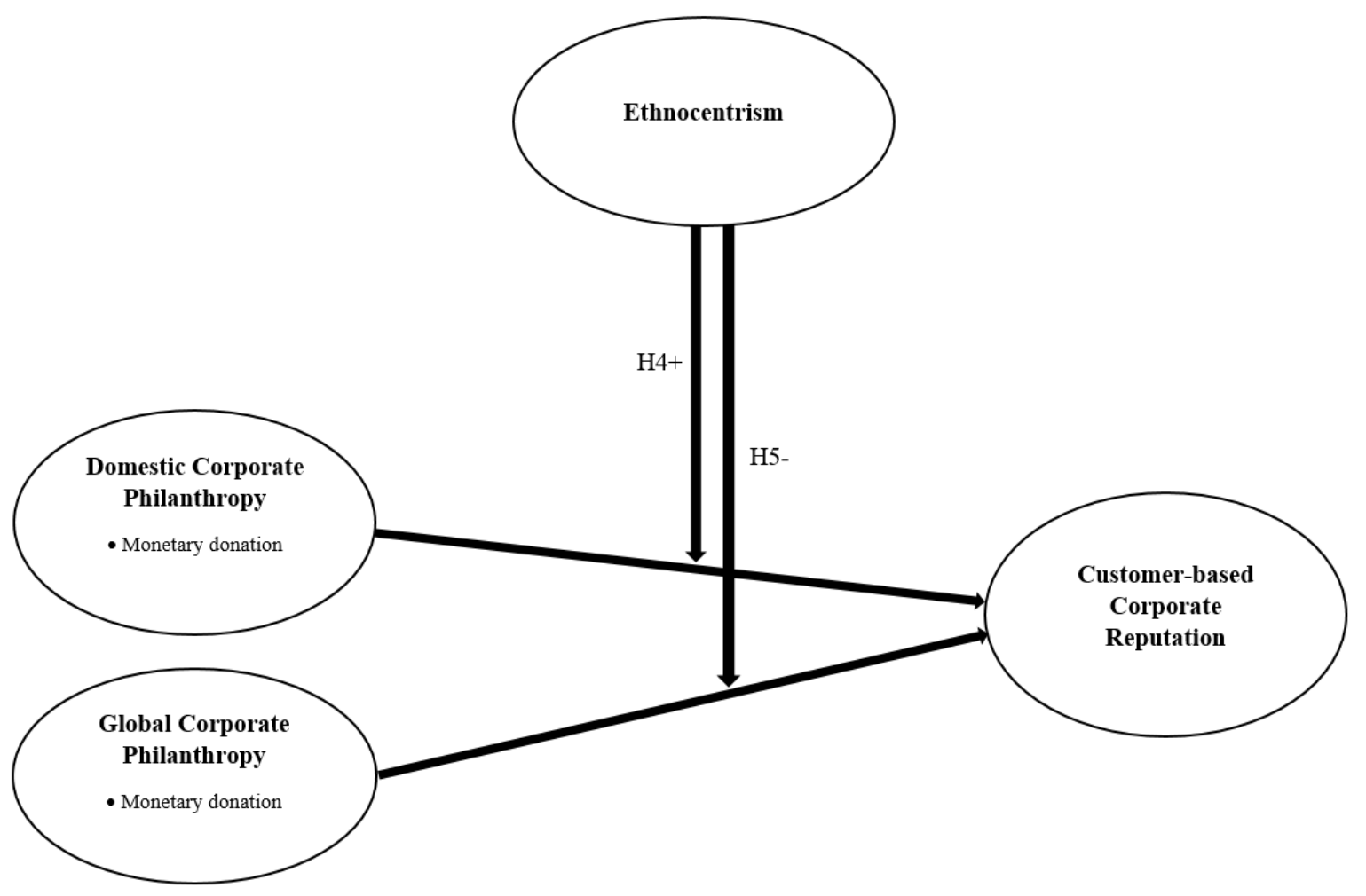

Figure 3.3 Study 2 Conceptual Model

\subsubsection{Hypotheses Development}

Previous research has investigated consumer ethnocentrism in relation to consumer attitude and purchase intention of local- and foreign-made products (Kaynak \& Kara, 2002; Maruyama \& Wu, 2015; Nguyen, Nguyen \& Barrett, 2008; Shimp \& Sharma, 1987). However, ethnocentrism is less examined in present CSR literature, yet provides an essential consideration for cross-national giving. Companies are increasingly willing to give abroad (Lieber, 2015; Muller \& Whiteman, 2009), cognisant of how philanthropy may strengthen international business profiles and appeal to domestic and international audiences (Brammer et al., 2009; Collins, 1993). Giving by corporations with a multinational profile is useful to build engagement with local communities (Van der Vegt et al., 2015), and is likely to be perceived as less self-promotional than domestic firm contributions (Mithani, 2017), underscoring the incentive of foreign giving. Less ethnocentric consumers are more likely to consider the interests of people abroad, who may in greater need of auxiliary resources (Shimp \& Sharma, 1987). Instead, highly ethnocentric individuals prefer to support and purchase locally-made goods (Shimp \& Sharma, 1987). Although consumer preferences for domestic 
and foreign charity vary markedly, highlighting the importance of confounding in-versus-out group positions when developing giving strategies (Schons et al., 2017). Domestic country biases are also inconsistent across cultures, varying based on relevant local product categories (Auger et al., 2010).

Philanthropy is also perceived uniquely across different cultures (Rampal \& Bawa, 2008). Following global giving, consumers with lower levels of ethnocentrism view company reputation more positively than highly ethnocentric counterparts (Szöcs, 2013). Focusing CSR activities domestically, versus abroad, also results in greater loyalty and purchase intention towards a brand (Russell \& Russell, 2010). Although, consumers that identify as global citizens experience weakened patronage and purchase intention compared to self-interested consumers (Russell \& Russell, 2010). This link suggests the moderation of cross-national philanthropy by exogenous consumer traits, such as ethnocentrism.

Moreover, Schons et al. (2017) noted that methodologies in previous charitable giving research assume an inherent preference of people toward their own in-groups and communities. This partiality only holds for a small proportion of society, necessitating a less biased approach to inquiry that comprises cross-national philanthropy (Schons et al., 2017). Following Szöcs' (2013) determination that ethnocentrism is negatively correlated with global giving, and positively linked to domestic donations, the established directionality is assumed to hold in a disaster context (see Figure 3.3). In essence, ethnocentric consumers continue to exalt the importance of localised response giving and negatively assess aid given abroad (Szöcs, 2013). These findings illuminate the following proposed hypotheses:

H4: When companies engage in domestic philanthropy, high (low) ethnocentric consumers will perceive stronger (weaker) reputational benefits than consumers low (high) in ethnocentrism.

H5: When companies engage in global philanthropy, high (low) ethnocentric consumers will perceive weaker (stronger) reputational benefits than consumers low (high) in ethnocentrism. 


\section{Chapter Four: Methodology}

The following chapter outlines the underpinning research approach and methodology used to conduct these studies. The chosen experimental design and conditions are detailed, describing philanthropic scenarios based on the objectives stated above. Data collection methods, questionnaire development, sampling, and data analysis strategy are also discussed.

\subsection{Research Approach}

The research paradigm inherently reflects a scholar's underpinning views and beliefs of academic inquiry that provide the philosophical position for investigation, referred to as epistemology and ontology (Creswell, 2014; Lather, 1986). The chosen paradigm influences how research is undertaken and, ultimately, understood (Creswell, 2014). Research in marketing traditionally spans from positivism to constructivism, with Deshpande (1983) first challenging the discipline's reliance on positivist perspectives to move towards a more balanced investigation model.

Positivism is founded on the belief of a single reality that is measured objectively through empirical study (Lincoln, Lynham \& Gruba, 2011). The constructivist paradigm differs by viewing knowledge as socially constructed through multiple realities, based on ever-changing individual and group perspectives (Lincoln et al., 2011). Research operationalised through quantitative and experimental methods sits towards the positivist end of the spectrum, working on testing theories through deductive reasoning (Rovai, Baker \& Ponton, 2014). Conversely, holistic understandings are developed within a constructivist lens, focusing on qualitative theory development and generation through inductive reasoning (Lincoln et al., 2011; Rovai et al., 2014). Positivism is not immune to criticism, as researchers contest the ability to universally verify a statement, such as formulated hypotheses, by a finite number of observations (Hudson \& Ozanne, 1988). Similarly, constructivism is undermined by questions of bias due to a reliance on subjectivity, limiting the ability to generalise findings (Creswell, 2014).

The proposed studies lie within the post-positivist zeitgeist, which ameliorates issues associated with a positivist approach, such as the suggestion of one objective reality. Post- 
positivism also focuses on determining the nature of relationships, yet recognises the fallibility of observations through inherent biases and error (Trochim, Donnelly \& Arora, 2016). As a result, the ontological assumptions of post-positivism acknowledge that reality can only be understood by researchers "imperfectly and probabilistically" (Lincoln et al., 2011, p. 98). From an epistemological perspective, post-positivism takes a modified dualist and objectivist position, assuming that the researcher and phenomena are independent entities while noting that absolute objectivity is not always possible (Salvador, 2016). Despite the inevitability of biases, researchers must attempt to minimise extraneous influence to ensure reliable results, and remain open to critical conjecture to inform findings (Creswell, 2014).

This research employed a post-positivist approach by examining established constructs and findings in a new context, objectively testing the impact of moderating variables. The intersection of disaster philanthropy and reputation comprises limited research, meaning findings should be viewed through a probabilistic reality, with more detailed analysis still to be considered. Armstrong (2013) demonstrated that disasters could be viewed through both extremes of positivism and constructivism, as positivist study focuses on measurable outcome variables, such as citizen displacement and fatalities. Comparatively, constructivism examines social factors, such as negligence in policy, or construction regulations that worsen disaster impact (Armstrong, 2013; Schwartz, 2012). A strictly positivist approach is less suited to this research, as perceptions of scepticism and ethnocentrism are subjective phenomena, interpreted and constructed by the social realities of individuals (Lincoln et al., 2011). However, each can be objectively measured as a human sensibility through established scales, and used to test for moderating impacts on the philanthropy-reputation relationship.

\subsection{Methodology}

A quantitative approach forms the basis of this paper's inquiry. Patton (2001) argued that postpositivist research should select a methodology that fits with its objectives. Through deductive logic, hypotheses have developed from current literature for empirical testing. Therefore, a quantitative methodology is appropriate to determine the nature of proposed relationships (Creswell, 2014; Rovai et al., 2014). Quantitative approaches fit within post-positivism, which remains focused on testing causal effects to develop a probabilistic understanding of reality. Quantitative study is limited in its explanation of why phenomena have occurred, but is 
generalisable for practitioners to apply findings and reproduce inquiry in different contexts (Easley, Madden \& Dunn, 2000).

Experimental design was the chosen quantitative methodology. Experiments test the nature of relationships by manipulating independent variables to assess impacts on a dependent variable, while holding other factors constant (Zikmund, Babin, Carr \& Griffin, 2013). Robust design ensures respondents are manipulated effectively between independent experimental conditions, with resulting differences in the dependent variable able to be compared (Zikmund et al., 2013). Previous research examining $\mathrm{CP}$ and corporate reputation has commonly applied an experimental approach (Bae \& Cameron, 2006; Elving, 2013; Kim, 2014; Kim \& Lee, 2009; Lii \& Lee, 2012; Shim \& Yang, 2016; Yoon et al., 2006). Experiments fit within the postpositivist canon by recognising the potential of extraneous factors to influence findings; meaning effects can only be considered probabilistically by maintaining control across subjects (Creswell, 2014).

Scenario-based designs were applied to situate respondents in a disaster context. Experimental studies regularly use scenarios and descriptive vignettes (Lii \& Lee, 2012; Nan \& Heo, 2007; Shim \& Yang, 2016; Szöcs, 2013), as does disaster-related CSR research (Hildebrand et al., 2017). Scenarios develop more novel and interesting lines of scholarly inquiry, opening the ability to unearth and explore complex research domains (Ramirez, Mukherjee, Vezzoli, \& Kramer, 2015). Ma and Zhan (2016) also posited that scholars should base crisis scenarios on real events to promote generalisability and realism for participants. Further, manipulating responses (monetary, employee time, forgoing giving) helps to reduce biases caused by memory lapses, rationalisation tendencies, and consistency factors (Grewal, Levy \& Lehmann, 2004).

\subsection{Research Design}

This research employed online experimental questionnaires. Experimental questionnaires are appropriate when testing hypotheses based on previously established relationships (Vargas, Duff \& Faber, 2017), with respondents able to be effectively manipulated, and confounding effects controlled. A true experiment was followed in each study, randomly assigning 
respondents across conditions, as opposed to a quasi-, non-random, experiment (Vargas et al., 2017). Online questionnaires are used effectively to generate responses and produce valid findings for research across the core disciplines of these studies: corporate philanthropy (Dean, 2003), corporate reputation (Hur, Kim \& Woo, 2014), consumer scepticism (Elving, 2013), and ethnocentrism (Szöcs, 2013).

Qualtrics hosted all three surveys, providing a robust digital research platform, which is accessible across different web-enabled devices. Major advantages of online survey collection are the flexibility of dissemination, speed in generating responses, and convenience for participants (Evans \& Mathur, 2005). Experimental conditions were also seamlessly integrated to ensure philanthropic conditions had been randomly assigned to reduce systematic bias, with between-subject differences explained by manipulations (Creswell, 2014). Further, respondents outside of the sample frame could be redirected to the end of the questionnaire, while participant completion of all items and scales was made mandatory to reduce incomplete datasets (Evans \& Mathur, 2005).

Anonymous online survey links were published across a range of social media platforms; namely, Facebook and Twitter. Further, the Blackboard pages of two undergraduate university marketing courses, and local community web platform, Neighbourly, aided in data collection. Social platforms offer a high volume and low-cost vehicle for survey dissemination (Evans \& Mathur, 2018), with more than 3.5 million active Facebook users over the age of 13 years old in 2018 (Statista, 2019b). The opportunity to win a \$75 New World grocery voucher was offered for completing a questionnaire, with winners randomly selected following the completion of data collection. Given resource and time constraints, an online questionnaire provided the most cost-efficient and convenient way to generate an appropriate number of participants for statistical analysis.

While holding many virtues, online surveys may be perceived as impersonal, punctuated by issues of privacy and security, low overall completion rates, and self-reporting error, due to not reading questions correctly (Evans \& Mathur, 2018; LaRose \& Tsai, 2014). Technological variations also limit the efficacy of online questionnaires, such as small screen size, and 
browser compatibility altering how questions are displayed (Evans \& Mathur, 2005). The use of Qualtrics minimised many of these issues to optimise compatibility for mobile-based users, which is an increasingly popular platform for survey completion (Evans \& Mathur, 2018). Further, $89 \%$ of the New Zealand population are active internet users, with the country in the top 15 worldwide for high-speed broadband penetration (OECD, 2019; Statista, 2019a). The ethics approval attained for this research, and anonymity in respondent identification, was made visible when first opening the survey to assuage concerns of privacy and information security. Manipulation checks were also included to overcome any reporting errors and poor participant cognition of scenarios.

\subsection{Experimental Procedure}

\subsubsection{Pre-Test}

Pre-testing is a critical component of robust empirical research, helping to inform survey design, remedy comprehension issues, and justify the chosen method (Van Teijlingen \& Hundley, 2001). A pre-test questionnaire was distributed to inform the research and ensure the survey instruments were robust for application in a disaster context, deploying a non-specific form of philanthropic response. Further, the pre-test was used to verify that the survey instrument was well-comprehended by participants concerning philanthropy, and respondents could recall the focal disaster. The initial pre-test garnered 67 respondents, finding that all scales were considered reliable in a disaster context, and explained sufficient variation to be used in the focal studies (see Appendix D). As a result of the initial pre-test, the final two elements of Wepener and Boshoff's (2015) CBR conceptualisation (good employer and service points) were removed due to perceived lack of relevance in a disaster setting (see Table 4.1). Similarly, the wording of Brønn \& Vrioni's (2000) four-item scepticism to CRM scale was amended to reflect a company broadly promoting or discussing its CSR initiatives, as opposed to claims on advertising and packaging labels (see Table 4.1).

The three final questionnaires were then distributed to a small subsample of the over 18-yearold, New Zealand-based, target population. As in Morris et al. (2013), feedback was garnered on scale comprehension, and the ability to effectively situate respondents in a disaster-based context. Participant feedback resulted in amendments to the final questionnaire scenario (see Appendix E), with the average duration of completion also noted. The main scenario-based 
design was simplified to focus on the 2016 7.8-magnitude Kaikōura earthquake, providing a recent event for participants to draw upon in answering scenarios. The philanthropic donor was also amended to resemble a for-profit, fictitious company (see Appendix E). Pre-test participants also suggested incentivising involvement with a form of reward, which may improve survey completion rates (Van Selm \& Jankowski, 2006). Consequently, the aforementioned random draw of $\$ 75$ New World vouchers was offered in each study to garner survey responses.

\subsubsection{Design and Measures}

All items were measured using a 7-point Likert scale (ranging from Strongly Disagree - 1, to Strongly Agree - 7). Some items were retrospectively re-coded to ensure participants had been paying appropriate attention, and represent the same directionality in data analysis. Table 4.1 contains all items across the three studies, with PowerHouse (Study 1A \& 1B) and Teletech (Study 2) employed interchangeably. 
Table 4.1 Operationalisation of Scales

\begin{tabular}{|c|c|c|}
\hline Scale / Source & Original Items & Adapted Items (if necessary) \\
\hline $\begin{array}{l}\text { Customer-based } \\
\text { corporate } \\
\text { reputation } \\
\text { (Wepener \& Boshoff, } \\
\text { 2015) }\end{array}$ & $\begin{array}{l}\text { Emotional appeal } \\
\text { - I have a good feeling about XY } \\
\text { - I admire XY } \\
\text { - I trust XY } \\
\text { - I am proud to be associated with XY } \\
\text { Social engagement } \\
\text { - XY supports good causes } \\
\text { - XY is committed to social responsibility (social issues) } \\
\text { - XY responds to the needs of communities } \\
\text { - XY reaches out to its social environment } \\
\text { Corporate performance } \\
\text { - XY appears to make financially sound decisions } \\
\text { - XY has good management in place } \\
\text { - The management of XY is held in high regard } \\
\text { - XY outperforms its competitors financially } \\
\text { Good Employer } \\
\text { - XY treats its employee well } \\
\text { - XY seems to pay attention to the needs of employees } \\
\text { - XY looks after the well-being of its employees } \\
\text { Service Points } \\
\text { - XY's online services are user-friendly } \\
\text { - XY's online services are effective } \\
\text { - Booking online with X is easy }\end{array}$ & $\begin{array}{l}\text { - } \quad \text { I have a good feeling about PowerHouse (Teletech) } \\
\text { - } \quad \text { I admire PowerHouse (Teletech) } \\
\text { - } \quad \text { I trust PowerHouse (Teletech) } \\
\text { - I am proud to be associated with PowerHouse (Teletech) } \\
\text { - } \quad \text { I like PowerHouse (Teletech) } \\
\text { - } \quad \text { PowerHouse (Teletech) supports good causes } \\
\text { - } \quad \text { PowerHouse (Teletech) is committed to social responsibility } \\
\text { - PowerHouse (Teletech) responds to the needs of communities } \\
\text { - } \quad \text { PowerHouse (Teletech) reaches out to its social environment } \\
\text { - PowerHouse (Teletech) appears to make financially sound } \\
\text { - } \quad \text { decisions } \\
\text { - } \quad \text { The manerHouse (Teletech) has good management in place }\end{array}$ \\
\hline $\begin{array}{l}\text { Scepticism towards } \\
\text { cause-related } \\
\text { marketing } \\
\text { (Brønn \& Vrioni, } \\
\text { 2000) }\end{array}$ & $\begin{array}{l}\text { - Most statements made by companies in advertising or } \\
\text { product labels about supporting non-profit organisations } \\
\text { are true } \\
\text { - Most statements made by companies in advertising, or on } \\
\text { product labels, about supporting non-profit organisations } \\
\text { are intended to mislead, rather than inform, the customer }\end{array}$ & $\begin{array}{l}\text { - Most statements made by companies in advertising or product } \\
\text { labels about supporting non-profit organisations are true } \\
\text { Most statements made by companies supporting non-profit } \\
\text { organisations are intended to mislead, rather than inform, the } \\
\text { customer }\end{array}$ \\
\hline
\end{tabular}


- $\quad$ Because most statements made by companies that they support non-profit organisations are exaggerated,

consumers would be better off if such statements were eliminated from advertising or package labels

- I do not believe most statements regarding support of nonprofit organisations made by organisations in advertising or package labels
- Because most statements made by companies that they support non-profit organisations are exaggerated, consumers would be better off if such statements were eliminated from being advertised or spoken about

- I do not believe most statements regarding support of non-profit organisations

\section{Ethnocentrism}

(Neuliep \&

McCroskey, 2013)
- Most other cultures are backward compared to my culture

- My culture should be the role model for other cultures

- Lifestyles in other cultures are just as valid as those in my culture

- Other cultures should try to be more like my culture

- People in my culture could learn a lot from other cultures

- Most people from other cultures just don't know what's good for them

- I respect the values and customs of other cultures

- Other cultures are smart to look up to our culture

- Most people would be happier if they lived like people in my culture

- People in my culture have just about the best lifestyles of anywhere

- Lifestyles in other cultures are not as valid as those in my culture

- I do not cooperate with people who are different

- I do not trust people who are different

- I dislike interacting with people from other cultures

- I have little respect for the value and customs of other cultures 


\subsubsection{Study $1 \mathrm{~A}$}

\subsubsection{Experimental Scenario Conditions}

A fictitious local energy provider, PowerHouse, represented the focal company administering philanthropic response, therein ensuring respondents held no previous associations to impact reputational evaluations. Fictitious companies are used frequently in experimental reputation research to control for established subject attitudes towards the abilities of companies (Bae \& Cameron, 2006; Elving, 2013; Kim, 2014; Kim \& Lee, 2009; Shim \& Yang, 2016; Yoon et al., 2006). Moreover, energy providers represent a large service industry that is highly relevant to consumers and can be captured effectively by CBR measures, such as Wepener and Boshoff's (2015) multidimensional service-based construct. Further, the utility industry is highly familiar to the targeted sample of New Zealand consumers over 18 years old, ensuring respondents were able to make thorough reputational assessments. Using an industry familiar and significant to sample consumers is consistent across previous CSR and philanthropic literature (Kim, 2014; Park et al., 2014; Shim \& Yang, 2016). Following the survey's completion, respondents were informed that PowerHouse represents a fictitious company, designed for this study (see Appendix A).

The monetary amount donated to the Red Cross was based on Lii and Lee's (2012) experimental study, which compares consumer judgments based on the type of CSR initiative. Lii and Lee (2012) operationalise $\$ 100,000$ as the donation value to a non-profit outfit following a mudflow disaster, resulting in significantly positive evaluations to a realistic level of giving. The in-kind employee volunteer contribution was valued at $\$ 100,000$ worth of overall labour, noted as staff members each providing 40 hours of assistance. The two contribution types were made equivalent in value to control for the possibility of confounding variations to perceptions of company involvement (Hildebrand et al., 2017).

As the benefactor of giving, the Red Cross represents a formally registered and globally recognised humanitarian organisation, operating as the leading response organisation to disasters and alleviation of human suffering (Walker \& Maxwell, 2009). Perceived as one of the most transparent and accountable non-profit organisations worldwide (Charity Navigator, 2019), the Red Cross is second in gross income among international aid organisations. The 
humanitarian group also houses the largest number of staff (McLeod, 2017), signifying a robust third-party facilitator of philanthropic activities.

The third scenario focused on PowerHouse minimising disruptions to its internal operations, forgoing external giving. Instead of immediately reacting through philanthropy, some companies may be overwhelmed by disaster circumstances, and reduce corporate spending incited by adverse economic conditions (Tilcsik \& Marquis, 2013). Hence, the third condition evaluated consumers' reputational views of bypassing philanthropy. The results of this condition can also be compared to the monetary- and time-based strategies to determine whether managers experience visible criticism when focusing firm resources internally. A between-subjects design ensured respondents received unique scenarios (see Table 4.2), and were less likely to be impacted by potential carry-over and demand effects of answering all conditions (Charness, Gneezy, \& Kuhn, 2012).

These studies focus on a real-life disaster that has occurred recently, helping to establish realism for participants (Ma \& Zhan, 2016). The 2016 7.8-magnitude Kaikōura earthquake is the focal disaster scenario, which resulted in widespread damage across Kaikōura and Wellington, totalling NZ\$2.14 billion in insurance claims, 57 injuries, and 2 deaths (Deloitte, 2017; Insurance Council of New Zealand, 2018). Kaikōura represents one of New Zealand's most devastating and costly natural disasters, and as a recent event, ensures familiarity for participants. Further, pre-testing (see 4.4.1. Pre-Test) demonstrates that participants value temporal proximity in disaster stimulus.

The use of a real-life event is consistent with previous studies in CSR and disasters (Bae \& Cameron, 2006; Hildebrand et al., 2017; Lii \& Lee, 2012). Given that consumer scepticism is measured as a moderating variable, it was also pertinent to base the studies on actual disasters, reducing any perceived scepticism towards fictitious study designs, or ability to guess the research objectives. Moreover, the noted research purpose was to, simply, investigate consumer perceptions, ensuring participants could not guess the experiment's purpose or consciously modify answers. 
Table 4.2 Study 1A Experimental Conditions

\begin{tabular}{|c|c|c|c|}
\hline $\begin{array}{c}\text { Philanthropic } \\
\text { response }\end{array}$ & $\begin{array}{c}\$ 100,000 \text { donation to the Red } \\
\text { Cross }\end{array}$ & $\begin{array}{c}\text { Employee voluntary time valued } \\
\text { at \$100,000 across all staff }\end{array}$ & $\begin{array}{c}\text { Minimising internal } \\
\text { disruptions to operations }\end{array}$ \\
\hline $\begin{array}{c}\text { Disaster } \\
\text { condition }\end{array}$ & 1 & 2 & 3 \\
\hline $\begin{array}{c}\text { Dependent } \\
\text { variable }\end{array}$ & Customer-based corporate reputation \\
\hline $\begin{array}{c}\text { Moderating } \\
\text { variable }\end{array}$ & Consumer scepticism & \multicolumn{2}{|c|}{} \\
\hline
\end{tabular}

\subsubsection{Measured Variables}

\section{Corporate Reputation}

Corporate reputation was measured through Wepener and Boshoff's (2015) customer-based corporate reputation scale; a construct that can be measured relatively parsimoniously with a high level of reliability (Walsh et al., 2009). Walsh and Beatty (2007) first developed CBR as a multidimensional affective attitude towards an organisation, and cross-validated the scale for generalisability (Walsh et al., 2009). Wepener and Boshoff (2015) updated the formative CBR scale, addressing issues with respondent comprehension, and weak overall construct validity and dimensionality. Extensive scale development highlights the applicability of CBR for large service organisations across non- and for-profit business models (Wepener \& Boshoff, 2015). These changes resulted in a service-based five dimension attitude $(\alpha>0.8)$ (see Table 4.1).

This research focuses on the first three elements of the CBR construct, as good employer and service points (digital) lack relevance in a disaster response context, which was verified through pre-testing. Positively correlated with important consumer antecedent and outcome variables, such as satisfaction, trust and loyalty, CBR is a robust measure through which to examine demand-side perceptions of giving. 


\section{Consumer Scepticism}

Consumer scepticism was measured by an adapted four-item scale, advanced by Brønn and Vrioni (2000) $(a>0.9)$, determining the degree to which consumers are disbelieving toward cause-related claims. Scepticism holds a fundamental role in shaping stakeholder perceptions toward a company, with high scepticism risking the rejection of claims made, and failure to purchase products (Skarmeas \& Leonidou, 2013). Brønn and Vrioni (2000) adapted their scale based on Mohr et al.'s (1998) formative instrument, shifting its focus towards broad-based CSR, rather than claims of responsibility within the natural environment. For the purposes of this study, the four-item scepticism scale was adapted to consider general statements made by companies about CSR initiatives, rather than advertising claims to promote generalisability (see Table 4.1).

Through a median split, the final consumer scepticism score was derived to identify consumers that exhibit high, versus low, scepticism. Median splits are widely used in established social responsibility and CRM literature to transform continuous variables into a dichotomous construct for between-group comparisons (Arendt \& Brettel, 2010; Chomvilailuk \& Butcher, 2010). More specifically, Mohr and Webb (2005) divided consumers exhibiting high and low socially responsible behaviour (SRCB), finding significant results when comparing differences of company evaluation and purchase intent across philanthropic and environmental obligations.

\subsubsection{Manipulation Checks}

Manipulation checks are an essential safeguard to identify and remove careless or inattentive respondents that undermine the veracity of research (Geuens \& De Pelsmacker, 2017). Following exposure to the disaster scenario and CBR items, respondents were asked: "How is PowerHouse helping the Red Cross following this disaster?" (see Appendix A). Respondents that did not identify the philanthropic condition to which they were exposed were removed from the dataset. Further, the duration of survey completion was analysed. Online questionnaires offering incentives risk completion by people who rush through surveys to collect a reward (Evans \& Mathur, 2018). Therefore, responses that lasted under 2 minutes were removed from the dataset, as pre-testing indicated an average length of 5 minutes to reasonably and attentively complete the survey. 
Finally, participants were asked about the purpose of this experiment by answering, "What do you think this study is about?" following all items. Experiments can be prone to response biases; in particular, demand characteristics in which participants alter their behaviour, and may try to guess the purpose of research (Martin, 1962). Random allocation in the betweensubjects design helped to ameliorate confounding demand effects (Charness et al., 2012). Further, robustness was ensured by scrutinising the dataset to remove participants suspicious about study objectives, and those explicitly reporting difficulties understanding questionnaire instructions (Hildebrand et al., 2017).

\subsubsection{Study $1 B$}

\subsubsection{Experimental Scenario Conditions}

Study 1B compares the reputational benefits of CP for a company adversely impacted by disaster, and a company with operations uninterrupted (see Table 4.3). Through betweensubjects design, respondents were randomly exposed to one of these conditions experienced by fictitious Wellington-based energy provider, PowerHouse. Both groups viewed the same disaster vignette describing the 2016 7.8-magnitude Kaikoura earthquake and its effects on Wellington (see Appendix B), with the sole manipulation between groups as to whether PowerHouse's operations are adversely impacted. The hypothetical philanthropic response of donating $\$ 100,000$ worth of overall employee volunteering time (40 hours per employee) remained identical across groups to maintain internal validity.

Table 4.3 Study 1B Experimental Conditions

\begin{tabular}{|c|c|c|}
\hline Disaster scenario & $\begin{array}{c}\text { 7.8-magnitude earthquake in Kaikōura } \\
\text { (Operations impacted) }\end{array}$ & $\begin{array}{c}\text { 7.8-magnitude earthquake in Kaikōura } \\
\text { (Operations not impacted) }\end{array}$ \\
\hline Study condition & 1 & 2 \\
\hline $\begin{array}{c}\text { Dependent } \\
\text { variable }\end{array}$ & Customer-based corporate reputation \\
\hline
\end{tabular}




\subsubsection{Measured Variables}

As in Study 1A, customer-based corporate reputation was measured using the same adapted scale advanced by Wepener and Boshoff (2015) (see Table 4.1).

\subsubsection{Manipulation Checks}

Manipulation checks were also included in the survey instrument to assess whether participants had correctly engaged with the manipulated scenario, asking: "Have PowerHouse's operations been disrupted as a result of the Kaikōura earthquake?" (see Appendix B). Respondents that answered incorrectly, relative to their experimental condition, were removed from further analysis to reduce the impact of inattention. However, carelessness was minimal due to the between-subjects design (Geuens \& De Pelsmacker, 2017). Similar to Study 1A, participants were ultimately asked to identify the research purpose, excluding those sceptical towards its aims, or expressing confusion to experimental procedures (Hildebrand et al., 2017).

\subsubsection{Study 2}

\subsubsection{Experimental Scenario Conditions}

In Study 2, the benefactor of philanthropy was manipulated between two countries (see Table 4.4). Respondents were randomly assigned between giving within a domestic context to assist the Kaikoura earthquake recovery, and providing assistance following the devastating 2018, 7.5-magnitude New Caledonia earthquake (Perry, 2018) (see Appendix C). Teletech, a fictitious Auckland-based telecommunications company, represented the philanthropic business. Auckland was not directly disrupted by the Kaikōura disaster, meaning Teletech was not bound by inherent structural pressures to donate within its direct community (Deloitte, 2017; Tilcsik \& Marquis, 2013). Auckland also represents New Zealand's largest local economy, closest significant geographical link to New Caledonia, and highest population of Pasifika people (Statistics NZ, 2019), suggesting a higher likelihood to provide direct aid than other New Zealand cities. Removing the effect of companies directly involved in disaster ensured Study 2 provided a different corporate perspective to Studies 1A and 1B.

The global and domestic giving scenarios utilised the neighbouring Pacific Island nation to maintain a realistic giving benefactor. New Zealand regularly provides aid to Pacific Island 
nations, with budgeted giving recently increased by 30\% (\$714 million) over the next four years to humanitarian and multilateral agencies (Ministry of Foreign Affairs \& Trade, 2018). This proclivity to donate was also evidenced following South Pacific Cyclone Gita in 2018, whereby several companies undertook fundraising or in-kind donations, including Vodafone (National Business Review, 2018) and The Coca-Cola Company (2018).

The monetary donation value of $\$ 100,000$ remained aligned with Lii and Lee (2012), and ensures internal consistency with previous levels of giving and the overall research. Comparatively, the alternate scenario saw Teletech provide philanthropic aid to the domestic Kaikōura disaster. Participants assigned to each condition were not informed of the corresponding disaster condition when completing the survey to avoid priming in the betweensubjects design (Creswell, 2014). Similar to Szöcs' (2013) examination of ethnocentrism in collective and individualistic cultures, Study 2 manipulates the selection of domestic and international giving to determine the reputational effects of philanthropy.

Table 4.4 Study 2 Experimental Conditions

\begin{tabular}{|c|c|c|}
\hline Disaster scenario & 7.8-magnitude earthquake in Kaikōura & 7.5-magnitude earthquake in New Caledonia \\
\hline Study condition & 1 & 2 \\
\hline $\begin{array}{c}\text { Dependent } \\
\text { variable }\end{array}$ & \multicolumn{2}{|c|}{ Customer-based corporate reputation } \\
\hline $\begin{array}{c}\text { Moderating } \\
\text { variable }\end{array}$ & Ethnocentrism \\
\hline
\end{tabular}

\subsubsection{Measured Variables}

As in Study 1A and Study 1B, corporate reputation is measured using Wepener and Boshoff's (2015) adapted CBR instrument (see Table 4.1). 
Ethnocentrism was measured using Neuliep and McCroskey's (2013) updated 15-item scale, with a robust internal consistency $(a>0.8)$. This scale asked consumers to express their level of agreement towards questions about their views towards other cultures and social groups (see Table 4.1). Neuliep and McCroskey's (1997) formative scale has been used widely across both social science and business disciplines, therefore helps to promote generalisability of findings. The updated instrument removes 7 questions with weak explanatory power to isolate 15 items that capture ethnocentrism (Neuliep \& McCroskey, 2013). Similar to scepticism, consumers were identified as high or low in ethnocentrism through a median split to create a dichotomous variable for between-group comparisons, following Tseng et al.'s (2018) consumer ethnocentrism procedure.

\subsubsection{Manipulation Checks}

In Study 2, a manipulation check followed the comparative scenarios of a company giving locally and globally, asking participants: "Where did this natural disaster take place?" (see Appendix C). Respondents that answered a location deviating from their experimental condition were removed from further analysis. Analogous to Study 1A and Study 1B, participants were once again asked to identify the purpose of this research, helping to minimise response bias and demand effects, adhering to established practices (Hildebrand et al., 2017; Martin, 1962).

\subsection{Research Sample}

The overall experiment used samples of New Zealand consumers over 18 years old, as disasters are non-discriminatory and can impact any autonomous consumers. Respondents outside of this sample frame were re-directed to the end of the surveys, and thanked for their participation. As the studies draw upon examples of domestic and Pacific Island disasters, New Zealand residents were the most appropriate sample frame. Participants are likely to be familiar with the scenario stimulus used, and able to provide informed responses, of which international consumers may be less aware. Extant corporate reputation and CSR research commonly adopts over 18-year-old student samples due to ease of accessibility as self-governing consumers (Elving, 2013; Lii \& Lee, 2012; Shim \& Yang, 2016; Szöcs, 2013; Yoon et al., 2006). 
As discussed, the experimental scenarios of Study 2 compared a New Zealand company responding to disasters within New Zealand, or in New Caledonia. The overall broad sample frame may capture some New Zealand consumers who also identify as Pasifika, leading to potential biases and skewed findings when comparing a New Zealand and Pacific Island benefactor (Rampal \& Bawa, 2008). Therefore, in Study 2, the responses of Pasifika participants were sectioned out and specifically compared to the remaining sample, ensuring there were no significant differences in CBR evaluations between groups. This procedure helps to reduce issues of cross-national biases, in which Pasifika respondents must negotiate a confounding Pacific Island benefactor in their judgments.

This research relied on purposive sampling, through the publication of surveys on Facebook, Twitter, Blackboard, and Neighbourly, with respondents required to meet age and country of residence criteria. Employing a number of dissemination platforms attempted to generate a range of age, income and education levels across participants. Although, this technique can result in self-selection bias, failing to capture an accurate representation of the target population (Hair, Black, Babin \& Anderson, 2010). The randomised exposure of respondents to experimental conditions helped to reduce the prevalence of such biases, assuming population differences are accounted for (Hair et al., 2010). Further, time and resource constraints meant a purposive approach was deemed appropriate, alongside the widespread internet access of local consumers (Statista, 2019a). The limitations of this technique are taken into consideration in the interpretation of findings and future research considerations.

Respondents were also encouraged to disseminate surveys across their own social networks, similar to Szöcs' (2013) dual-use of judgment and respondent referral techniques in a reputation-based study. Social media is suitable for referral methods, with platforms offering integrated sharing capabilities of online questionnaire links (Baltar \& Brunet, 2012). Similar to a purposive approach, respondent referrals are criticised for failing to capture a heterogeneous sample (Hair et al., 2010). However, many accessible platforms for organic, low-cost data collection, such as Reddit, now prohibit the recruitment of users for research (Reddit, 2019). These circumstances meant that trusted social network referrals were relied upon as an auxiliary measure to generate sufficient access to the target population. 


\subsubsection{Sample Size}

Geuens and De Pelsmacker (2017) suggest 30 to 40 participants per experimental condition to ensure sufficient statistical power at the $95 \%$ confidence level. Hair et al. (2010) also recommend a minimum of 30 to 50 subjects per cell to reduce sampling error and the detrimental impact of non-normality. Study 1A contained three experimental conditions, requiring an absolute minimum of 90 participants to test the differences between CBR perceptions of each philanthropic strategy, and examine the effect of high and low consumer scepticism. Further, Study 1B and Study 2 were based on two primary conditions, meaning each study required a minimum of 60 responses, respectively, to determine CBR differences. Although, Study 2 sought higher participation, as it also compared high and low ethnocentrism and aimed to generate a wide spread of ethnocentric tendencies. Approximately 50 complete respondents per condition were targeted for each study, ensuring that participants who failed manipulation checks could be removed from further analysis. Further, a greater number of responses helps to provide a richer spectrum of consumer scepticism and ethnocentrism perceptions. Alongside randomised assignment to conditions, Qualtrics also allowed real-time tracking of response numbers, ensuring each study met its targeted participants.

\subsection{Data Analysis Strategy}

Following data collection through Qualtrics, responses were processed and analysed using SPSS statistical analysis software. Respondents that failed to complete the survey were first removed, before assessing manipulation checks to refine the data and ensure all respondents met standard procedures. The data was then coded and explored with descriptive statistics and factor analyses to assess item and construct validity. A series of independent sample $t$ tests and ANOVA, with post hoc analyses, were conducted to test the proposed hypotheses.

\subsection{Ethics Approval}

This research was granted ethics approval by Victoria University of Wellington's Pipitea Human Ethics Committee (Application ID: \#26872). Participant anonymity has been ensured by the use of anonymous online survey links. Qualtrics collected responses, with no personal information garnered to identify individual involvement. Prize draws were also carried out using questionnaires independent to the core studies. The aggregation of data through analysis meant findings are not reported with respect to unique participants; instead, in an aggregated form of insights. 


\section{Chapter Five: Results}

This chapter presents a quantitative analysis of the results found in each study. Descriptive statistics are first discussed, before assessing the reliability and validity of findings. The hypotheses are tested using independent sample $t$ tests and analysis of variance (ANOVA).

\subsection{Validity \& Reliability}

Face validity refers to the appropriateness of a scale or procedure in measuring a desired construct, while also ensuring items are comprehended easily by respondents (Hair et al., 2010). All scales used in this research are established as reliable within the literature. Pretesting within the target population, and revisions to the wording of scales in a disaster context, helped to promote face validity and ensure robust analytical procedure. All constructs were also assessed for overall validity to ensure scale items accurately reflect the measured variables.

Convergent validity was established across the scales and experimental conditions using a number of factor analyses. The final usable dataset met the minimum requirements for further statistical analysis to be considered factorable, with a Kaiser-Meyer-Olkin (KMO) value over .50 and Bartlett's Test of Sphericity of $p<0.001$ (Kaiser, 1974). All communalities of scale items were also above .50, which Hair et al. (2010) identify as the minimum acceptable threshold to represent the proportion of common variance in each item. Finally, factor loadings were examined to check for issues with cross-loading between constructs (Hair et al., 2010). Factors loads all met the established criteria above .70 for robust statistical practice, or were removed from further statistical analysis (Hair et al., 2010).

Scale reliability was also considered to ensure the research procedure was able to garner consistent results over time, which is particularly important due to its newfound application in a disaster context. The Cronbach's alpha value of all constructs and conditions was above the accepted threshold of 0.7 , therein suggesting scale reliability for further statistical testing, alongside pre-test measures (Allen, Bennett \& Heritage, 2014). Appendix G contains the full factor analysis for each study. 


\subsection{Study 1A}

\subsubsection{Response Analysis}

The questionnaire for Study 1A garnered 375 total participants, with 225 providing complete responses. A further 19 respondents were deemed invalid, failing to identify the correct type of philanthropy administered by PowerHouse, leaving 206 datasets appropriate for statistical analysis. A cross-tabulation illustrated that each philanthropic condition received between 66 and 73 usable responses, which is within the recommended per cell guideline (Hair et al., 2010).

\subsubsection{Descriptive Statistics}

The sample of Study 1A was primarily young, exemplified by $61.7 \%$ of participants between the ages of 18-25 years. Although, $17.5 \%$ of the sample sat between $26-45$ years, and $15.0 \%$ aged 46-64 years, providing some spread in age. Further, this research attracted a higher female cohort (75.2\% of participants). Education attainment was evenly spread, with most participants either holding a high school certificate as their highest form education $(34.0 \%)$, or a Bachelor's degree $(34.0 \%)$. The overall descriptive statistics for Study 1A are reported in Table 5.1.

Table 5.1 Study 1A Descriptive Statistics

\begin{tabular}{|c|c|c|}
\hline & Frequency & Percentage of Sample (\%) \\
\hline \multicolumn{3}{|l|}{ Age } \\
\hline 18 to 25 years & 127 & 61.7 \\
\hline 26 to 45 years & 36 & 17.5 \\
\hline 46 to 64 years & 31 & 15.0 \\
\hline 65 years and over & 12 & 5.8 \\
\hline Total & 206 & 100 \\
\hline \multicolumn{3}{|l|}{ Gender } \\
\hline Male & 51 & 24.8 \\
\hline Female & 155 & 75.2 \\
\hline Gender diverse & 0 & 0 \\
\hline Total & 206 & 100 \\
\hline \multicolumn{3}{|l|}{ Education Attainment } \\
\hline No qualification & 2 & 1.0 \\
\hline High School Certificate/NCEA Level 3 & 70 & 34.0 \\
\hline Tertiary Diploma & 22 & 10.7 \\
\hline Bachelor's Degree & 70 & 34.0 \\
\hline Honours Degree & 14 & 6.8 \\
\hline Master's Degree & 25 & 12.0 \\
\hline Doctorate Degree & 3 & 1.5 \\
\hline Total & 206 & 100 \\
\hline \multicolumn{3}{|l|}{ Enrolled in Study } \\
\hline Yes & 100 & 48.5 \\
\hline No & 106 & 51.5 \\
\hline Total & 206 & 100 \\
\hline
\end{tabular}




\subsubsection{Factor Analysis}

The factor analysis for the 12-item CBR scale (monetary donation) illustrates that $72.6 \%$ of reputation variance can be explained by underlying latent factors. CBR_3, CBR_4 and CBR_5 did not meet the established requirement for factor loads and were therefore considered for deletion, as reported in Table 5.2. See Appendix F for the full form of item abbreviations.

Table 5.2 Factor Analysis: Monetary Donation

\begin{tabular}{|c|c|c|c|c|}
\hline & & Variance Explained & $\begin{array}{c}\text { Cronbach's } \\
\text { Alpha }\end{array}$ & KMO \\
\hline Scenario 1 & $\begin{array}{l}\text { Customer-based } \\
\text { Corporate Reputation }\end{array}$ & \multirow{8}{*}{$72.6 \%$} & \multirow{8}{*}{.931} & \multirow{8}{*}{$\begin{array}{c}.876 \\
p<.001\end{array}$} \\
\hline \multirow{7}{*}{$\begin{array}{l}\$ 100,000 \text { donation } \\
\text { to Red Cross }\end{array}$} & $\begin{array}{l}\text { CBR_1 } \\
\text { CBR_2 } \\
\text { CBR 6 }\end{array}$ & & & \\
\hline & CBR_7 & & & \\
\hline & CBR_8 & & & \\
\hline & CBR_9 & & & \\
\hline & CBR_10 & & & \\
\hline & CBR_11 & & & \\
\hline & CBR_12 & & & \\
\hline
\end{tabular}

The second reputation-based factor analysis (employee time) indicates that $69.7 \%$ of the variance in CBR perceptions is accounted for by factors of CBR. CBR_4, CBR_6, CBR_7, CBR_8, and CBR_9 did not meet the minimum requirements for factor analysis and were removed before continuing with statistical procedure, which is reported in Table 5.3.

Table 5.3 Factor Analysis: Employee Time

\begin{tabular}{|c|c|c|c|c|}
\hline & & Variance Explained & $\begin{array}{c}\text { Cronbach's } \\
\text { Alpha }\end{array}$ & KMO \\
\hline Scenario 2 & $\begin{array}{l}\text { Customer-based } \\
\text { Corporate Reputation }\end{array}$ & & & \\
\hline $\begin{array}{l}\text { Employee } \\
\text { voluntary time } \\
\text { valued at } \$ 100,000 \\
\text { across all staff }\end{array}$ & $\begin{array}{l}\text { CBR_1 } \\
\text { CBR_2 } \\
\text { CBR_3 } \\
\text { CBR_5 } \\
\text { CBR_10 } \\
\text { CBR_11 } \\
\text { CBR_12 }\end{array}$ & $69.7 \%$ & .868 & $\begin{array}{c}.803 \\
p<.001\end{array}$ \\
\hline
\end{tabular}


Table 5.4 reports the final CBR factor analysis, relating to PowerHouse forgoing philanthropy and focusing on minimising disruptions to its internal operations. $78.0 \%$ of the variance is explained by the components of CBR. CBR_4 and CBR_12 failed to meet the minimum criteria for further analysis and were removed from the dataset.

Table 5.4 Factor Analysis: Minimising Internal Disruptions

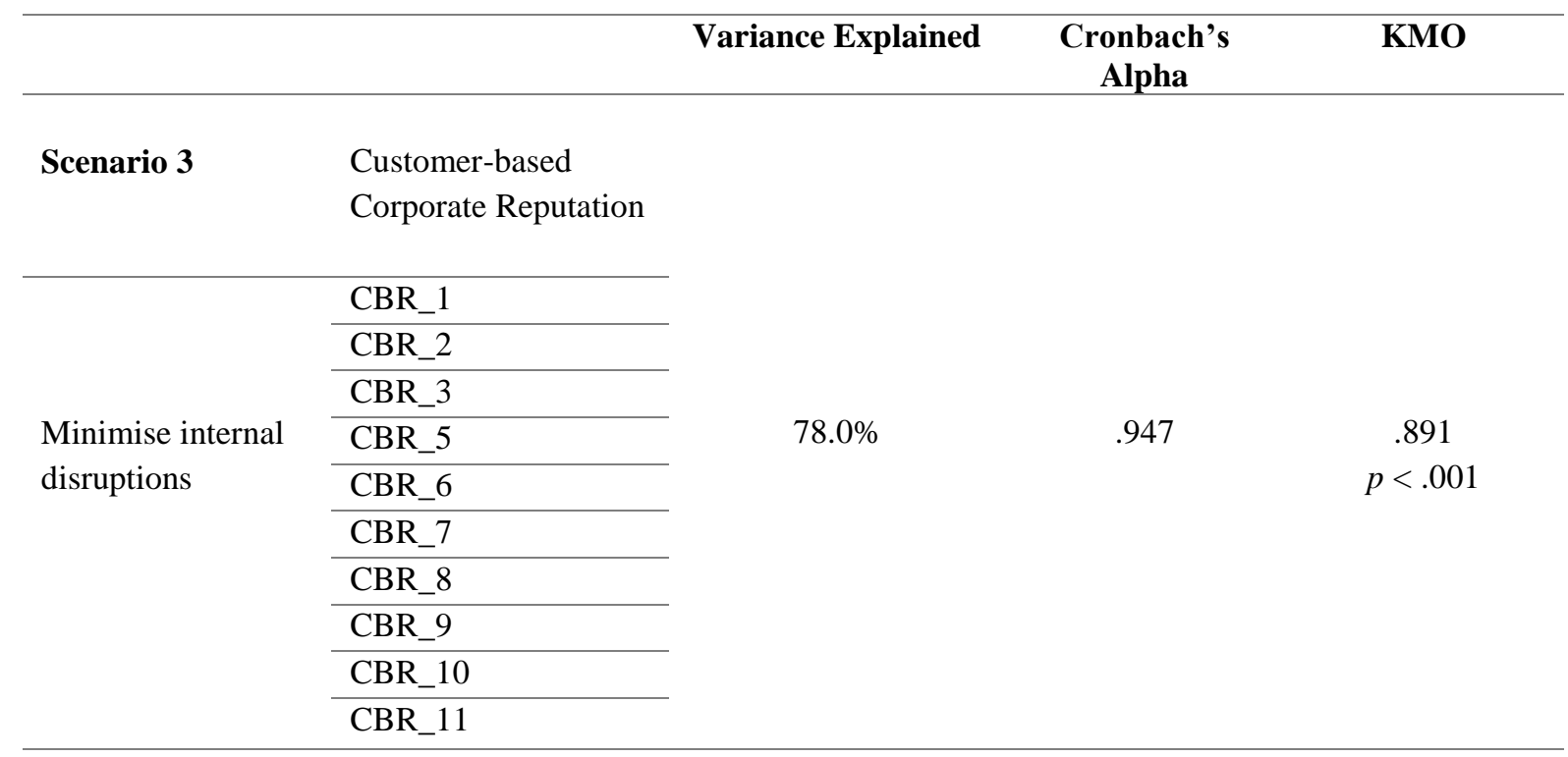

Results of the factor analysis for consumer scepticism are reported in Table 5.5. The total variance explained output indicates that $64.6 \%$ of the variance can be accounted for by one factor. Scept_3 did not meet the minimum criteria for factor analysis, leading to its removal from further research as an explanatory item.

Table 5.5 Factor Analysis: Consumer Scepticism

\begin{tabular}{llccc}
\hline & & Variance Explained & $\begin{array}{c}\text { Cronbach's } \\
\text { Alpha }\end{array}$ & KMO \\
\hline \multirow{2}{*}{$\begin{array}{l}\text { Consumer } \\
\text { Scepticism }\end{array}$} & Scept_1 & & & .668 \\
\cline { 2 - 2 } & Scept_2 & $64.6 \%$ & .726 & $p<.001$ \\
\hline
\end{tabular}




\subsubsection{Non-response Bias}

Non-response bias is evident when participant responses differ in significant and meaningful ways from members of the population who did not respond, undermining the validity of the findings (Armstrong \& Overton, 1977). Through the successive waves extrapolation method proposed by Armstrong and Overton (1977), respondents who contributed later in the data collection phase are assumed to have participated due to increased stimulus for involvement in the experiment. The results indicate whether non-response impacted the validity of this research. After splitting the data into two waves of response data, an independent samples $t$ test comparing consumer scepticism between waves found no statistically significant difference between scepticism evaluations (Mfirst $=3.684, S D=1.00$ vs Msecond $=3.635, S D=.879$; $t(206)=.380, p=.704)$. These findings suggest that non-response bias was not evident in the data and analysis could continue.

\subsubsection{Assumptions of One-Way ANOVA}

After conducting comprehensive factor analyses on all items to ensure validity and reliability, the items were computed into averages for each construct across scenarios. Two of the core assumptions of one-way ANOVA are endogenous to the methodological approach. The dependent variable (CBR) was observed using a scale of measurement, and independence was maintained by respondents only completing the questionnaire once. Each group of scores should also be approximately normally distributed. Table 5.6 reports the skewness and kurtosis of the dataset, indicating the extent to which it deviates from perfectly normal distribution. The CBR score of all scenarios, and high, versus low, scepticism CBR conditions are within the acceptable range of +2 to -2 for skewness, and +3 to -3 for kurtosis (Allen et al., 2014). ANOVA is typically still considered robust, even if there are moderate violations of normality assumptions (Allen et al., 2014). The homogeneity of variance was also evaluated, to ensure an approximately equal amount of variability in the reporting figures of each group. Levene's statistic was not significant at $\alpha=.05, F(2,203)=2.776, p=.065$. Therefore, the assumption of homogeneity of variance was not violated, and the proposed statistical testing could be continued. 
Table 5.6 Study 1A Normality Statistics

\begin{tabular}{lcccc}
\hline & \multicolumn{2}{c}{ Skewness } & Kurtosis \\
\cline { 2 - 4 } & Statistic & Std. Error & Statistic & Std. Error \\
\hline Monetary Donation & -.029 & .295 & .041 & .582 \\
\hline Employee Time & .193 & .293 & -.740 & .578 \\
\hline $\begin{array}{l}\text { Minimising internal } \\
\text { disruptions }\end{array}$ & .087 & .281 & -.750 & .555 \\
\hline $\begin{array}{l}\text { High Scepticism } \\
\text { CBR Group }\end{array}$ & -.031 & .257 & .002 & .695 \\
\hline $\begin{array}{l}\text { Low Scepticism } \\
\text { CBR Group }\end{array}$ & .660 & .354 & -.119 & \\
\hline
\end{tabular}

\subsubsection{Hypothesis Testing: Corporate Philanthropy \& Reputation}

A one-way between groups ANOVA was used to investigate the impact of different philanthropic strategies on customer-based corporate reputation. The ANOVA was statistically significant, suggesting that consumer evaluations of corporate reputation were influenced by PowerHouse's choice of philanthropic initiative, $F(2,204)=64.198, p<.001, n^{2}=.632$.

Post hoc analyses with Tukey's HSD $(\alpha=.05)$ elucidates that consumers perceive reputation significantly worse for a company forgoing external philanthropy $(M=3.825, S D=1.099)$, than when a company donates money $(M=5.404, S D=.806)$ or employee time $(M=5.284$, $S D=.811)$. Interestingly, there was no significant difference between the CBR scores of employee time and monetary donation $(p=.732)$, suggesting that the null relationship hypothesised holds true. In other words, respondents perceived an equivalent level of positive reputational value in either form of philanthropic initiative. The overall between-subjects effect size $(d=1.018)$ is considered large in magnitude, approaching Sawilowsky's (2009), albeit arbitrary, characterisation as 'very large'. Relative effect sizes comparing forgoing philanthropy and monetary donation $(d=1.954)$, or employee time $(d=1.798)$ are also both classified as very large. The results of the one-way ANOVA and post hoc analyses are reported in Table 5.7 and Table 5.8 . 
Table 5.7 One-Way ANOVA: Corporate Philanthropy \& Reputation

\begin{tabular}{lccccc} 
& \multicolumn{1}{c}{$\begin{array}{c}\text { Sum of } \\
\text { Squares }\end{array}$} & df & $\begin{array}{c}\text { Sig. } \\
(2-\text {-tailed })\end{array}$ & F \\
\hline $\begin{array}{l}\text { Corporate } \\
\text { philanthropy } \\
\begin{array}{l}\text { scenario } \\
(\mathrm{CBR})\end{array}\end{array}$ & Between Groups & 109.188 & 2 & & \\
\cline { 2 - 4 } & Within Groups & 172.632 & 203 & .030 & \\
\hline
\end{tabular}

Table 5.8 Post Hoc Analyses: Corporate Philanthropy \& Reputation

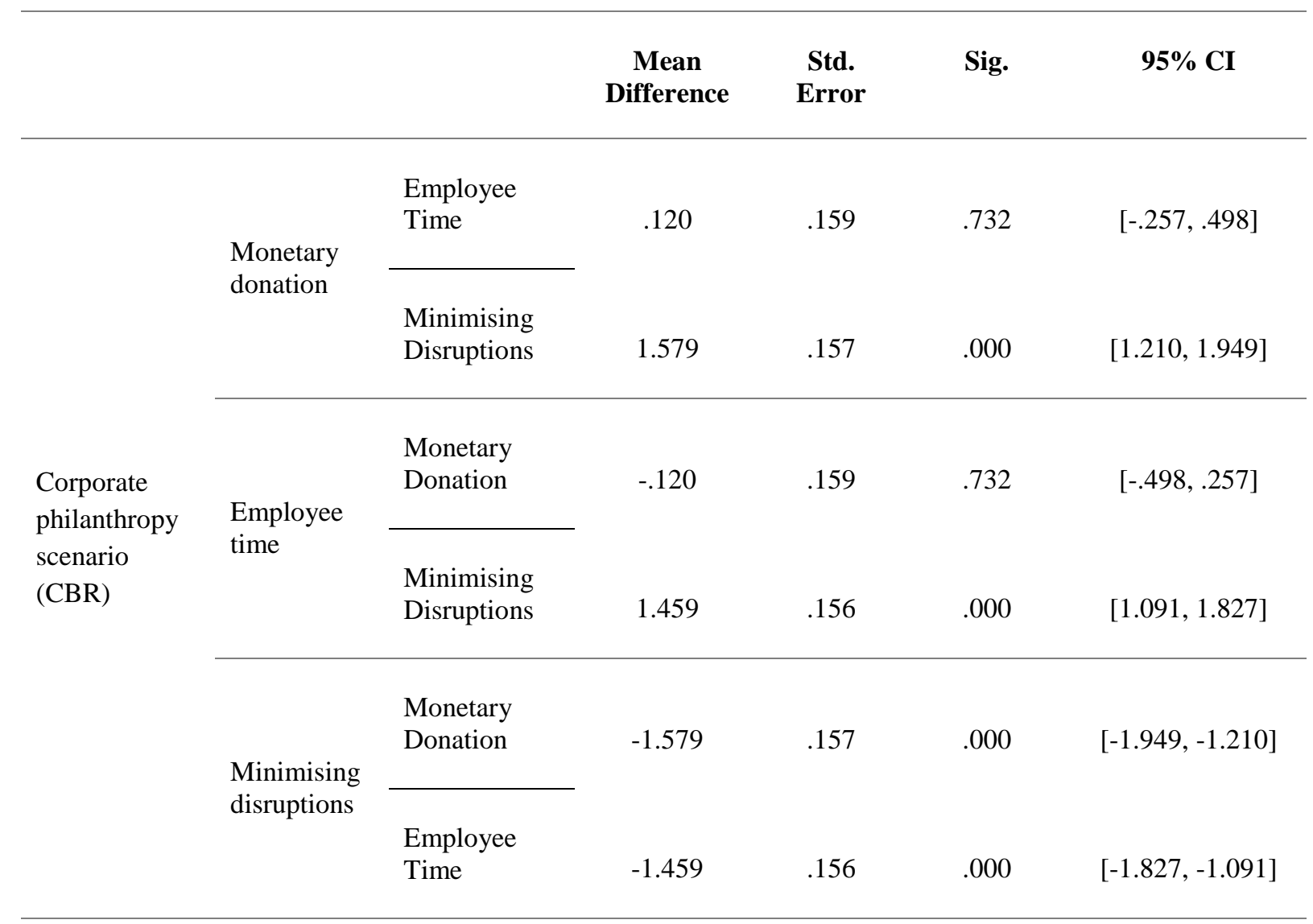




\subsubsection{Hypothesis Testing: Corporate Philanthropy \& Consumer Scepticism}

An independent samples $t$ test was conducted to determine the impact of consumer scepticism on the relationship between CP and corporate reputation. Only the CBR scores of participants exposed to the giving conditions (monetary donation, employee time) were included in this analysis. Study 1A examines the impact of scepticism in relation to external, non-reciprocal philanthropy, which renders the condition of bypassing philanthropy superfluous to analysis. After exploring frequencies within the data, the median scepticism score was identified $(\bar{x}=$ 3.67) by following Iacobucci, Posavac, Kardes, Schneider and Popovich's (2015) procedure for robust median split analyses. As a result, two groups expressing relatively low ( $\mathrm{n}=88,<$ 3.67 , and relatively high $(n=45,>3.68)$, scepticism were identified.

Levene's test was not significant, indicating that the assumption of homogeneity of variance had not been violated, therein equal variances can be assumed. The $t$ test was statistically significant $(\alpha=.05)$, as consumers exhibiting low scepticism $(M=5.425, S D=.777)$ perceived reputation more positively than consumers who reported greater scepticism $(M=5.139, S D=$ .786), $t(131)=2.188, p=.030$. Further analysis indicates an effect size of $d=.40$, approaching a medium $(d=.50)$ level of relative significance between group evaluations of CBR when introducing scepticism as a moderating variable (Cohen, 1988).

Table 5.9 Independent Samples t Test: Corporate Philanthropy \& Consumer Scepticism

\begin{tabular}{|c|c|c|c|c|c|}
\hline Mean & $\begin{array}{c}\text { Std. } \\
\text { Deviation }\end{array}$ & $t$ & df & $\begin{array}{c}\text { Sig. } \\
\text { (2-tailed) }\end{array}$ & 95\% CI \\
\hline 5.452 & .777 & \multirow{3}{*}{2.188} & \multirow{3}{*}{131} & \multirow{3}{*}{.030} & \multirow{3}{*}[.029,.596]{} \\
\hline & & & & & \\
\hline 5.139 & .786 & & & & \\
\hline
\end{tabular}

While not directly hypothesised, further analysis was conducted to delineate the type of philanthropy (monetary donation, employee time), and assess whether scepticism had a significantly stronger impact on reputation for a particular form of giving. A factorial betweengroups ANOVA was conducted to investigate any CBR differences. Beyond the previously 
reported main effect of scepticism impacting CBR judgments, the ANOVA found no statistically significant interaction effect between the type of philanthropy and levels of consumer scepticism $F(1,129)=.028, p=.869$.

\subsection{Study 1B}

\subsubsection{Response Analysis}

154 participants attempted the questionnaire for Study 1B, with 119 providing complete responses. 8 responses were removed before further analysis after failing the manipulation check as to whether PowerHouse's operations had been adversely impacted. Cross-tabulations indicated between 53 and 58 usable responses for each of the two conditions, above the established minimum for group comparisons (Hair et al., 2010).

\subsubsection{Descriptive Statistics}

Study 1B also attracted a chiefly young sample, illustrated by $62.2 \%$ of participants aged between 18 and 25 years, while $46.8 \%$ of respondents were currently enrolled in study. $61.3 \%$ of participants had gained some form of tertiary qualification, with $38.7 \%$ holding a high school qualification as their highest level of education. Females also responded prolifically to the research, as $80.2 \%$ of the study cohort identified as such. The descriptive statistics for Study 1B are reported in Table 5.10. 
Table 5.10 Study 1B Descriptive Statistics

\begin{tabular}{|c|c|c|}
\hline & Frequency & Percentage of Sample (\%) \\
\hline \multicolumn{3}{|l|}{ Age } \\
\hline 18 to 25 years & 69 & 62.2 \\
\hline 26 to 45 years & 21 & 18.9 \\
\hline 46 to 64 years & 14 & 12.6 \\
\hline 65 years and over & 7 & 6.3 \\
\hline Total & 111 & 100 \\
\hline \multicolumn{3}{|l|}{ Gender } \\
\hline Male & 22 & 19.8 \\
\hline Female & 89 & 80.2 \\
\hline Gender diverse & 0 & 0 \\
\hline Total & 111 & 100 \\
\hline \multicolumn{3}{|l|}{ Education } \\
\hline $\begin{array}{l}\text { High School Certificate/ } \\
\text { NCEA Level } 3\end{array}$ & 43 & 38.7 \\
\hline Tertiary Diploma & 14 & 12.7 \\
\hline Bachelor's Degree & 27 & 24.3 \\
\hline Honours Degree & 8 & 7.2 \\
\hline Master's Degree & 18 & 16.2 \\
\hline Doctorate Degree & 1 & 0.9 \\
\hline Total & 111 & 100 \\
\hline \multicolumn{3}{|c|}{ Enrolled in Study } \\
\hline Yes & 52 & 46.8 \\
\hline No & 59 & 53.2 \\
\hline Total & 111 & 100 \\
\hline
\end{tabular}

\subsubsection{Factor Analysis}

The factor analysis for the 12-item CBR scale (operations impacted) demonstrates that $67.2 \%$ of the variance can be explained by the underlying components of CBR, as reported in Table 5.11. CBR_10 did not meet the minimum criteria of proportion explained by underlying latent factors, and was therefore removed from further analysis.

Table 5.11 Factor Analysis: Operations Impacted

\begin{tabular}{|c|c|c|c|c|}
\hline & & Variance Explained & $\begin{array}{c}\text { Cronbach's } \\
\text { Alpha }\end{array}$ & KMO \\
\hline Scenario 1 & $\begin{array}{l}\text { Customer-based } \\
\text { Corporate Reputation }\end{array}$ & & & \\
\hline $\begin{array}{l}\text { Operations } \\
\text { impacted }\end{array}$ & $\begin{array}{l}\text { CBR_1 } \\
\text { CBR_2 } \\
\text { CBR_3 } \\
\text { CBR_4 } \\
\text { CBR_5 } \\
\text { CBR_6 } \\
\text { CBR_7 } \\
\text { CBR_8 } \\
\text { CBR_9 } \\
\text { CBR_11 } \\
\text { CBR_12 }\end{array}$ & $67.2 \%$ & .930 & $\begin{array}{c}.896 \\
p<.001\end{array}$ \\
\hline
\end{tabular}


Table 5.12 reports the factor analysis for the 12-item CBR scale (operations not impacted), demonstrating that $70.2 \%$ of the variance can be explained by the components of CBR. Again, CBR_10 did not meet the minimum criteria for factor loads ( $>0.7)$, and was therefore removed from further analysis.

Table 5.12 Factor Analysis: Operations Not Impacted

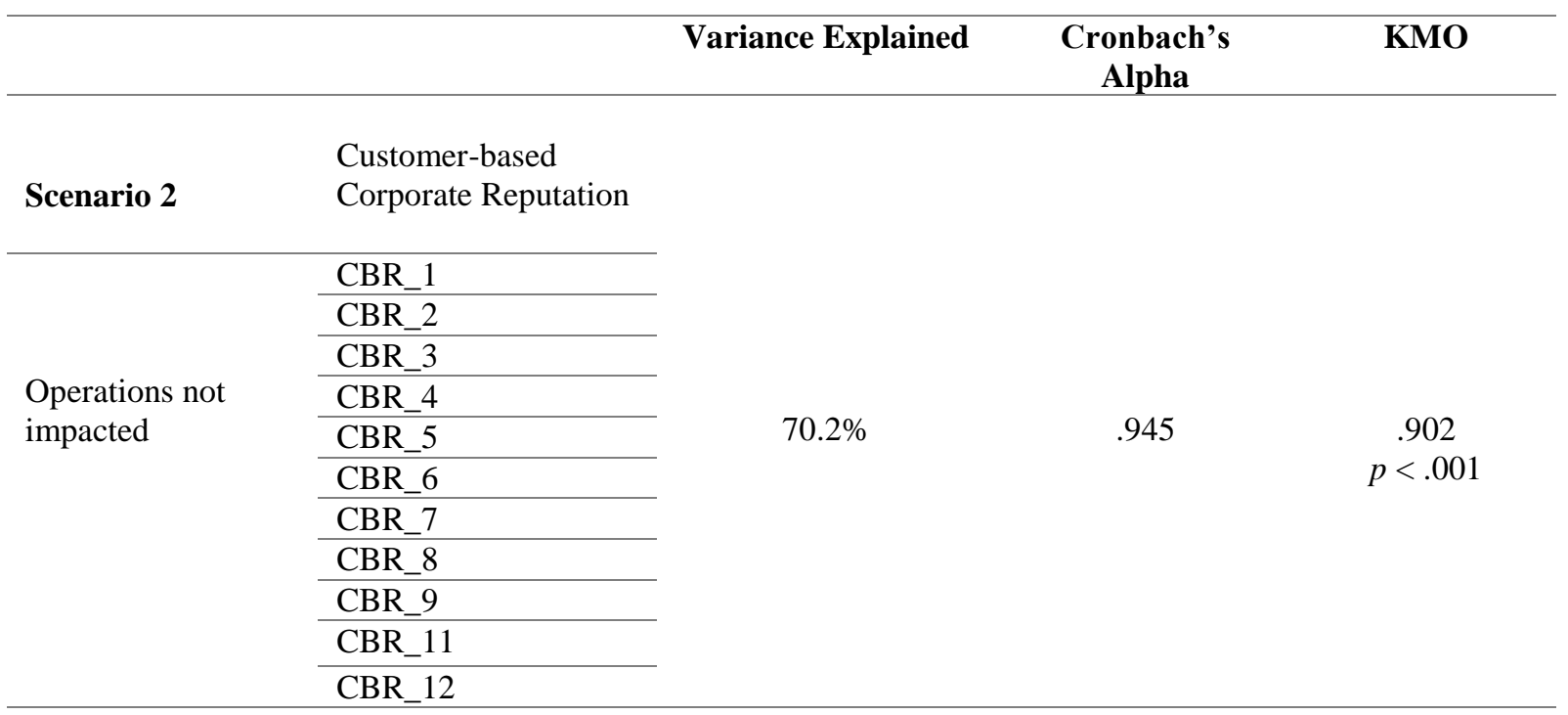

\subsubsection{Hypotheses Testing: Adverse Operational Impacts}

An independent samples $t$ test was conducted to determine whether corporate philanthropy resulted in stronger reputational benefits for a company with operations adversely impacted from a disaster $(\mathrm{n}=58)$, compared to an organisation uninterrupted $(\mathrm{n}=53)$. The Shapiro-Wilk statistic of both groups is not significant, indicating that the assumption of normality was not violated. Similarly, Levene's test was not significant, suggesting that the assumption of homogeneity of variance had also not been breached, thus equal variances can be assumed. The assumption of independence and dependent scale measurement were inherent to the research methodology. The $t$ test was statistically significant ( $\alpha=.05$ ), with the reputation of a firm experiencing impacted operations $(M=5.522, S D=.775)$ perceived more positively than a company with operations uninterrupted following giving $(M=4.909, S D=.849), t(109)=$ $3.977, p<.001$. Table 5.13 reports the full results of this test. 
Further analysis indicates an effect size of $d=.75$, broadly defined by Cohen (1988) as between medium $(d=.50)$ and large $(d=.80)$. In other words, the mean CBR evaluations toward a disrupted firm are at approximately the $78^{\text {th }}$ percentile of the operations uninterrupted group, indicating a relatively large difference in CBR scores between conditions.

Table 5.13 Independent Samples t Test: Adverse Operational Impacts

\begin{tabular}{|c|c|c|c|c|c|c|c|}
\hline & & Mean & $\begin{array}{c}\text { Std. } \\
\text { Deviation }\end{array}$ & $t$ & df & $\underset{\text { (2-tailed) }}{\text { Sig }}$ & $95 \% \mathrm{CI}$ \\
\hline \multirow{2}{*}{$\begin{array}{l}\text { Customer- } \\
\text { based } \\
\text { Corporate } \\
\text { Reputation }\end{array}$} & $\begin{array}{l}\text { Operations } \\
\text { adversely } \\
\text { impacted }\end{array}$ & 5.522 & .775 & \multirow{2}{*}{3.977} & \multirow{2}{*}{109} & \multirow{2}{*}{.000} & \multirow{2}{*}[.307,.918]{} \\
\hline & $\begin{array}{l}\text { Operations } \\
\text { not impacted }\end{array}$ & 4.909 & .849 & & & & \\
\hline
\end{tabular}

\subsection{Study 2}

\subsubsection{Response Analysis}

Study 2 garnered 258 responses, with 200 participants completing the questionnaire. 6 respondents were removed after failing to identify the correct location for giving, including answers such as "Japan", or expressing confusion toward the questionnaire procedure. A crosstabulation indicated 95 responses for the domestic giving condition, and 99 exposed to the New Caledonia scenario, sufficient for statistical analysis (Hair et al., 2010).

\subsubsection{Descriptive Statistics}

Study 2 attracted the highest proportion of 18 to 25-year-old participants (71.6\%), likely due to publication on a class Blackboard page. Moreover, $57.7 \%$ of respondents were currently enrolled in study, as reported in Table 5.14. The sample was also mostly female (75.3\%), with most having attained a high school certificate as their highest form of education (43.3\%). Dominantly student populations are common in corporate reputation and ethnocentrism research (Lii \& Lee, 2012; Shim \& Yang, 2016; Szöcs, 2013), therefore, it was deemed appropriate to continue analysis of the proposed hypotheses. 
Table 5.14 Study 2 Descriptive Statistics

\begin{tabular}{|c|c|c|}
\hline & Frequency & Percentage of Sample (\%) \\
\hline \multicolumn{3}{|l|}{ Age } \\
\hline 18 to 25 years & 139 & 71.6 \\
\hline 26 to 45 years & 29 & 15.0 \\
\hline 46 to 64 years & 17 & 8.8 \\
\hline 65 years and over & 9 & 4.6 \\
\hline Total & 194 & 100 \\
\hline \multicolumn{3}{|l|}{ Gender } \\
\hline Male & 47 & 24.2 \\
\hline Female & 146 & 75.3 \\
\hline Gender diverse & 1 & 0.5 \\
\hline Total & 194 & 100 \\
\hline \multicolumn{3}{|l|}{ Education } \\
\hline No qualification & 4 & 2.1 \\
\hline $\begin{array}{l}\text { High School Certificate/NCEA } \\
\text { Level } 3\end{array}$ & 84 & 43.3 \\
\hline Tertiary Diploma & 21 & 10.8 \\
\hline Bachelor's Degree & 54 & 27.8 \\
\hline Honours Degree & 9 & 4.6 \\
\hline Master's Degree & 20 & 10.3 \\
\hline Doctorate Degree & 2 & 1.1 \\
\hline Total & 194 & 100 \\
\hline \multicolumn{3}{|l|}{ Enrolled in Study } \\
\hline Yes & 112 & 57.7 \\
\hline No & 82 & 42.3 \\
\hline Total & 194 & 100 \\
\hline
\end{tabular}

\subsubsection{Factor Analysis}

The first factor analysis in Study 2 is reported in Table 5.15, with $66.0 \%$ of the variance accounted for by the latent factors of CBR. CBR_3, CBR_4, CBR_5, CBR_10, CBR_11, and CBR_12 did not meet the minimum requirements for analysis, and were removed to ensure robust statistical design.

Table 5.15 Factor Analysis: Domestic Giving

\begin{tabular}{|c|c|c|c|c|}
\hline & & Variance Explained & $\begin{array}{c}\text { Cronbach's } \\
\text { Alpha }\end{array}$ & KMO \\
\hline Scenario 1 & $\begin{array}{l}\text { Customer-based } \\
\text { Corporate } \\
\text { Reputation }\end{array}$ & & & \\
\hline Domestic Giving & $\begin{array}{l}\text { CBR_1 } \\
\text { CBR_2 } \\
\text { CBR_6 } \\
\text { CBR_7 } \\
\text { CBR_8 } \\
\text { CBR_9 }\end{array}$ & $66.0 \%$ & .773 & $\begin{array}{c}.838 \\
p<.001\end{array}$ \\
\hline
\end{tabular}


The factor analysis for the global giving context is reported in Table 5.16. The total variance explained output indicates that $65.9 \%$ of the variance is accounted for by the CBR items. CBR_3, CBR_6, CBR_7, CBR_8,CBR_9, and CBR_10 did not meet the minimum criteria for analysis, and were removed from the dataset before continuing with statistical analysis.

Table 5.16 Factor Analysis: Global Giving

\begin{tabular}{|c|c|c|c|c|}
\hline & & Variance Explained & $\begin{array}{c}\text { Cronbach's } \\
\text { Alpha }\end{array}$ & KMO \\
\hline Scenario 2 & $\begin{array}{l}\text { Customer-based } \\
\text { Corporate Reputation }\end{array}$ & & & \\
\hline Global Giving & $\begin{array}{l}\text { CBR_1 } \\
\text { CBR_2 } \\
\text { CBR_4 } \\
\text { CBR_5 } \\
\text { CBR_11 } \\
\text { CBR_12 }\end{array}$ & $65.9 \%$ & .832 & $\begin{array}{c}.764 \\
p<.001\end{array}$ \\
\hline
\end{tabular}

Results of the factor analysis for ethnocentrism are reported in Table 5.17. The total variance output demonstrates that $62.7 \%$ of the variance can be explained by one component. Several items failed to meet the minimum criteria for robust data analysis and were therefore removed from further research, including Ethno_1, Ethno_3, Ethno_5, Ethno_6, Ethno_7, Ethno_8, Ethno_10, and Ethno_11.

Table 5.17 Factor Analysis: Ethnocentrism

\begin{tabular}{|c|c|c|c|c|}
\hline & & Variance Explained & $\begin{array}{c}\text { Cronbach's } \\
\text { Alpha }\end{array}$ & KMO \\
\hline \multirow{7}{*}{ Ethnocentrism } & Ethno_2 & \multirow{7}{*}{$62.7 \%$} & \multirow{7}{*}{.841} & \multirow{7}{*}{$\begin{array}{c}.832 \\
p<.001\end{array}$} \\
\hline & Ethno_4 & & & \\
\hline & Ethno_9 & & & \\
\hline & Ethno_12 & & & \\
\hline & Ethno_13 & & & \\
\hline & Ethno_14 & & & \\
\hline & Ethno_15 & & & \\
\hline
\end{tabular}

\subsubsection{Non-response Bias}

Non-response bias was also assessed in Study 2 to ensure participant responses did not differ in significant and meaningful ways from members of the population who did not respond. Again, this procedure was undertaken using Armstrong and Overton's (1977) successive waves extrapolation method to ensure the validity of findings. After splitting the data into two waves 
of responses based on survey completion date, an independent samples $t$ test compared reporting of ethnocentrism between each group. The test found no statistically significant difference between ethnocentrism $(M f i r s t=1.924, S D=.775$ vs Msecond $=2.019, S D=.866$; $t(192)=-.810, p=.419$. This suggests that non-response bias was not evident in the data.

\subsubsection{Assumptions for Independent Samples $t$ Test}

After conducting comprehensive factor analyses on all items to ensure validity and reliability, the items were computed into averages for each construct across the two scenarios of global and domestic giving. After exploring frequencies within the data, the median of ethnocentrism was identified $(\bar{x}=1.80)$, and used to split participants into groups expressing relatively lower $(\mathrm{n}=102,<1.80)$ and relatively higher $(\mathrm{n}=92,>1.81)$ levels of ethnocentrism. Further statistical assumptions were met by measuring CBR using a scale, and ensuring all observations were independent as respondents could only complete the questionnaire once. Table 5.18 reports the skewness and kurtosis of the dataset, demonstrating that all groups are in the accepted range of normality to continue with analysis (Allen et al., 2014). The homogeneity of variance was also evaluated, to ensure an approximately equal amount of variability in each group's reporting figures, and is reported alongside results of independent sample $t$ tests.

Table 5.18 Study 2 Normality Statistics

\begin{tabular}{lcccc}
\hline & \multicolumn{2}{c}{ Skewness } & \multicolumn{2}{c}{ Kurtosis } \\
\cline { 2 - 5 } & Statistic & Std. Error & Statistic & Std. Error \\
\hline $\begin{array}{l}\text { Domestic Giving } \\
\text { (Low Ethnocentrism) }\end{array}$ & .270 & .350 & -.621 & .688 \\
\hline $\begin{array}{l}\text { Domestic Giving } \\
\text { (High Ethnocentrism }\end{array}$ & .077 & .347 & -.730 & .681 \\
\hline $\begin{array}{l}\text { Global Giving } \\
\text { (Low Ethnocentrism) }\end{array}$ & .180 & .350 & -.988 & .688 \\
\hline $\begin{array}{l}\text { Global Giving } \\
\text { (High Ethnocentrism) }\end{array}$ & .748 & .347 & -.088 & .681 \\
\hline
\end{tabular}

\subsubsection{Hypothesis Testing: Domestic Giving \& Ethnocentrism}

An independent samples $t$ test was conducted to determine whether high ethnocentric consumers $(n=47)$ hold more positive CBR perceptions towards domestic philanthropy, compared to less ethnocentric consumers $(n=48)$. Levene's test was not significant, indicating that the assumption of homogeneity of variance had not been violated and equal variances 
could be assumed. The $t$ test was not statistically significant $(\alpha=.05)$, as reported in Table 5.19. More ethnocentric consumers $(M=4.817, S D=.678)$ did not view reputation more positively when a firm gave within its own country, compared to less ethnocentric consumers $(M=5.116, S D=.789), t(93)=1.978, p=.051$. Interestingly, the $t$ test results approached significance for the opposite directionality; that is, low ethnocentric consumers holding more positive evaluations of reputation for a company choosing to give locally than those exhibiting higher ethnocentrism. Further, an independent samples $t$ test comparing the CBR judgments of Pasifika participants $(M=5.146, S D=1.11)$ to non-Pasifika respondents $(M=4.961, S D=$ $.736), t(93)=.483, p=.630$ demonstrated no significant difference in evaluations of reputation between each group. Hence, cross-national biases for giving did not appear to hinder the veracity of these findings.

Table 5.19 Independent Samples $t$ Test: Domestic Giving \& Ethnocentrism

\begin{tabular}{|c|c|c|c|c|c|c|c|}
\hline & & Mean & $\begin{array}{c}\text { Std. } \\
\text { Deviation }\end{array}$ & $\mathbf{t}$ & df & $\begin{array}{c}\text { Sig. } \\
\text { (2-tailed) }\end{array}$ & $95 \%$ CI \\
\hline \multirow{2}{*}{$\begin{array}{l}\text { Customer- } \\
\text { based } \\
\text { Corporate } \\
\text { Reputation }\end{array}$} & $\begin{array}{l}\text { Low } \\
\text { Ethnocentrism }\end{array}$ & 5.116 & .789 & \multirow{2}{*}{1.163} & \multirow{2}{*}{97} & \multirow{2}{*}{.051} & \multirow{2}{*}{$-.001, .599$} \\
\hline & $\begin{array}{l}\text { High } \\
\text { Ethnocentrism }\end{array}$ & 4817 & 678 & & & & \\
\hline
\end{tabular}

\subsubsection{Hypothesis Testing: Global Giving \& Ethnocentrism}

An independent samples $t$ test was conducted to determine whether low ethnocentric consumers $(\mathrm{n}=54)$ hold significantly more positive CBR perceptions toward global philanthropy, compared to more ethnocentric consumers $(n=45)$. Levene's test was not significant, indicating that the assumption of homogeneity of variance had not been violated, therein equal variances can be assumed. The $t$ test was not statistically significant $(\alpha=.05)$, as less ethnocentric consumers $(M=4.969, S D=.780)$ did not view reputation more positively when a firm gave within its own country, compared to more ethnocentric consumers $(M=$ $4.800, S D=.811), t(97)=1.055 p=.294$. While the mean CBR score for low ethnocentrism consumers was greater, there was no significant difference between groups, as reported in Table 5.20. Further, an independent samples $t$ test comparing the CBR score of Pasifika 
participants $(M=4.766, S D=.440)$ to non-Pasifika respondents $(M=5.043, S D=.722), t(97)$ $=-.846, p=.400$ demonstrated no significant difference in evaluations of reputation between each group. Therefore, cross-national biases for giving did not appear to hinder the validity of these findings.

Table 5.20 Independent Samples t Test: Global Giving \& Ethnocentrism

\begin{tabular}{|c|c|c|c|c|c|c|c|}
\hline & & Mean & $\begin{array}{c}\text { Std. } \\
\text { Deviation }\end{array}$ & $\mathbf{t}$ & df & $\begin{array}{c}\text { Sig. } \\
\text { (2-tailed) }\end{array}$ & $95 \% \mathrm{CI}$ \\
\hline \multirow{2}{*}{$\begin{array}{l}\text { Customer- } \\
\text { based } \\
\text { Corporate } \\
\text { Reputation }\end{array}$} & $\begin{array}{l}\text { Low } \\
\text { Ethnocentrism }\end{array}$ & 4.969 & .780 & \multirow[b]{2}{*}{1.055} & \multirow[b]{2}{*}{97} & \multirow[b]{2}{*}{.294} & \multirow[b]{2}{*}[-.149,.487]{} \\
\hline & $\begin{array}{l}\text { High } \\
\text { Ethnocentrism }\end{array}$ & 4.800 & .811 & & & & \\
\hline
\end{tabular}


Table 5.21 Summary of Hypothesis Results

\begin{tabular}{|c|c|c|c|c|}
\hline & Hypothesis & $\begin{array}{l}\text { Research } \\
\text { Objective }\end{array}$ & Significance & Outcome \\
\hline H1a & $\begin{array}{l}\text { Monetary donations and employee time } \\
\text { will have a commensurate positive impact } \\
\text { on customer-based corporate reputation }\end{array}$ & RO1 & $p=.732^{1}$ & Supported \\
\hline H1b & $\begin{array}{l}\text { Forgoing philanthropy to minimise internal } \\
\text { disruptions will be less beneficial to } \\
\text { reputation than donating money }\end{array}$ & $\mathrm{RO} 2$ & $p<.001$ & Supported \\
\hline H1c & $\begin{array}{l}\text { Forgoing philanthropy to minimise internal } \\
\text { disruptions will be less beneficial to } \\
\text { reputation than donating employee time }\end{array}$ & $\mathrm{RO} 2$ & $p<.001$ & Supported \\
\hline $\mathbf{H} 2$ & $\begin{array}{l}\text { Consumers less sceptical about the CSR } \\
\text { motives of a company will perceive } \\
\text { corporate philanthropy more positively } \\
\text { than highly sceptical consumers }\end{array}$ & RO3 & $p=.030$ & Supported \\
\hline H3 & $\begin{array}{l}\text { Donating employee time following adverse } \\
\text { impacts to operations will have a more } \\
\text { positive effect on reputation, than when } \\
\text { companies are not adversely affected }\end{array}$ & $\mathrm{RO} 4$ & $p<.001$ & Supported \\
\hline H4 & $\begin{array}{l}\text { When companies engage in domestic } \\
\text { philanthropy, high (low) ethnocentric } \\
\text { consumers will perceive stronger (weaker) } \\
\text { reputational benefits than consumers low } \\
\text { (high) in ethnocentrism }\end{array}$ & RO5 & $p=.051$ & Not Supported \\
\hline H5 & $\begin{array}{l}\text { When companies engage in global } \\
\text { philanthropy, high (low) ethnocentric } \\
\text { consumers will perceive weaker (stronger) } \\
\text { reputational benefits than consumers low } \\
\text { (high) in ethnocentrism }\end{array}$ & RO5 & $p=.294$ & Not Supported \\
\hline
\end{tabular}

\footnotetext{
${ }^{1} \mathrm{H} 1 \mathrm{a}$ is a null hypothesis, stipulating no significant difference between forms of giving. The resulting $p$-value is above 0.05 , therefore supporting that monetary giving and employee time have equivalent positive impact.
} 


\section{Chapter Six: Discussion}

The following chapter interprets the findings of each study, situating analysis in relation to extant literature and theoretical understanding of corporate philanthropy, reputation, consumer scepticism, and ethnocentrism.

\subsection{Study $1 \mathrm{~A}$}

\subsubsection{Corporate Philanthropy \& Giving Type}

As hypothesised, Study 1A found that, during a disaster, monetary and employee time donations have a commensurate positive impact on customer-based reputation. Previous research establishes that monetary donations are valued more broadly by stakeholders (Brammer \& Millington, 2005; Gao et al., 2012). However, the findings corroborate that inkind contributions and giving that involves employees can be equally beneficial during circumstances deemed uncontrollable, such as a disaster (Hildebrand et al., 2017; Muller \& Kräussl, 2011b). Converse to the suggestion that in-kind giving results in stronger reputational benefits (Hildebrand et al., 2017), Study 1A shows that consumers do not hold an overriding preference between philanthropic types. Hildebrand et al. (2017) included a more detailed news report of a disaster in their study, describing how employee volunteers aided in the procurement and distribution of foods and medicines. Study 1A, on the other hand, only mentioned that employee time would be donated to the Red Cross (see Appendix A). Therefore, it is possible that when information is detailed about how employee time was spent, an in-kind response is preferable to monetary contributions.

A further differentiating aspect of this study is its focus on a company in the midst of a disaster, rather than firms administering philanthropy from outside of crises (Gao \& Hafsi, 2015; Lii \& Lee, 2012). The unique findings highlight that a company's involvement within disasters may ultimately weaken the importance of contribution type to consumers. Results of hypotheses $1 \mathrm{~b}$ and $1 \mathrm{c}$ demarcate this contention, explicitly demonstrating that either form external philanthropy is perceived significantly more positively than for a company to recover internally from the disaster (Lii \& Lee, 2012; Peterson 2018). The comparison of monetary and employee time donations, against forgoing giving, illustrates the strength with which consumers prefer disaster response that directly benefits stakeholders external to the firm (Hildebrand et al., 
2017). Consumers appear to exhibit little concern for the possibility of reduced service quality when companies prioritise post-disaster philanthropy, indicating that failures to give could generate damaging associations toward self-interest (Ellen et al., 2000). As evaluations of a company are significantly more favourable toward disaster aid than an ongoing cause (Ellen et al., 2000), the form of contribution may provide little further insight for marketers than a general instruction to assist (Zagefka, Noor, Brown, de Moura \& Hopthrow, 2011). While employee time is broadly favoured in uncontrollable conditions, a desire for direct assistance and disaster relief overrides the established contribution type as a salient heuristic (Day et al., 2012). Consumer understandings of the post-disaster environment are also likely to be highly variable and disparate, with disasters unpredictable in terms of magnitude, damage avoidability and victim needs (Baker, 2009; Ellen et al., 2000). Consequently, the similar evaluation of employee time and monetary donation is contextualised as participants in this study were given limited empirical detail of the disaster contexts to manipulate responses further.

From an applied perspective, voluntary employee time may be a more congruent activity in lower level disasters to assist in clean-up activities (Whittaker et al., 2015), or for firms with strong local community ties (Bin \& Edwards, 2009). Similarly, offering voluntary aid is a compatible activity for those with disrupted operations and limited post-disaster monetary resources, whereby employees can use idle time to administer assistance (Australian Government, 2018; Morris, 2018). In comparison, monetary donations could be more relevant to consumers following a large-scale crisis (Brooks, 2017). For an event that results in significant closures, such as the long-term cordon of the Christchurch CBD following the 2011 series of earthquakes (Brand \& Nicholson, 2016), layman voluntary work holds little benefit to consumers affected by significant displacement. Monetary donations to a recognised thirdparty provide greater flexibility and expertise to disseminate giving, addressing issues of subsistence that must be renegotiated following a large-scale disaster, including access to power, running water, and healthcare (Baker, 2009). In short, context is a central determinant for consumers to make recognisable distinctions between employee time and monetary donations. The findings, therefore, refute the steadfast notion that philanthropy is a good for which clear preferences exist (Szöcs, 2013), as preferences are conditional on the disaster context. 


\subsubsection{Corporate Philanthropy \& Consumer Scepticism}

Previous inquiry suggests that the effectiveness of social responsibility, of which philanthropy is an expression, is impacted by consumer scepticism to CSR initiatives (Skarmeas \& Leonidou, 2013; Sankar \& Bhattacharya, 2001). This study finds a similar sentiment during disasters, illustrating that a more sceptical posture towards CSR results in less favourable perceptions of reputation, compared to consumers reporting low scepticism. This is consistent with extant literature showing that suspicion towards the true intentions of CSR activities is likely to weaken consumer attitudes towards the company (Bae \& Cameron, 2006; BeckerOlsen et al., 2006; Elving, 2013). As opposed to simple attitudinal evaluations, these results show that scepticism also has a moderating impact on reputation from a customer perspective.

While the hypothesis was supported, it is of interest that a disaster setting did not suspend scepticism toward assessments of reputation, whereby community needs for post-disaster relief outweigh suspicion toward the motives for giving (Baker, 2009; Ellen et al., 2000). This research focused its measurement on dispositional suspicion, evaluating scepticism as an exogenous, enduring trait of distrust to organisational CSR initiatives (Mohr et al., 1998; Obermiller \& Spangenberg, 1998). In comparison, situational scepticism could be more likely to garner lower consumer suspicion during a disaster (Chen, Cheng, Hung-Baesecke \& Jin, 2019). Moreover, Vanhamme and Grobben (2009) identify a short-term reputation for CSR as a cue for consumer scepticism, with Gardberg et al. (2017) also acknowledging that an established reputation for CSR helps to provide organisational buffering from external shocks. This trend may explain why short-term giving, incited by direct disaster response, results in weaker judgments of reputation for high scepticism consumers. Natural disasters are highly unpredictable, providing little warning for company stakeholders to shape their portfolio of CSR activities. Findings underscore the strategic importance of developing an established track-record for social responsibility, situating Vanhamme and Grobben's (2009) findings into a disaster context. Significant reputational benefits are rendered from disaster philanthropy, but irregular and inconsistent CSR initiatives may dilute these opportunities.

The use of a fictitious company that was unfamiliar to respondents is also a contributing factor to the ultimate findings, as pre-established positive perceptions toward a company limit scepticism about its CSR activities (Elving, 2013). Respondents had no previous associations 
of the philanthropic company through which to use as a frame of reference when interpreting its donation activities. A lack of company legitimacy can incite even more sceptical responses from consumers, which a fictitious company is unlikely to achieve (Ashford \& Gibbs, 1990). Moreover, little information was provided about the means through which philanthropic initiatives were communicated, which is a significant determinant in consumer perceptions of CSR activities (Becker-Olsen et al., 2006; Elving, 2013). Consumer evaluations of CRM are also tied to the type of industry in which a company is operating, with power providers at risk of negative connotations due to harmful production externalities (Elving, 2013), therein highlighting further background factors that may influence sceptical postures.

Interestingly, after contribution type was delineated to compare high and low scepticism consumers within each scenario, both forms of giving elicited comparative suspicion of giving. The results further develop the idea that consumers perceive employee time and monetary donations as of similar overall value during a disaster, even when introducing one's sceptical disposition. While in-kind employee time donations may be associated with feelings of respect to the donator (Liu \& Aaker, 2008), and monetary donations as a purely economic exchange (Vohs, Mead \& Goode, 2006), a disaster context yields corresponding sceptical evaluations.

\subsection{Study 1B}

The purpose of this research was to specifically examine how a firm's position within a disaster can impact upon reputational perceptions of philanthropy, thereby extending Study 1A's findings. It was anticipated that a company adversely impacted by a disaster would garner stronger reputational benefits from giving, compared to a company uninterrupted. The results exhibit a positive consumer sentiment toward either context for helping, yet support the hypothesised main effect of stronger reputational benefits for adversely impacted businesses. Consumers reward the tendency of companies to give more when holding a physical presence near a disaster (Crampton \& Patten, 2008; Muller \& Whiteman, 2009). Giving applies a halo of positive associations toward adversely impacted donors (Williams \& Barrett, 2000), whereby businesses can enjoy dual external and internal perceptions of a 'warm glow' from helping in a selfless manner (Andreoni, 1990). 
This study extends present understanding of perceived controllability in disaster research, demonstrating that company adversity is a predictor of reputational benefits. It has been previously acknowledged that while impacted companies may focus inwards (Muller \& Kräussl, 2011a), disasters attributed to natural causes elicit higher donations than human-made causes (Zagefka et al., 2011), or controllable circumstances (Hildebrand et al., 2017). However, circumstances unique to a business emerge as a confounding factor in reputational evaluations. In other words, companies cannot rely upon uncontrollable circumstances as an inoculation against less favourable reactions toward giving (Hildebrand et al., 2017). Perceived controllability is a useful indication of likely consumer sentiment, but the extent of adverse impacts offers more nuanced insights during disasters.

Through a psychological lens, Staub and Vollhardt (2008) proposed that victimisation can embolden people to engage in greater prosocial behaviours, coined as altruism born of suffering. Such giving results in strengthened wellbeing and health for the donor, and promotes perceptions of individual competence and efficacy (Irani, 2018). In a similar vein to the individual rewards of wellbeing and assessments of competence, consumers imbue businesses with positive reputational perceptions when participating in altruistic behaviours borne out of adverse circumstances. Corporate reputation is also justifiably viewed as a core determinant of business wellbeing (Murray, 2004), highlighting a theoretical overlap from psychological findings to a business setting.

Godfrey (2005) argued that critical determinants through which to foster moral capital, or goodwill, are transparency, stability and responsiveness in giving. The findings suggest that overall context is equally, if not more, important in post-disaster stakeholder evaluations, as the extent of operational disruptions significantly influences consumer judgments. Situating Staub and Vollhardt's (2008) principle of altruism born of suffering in a company context allows businesses the opportunity to access associations of genuine altruism from consumers; that is, where the cost (or risk) of helping outweighs perceived benefits (Foster, Wenseleers \& Ratnieks, 2006). Philanthropy perceived as altruistic and devoid of conscious self-interest (Hoffman, 1978) results in strengthened moral capital toward the donator (Godfrey, 2005), and fosters more positive attitudes toward the charitable company (Bae \& Cameron, 2006). Altruistic philanthropy underscores the importance of reducing consumer perceptions that 
donations are an attempt at ingratiation (Ellen et al., 2000; Godfrey, 2005), responding to the community's disaster relief needs at the expense of its own operations. While the short-term effects of CP for a detrimentally impacted business promotes altruism and reputation, it is still unclear whether this is an enduring cognitive link, or if consumer evaluations eventually return to a baseline level. Longitudinal research may better identify the perceptions of altruistic philanthropy over time.

Significantly more positive reputational assessments for those adversely impacted may also link to the risk taken by firms in fraught conditions. Adverse economic conditions are likely to reduce aggregate corporate giving (Muller \& Kräussl, 2011a; Tilcsik \& Marquis, 2013), suggesting that companies who, instead, exceed expectations by absorbing risk and promoting philanthropic initiatives could earn substantial benefits. In addition, organisations that are a victim of a crisis evoke sympathy from stakeholders (Coombs, 2007; Stockmeyer, 1996), which points to lower expectations of CSR in such uncontrollable circumstances (Hildebrand et al., 2017). Oliver's (1977) formative expectation confirmation paradigm elucidates this hypothesis, as consumers inherently anticipate and predict associative characteristics toward a service or brand. The extent to which expectations are exceeded results in post-engagement satisfaction and positive attitudes (Becker-Olsen et al., 2006). As a consequence, the disconfirmation of lowered company expectations explains more favourable reputation for a victimised businesses, extending Oliver (1977) into a unique context.

Finally, applying a dual economic-psychological perspective, views of individual charitable giving are also mediated through perceptions of sacrifice (Gipp, Kalafatis \& Ledden, 2008), rewarding those who absorb significant personal costs, while questioning the morals of others (Dees, 2012). Wealthy individual donors have a lower opportunity cost of giving, and are seen as less generous compared to low-income consumers who give smaller amounts, yet achieve higher generosity status (Bracha \& Vesterlund, 2017). Therefore, poor-and-generous associations are viewed as positive by consumers, and rich-and-stingy perceptions as negative (Bracha \& Vesterlund, 2017), further contextualising that the benefits of giving are directly influenced by idiosyncratic circumstance and perceived altruistic sacrifice. The results extend knowledge of consumer perceptions toward charity and donations, finding empirical evidence that bears out Bracha and Vesterlund's (2017) findings at a company level. In short, this paper 
applies previous findings to advance the newfound corporate principle of 'helping when hurting'; encapsulating the philosophy of disaster relief that is rewarded by consumers.

\subsection{Study 2}

The final study sought to address a lack of research comparing reactions toward philanthropic benefactors (Brammer et al., 2009). Preferences toward the geographic location of giving vary markedly (Auger et al., 2010; Schons et al., 2017), with ethnocentrism proposed as a relevant moderating factor to highlight where consumers favour philanthropy following disasters. It was anticipated that the reputational benefits of domestic philanthropy would be strengthened by high levels of ethnocentrism, while administering giving overseas would be perceived more favourably by low ethnocentrism consumers (Szöcs, 2013). These hypotheses were not empirically supported, first suggesting that the extent to which consumers favour their community or cultural group does not impact perceptions of reputation, following domestic giving. In simple terms, consumers with a higher level of ethnocentrism do not hold a notable preference toward domestic CP during a disaster. Moreover, consumers who exhibit lower levels of ethnocentrism, known as global citizens, fail to perceive reputation more positively when aiding countries abroad. The overall findings are inconsistent with formative research surrounding geographic preferences for giving (Russell \& Russell, 2010; Schons et al., 2017), and Szöcs (2013), who identified the significant moderating impact of ethnocentrism in the philanthropy-reputation relationship.

Few normative guidelines explain this relationship in a disaster-specific context, but it is clear that contextual factors have a significant impact on evaluations of CBR following philanthropy (Park et al., 2014; Szöcs et al., 2016). The use of a widespread disaster context may have exorcised ethnocentrism as a moderating factor, implying a high degree of immediacy with which access to day-to-day necessities must be addressed for relief (Baker, 2009). As a result, consumers have little time to reference cognitive ethnocentric cues that inform assessments of reputation, and rely on immediate assessments to determine geographic preferences. Similarly, disasters can promote strengthened community resilience and cohesion (Berkes \& Ross, 2013), diminishing out-group postures when evaluating donations. 
An intrinsic consumer desire to give back to the international community has a significant effect on philanthropic preferences, particularly toward poorer countries (Schons et al., 2017). Schons et al. (2017) also acknowledged that perceived need and importance of a cause are significant determinants for consumers who favour foreign giving. Comparatively, expectations to promote domestic causes following crises may explain why low ethnocentric consumers override their hypothesised proclivity to prefer CP abroad (Szöcs et al., 2016). Ultimately, preferences for giving are inconsistent across cultures and industries (Auger et al., 2010). Therefore, it is reasonable to expect the application of different industries and countries to yield different results, such as in cultures expressing high levels of ethnocentrism, including the United States (Tsai, Yoo \& Lee, 2013).

The cultural context of New Zealand society also illuminates findings (Rampal \& Bawa, 2008). New Zealand is a loosely-knit society, with a relatively low degree of interdependence among consumers (Hofstede Insights, 2019). In collectivist societies, attitudes toward philanthropic discourse are more reliant on the extent to which giving is helpful for local communities (Szöcs, 2013). CP attitudes are less dependent on the benefactor in an individualist culture, considering existing company perceptions, and the type of cause supported (Szöcs, 2013). The application of a similar cause across both overseas and domestic giving ( $\$ 100,000$ donation to the Red Cross) resulted in no significant difference in reputation evaluation, overriding confounding effects of ethnocentrism. Although, the use of a fictitious company meant local consumers held no pre-established attitudes through which to mediate assessments of $\mathrm{CP}$, which may also explain inconsistent overall conclusions.

Further, findings must be considered with acknowledgement of the low ethnocentrism sentiment reported by participants. A median ethnocentrism split was operationalised at only 1.80 on a 7-point Likert scale, demonstrating the sample's low ethnocentric tendencies. Ethnocentrism, by definition, engenders ethical implications by proposing a societal splinter of in-groups and out-groups, therefore can be morally problematic and dangerous when seeking to compare cultural groups (Negy, Shreve, Jensen \& Uddin, 2003; Szöcs, 2013). As a result, further analysis has not been sought to query these findings among participants. The highly negative skew of ethnocentrism in the data, however, may have resulted in a floor effect, as the survey instrument was unable to sufficiently capture even lower levels of ethnocentrism 
(Hessling, Schmidt \& Traxel, 2011). While ensuring anonymity, participants may have selfreported more socially desirable answers of low ethnocentrism to fit everyday moral guidelines (Negy et al., 2003), or due to privacy concerns in an online survey (Evans \& Mahur, 2018). Investigating ethnocentrism with the use of a primarily young sample (71.6\% aged 18-25) is an additional explanatory factor, as older consumers exhibit significantly higher ethnocentrism than young cohorts (Aziz et al., 2014). The overall restrictions in the sample limit the ability to examine significant ethnocentric differences, weakening its proposed moderating role. Although, this discussion has demonstrated a plurality of relevant explanations in relation to the experiment's findings that develop knowledge of ethnocentrism. 


\section{Chapter Seven: Conclusions \& Implications}

The final chapter summarises this research, synthesising findings of each study into overall conclusions, and outlining theoretical and managerial insights. Limitations of the research are discussed, alongside future avenues of study borne out of this paper's conclusions.

\subsection{Overall Conclusions}

The primary purpose of this research was to extend the established literature surrounding corporate philanthropy, examining variables that moderate the relationship between philanthropy and reputation in a disaster context. Previous studies have failed to carefully evaluate $\mathrm{CP}$ through a customer-centric view of reputation, and develop integrative analyses with a more diverse range of intervening variables (Gautier \& Pache, 2015). This paper shows the competitive value of philanthropic initiatives during a disaster to foster feelings of reputational goodwill, particularly when perceived as genuinely altruistic. In short, companies should seize the reputational opportunities afforded through philanthropy during disasters.

Three studies were operationalised to satisfy the objectives of this research. Study 1A first determined that donations of money and employee volunteering time have an equivalent positive effect on consumer perceptions of corporate reputation following a disaster. The findings also demonstrated that each form of external giving had a significantly more positive impact on reputation than when a company chose to bypass giving to minimise disaster-related disruptions to its operations. However, consumers with a predisposition of scepticism towards the motives of CSR view reputation less positively, even when firms are administering disaster relief. Monetary donations and employee volunteering are also both moderated to a similar degree by scepticism, showcasing the difficulty of overcoming consumer suspicions.

Next, Study 1B determined that disaster response philanthropy was perceived significantly more positively by consumers when administered by an adversely impacted firm, compared to an uninterrupted corporation. Finally, Study 2 found that ethnocentrism did not moderate reputational evaluations for firms giving to domestic disaster causes, resulting in similar perceptions between consumers reporting low and high ethnocentrism. In a similar vein, 
consumers did not alter their reputational perceptions in light of ethnocentrism when a firm gave to an overseas disaster benefactor.

\subsection{Theoretical Contributions}

The findings of this paper contribute to theoretical knowledge in philanthropic literature, broadening understandings of consumer reactions to CSR and non-reciprocal giving (Peloza \& Shang, 2011). Consumer-led insights are distinct from recent research considering financial measures (Mithani, 2017), employee satisfaction (Block et al., 2017), and post hoc analyses of third-party reputation measures (Peterson, 2018). Wepener and Boshoff's (2015) CBR conception has been proven as applicable in a disaster context, albeit in a condensed format, highlighting cross-situational validity and robust development from its previous iterations (Walsh \& Beatty, 2007).

Earlier studies have produced inconsistent conclusions as to whether voluntary employee time or monetary donations are perceived more positively by consumers (Brammer \& Millington, 2005; Hildebrand et al., 2017). This research has demonstrated that preferential typology of contribution may be a null debate for companies amid a disaster, with both tested practices viewed favourably. Further, it identifies greater complexity and situating elements that moderate the main philanthropy-reputation relationship, which scholars have characterised as scarce in philanthropic inquiry (Gautier \& Pache, 2015). To the author's knowledge, scepticism to motives concerning philanthropy has not yet been examined in disaster literature, ushering future scholars to begin considering such obfuscating factors. Further delineation of consumers' sceptical postures is needed, such as the short-term nature of disaster response giving (Vanhamme \& Grobben, 2009), to minimise detrimental effects on reputation. The findings also echo the strategic importance of CSR (Becker-Olsen et al., 2006; Park et al., 2014), yet acknowledge that CP should not be viewed merely as a marketing activity, given that altruistic perceptions shape reputational evaluations (Galaskiewicz, 1989).

Few researchers have considered how an organisation's post-disaster circumstances alter stakeholder viewpoints, expanding on knowledge of perceived controllability (Hildebrand et al., 2017). By diagnosing operational disruptions as a determinant in perceptions of reputation, 
this research shows that altruism born of suffering is relevant in corporate and sociological contexts. Further, its findings explicitly detail the perceived benefits received by an impacted donor, which Staub and Vollhardt (2008) fail to comprehensively address. Operational disruption is introduced as a contextual element to the mix of disaster-related factors that impact perceptions of a company (Ellen et al., 2000), and the optimal conditions for giving to foster moral capital (Godfrey, 2005). The negative relationship between individual wealth and perceptions of donations (Bracha \& Vesterlund, 2017) is also emulated at the company level. Mirroring Bracha and Vesterlund's (2017) portrayal of individuals as poor-and-generous, or rich-and-stingy, this paper characterises companies as either impacted-and-altruistic, or uninterrupted-yet-trying as a novel addition to the canon of philanthropy.

Limited understanding of giving to domestic versus global benefactors is addressed (Brammer et al., 2009; Gautier \& Pache, 2015), by measuring consumer perceptions of local philanthropy and giving administered to a different country. This research adds more nuanced empirical knowledge by assessing ethnocentrism in relation to the geographic setting for relief giving, helping to disentangle consumer preferences of philanthropy. Moreover, the methodological approach does not assume that consumers hold inherent in-group identities, addressing a troubling tendency in established literature (Schons et al., 2017). The intersection of philanthropy, ethnocentrism and reputation has not been considered through the lens of disaster giving, applying Szöcs’ (2013) work in an emergent setting. Ethnocentrism may be a less pertinent indicator of geographic preference in adverse circumstances. However, this appears contingent on the social interdependence in a society (Szöcs et al., 2016), and the age group of stakeholders (Aziz et al., 2014)

\subsection{Managerial Implications}

From a managerial perspective, these insights inform high-level decision-making in times of distress, to optimise the benefits of corporate philanthropy. Findings are presented directly through the lens of consumers, gaining a first-hand perspective of this important stakeholder group. The research contributions are of great value to vulnerable companies, with robust crisis response initiatives a pivotal determinant to achieve positive consumer perceptions. Managers are challenged to refrain from looking inwards during a disaster (Muller \& Kräussl, 2011a), and engage in giving to access positive and altruistic assessments of corporate reputation. The 
decision to focus on internal stakeholders by minimising disruptions not only fails to foster reputational goodwill, but can result in decidedly negative perceptions toward a company, eroding established reputation. Therefore, managers should exercise haste in developing disaster relief plans for philanthropy to seize reputational opportunities afforded in fraught contexts. The commensurate positive impact of employee time and monetary donations suggests that firms are also afforded the luxury of evaluating their idiosyncratic circumstances to determine the most congruent response fit. For example, SME closures that precipitate employee idle time means voluntary work is an appropriate response mechanism to optimise the firm's situational capabilities, compared to large monetary gifts.

While it is prudent to think of post-disaster philanthropy from a strategic perspective, consumer scepticism threatens its unique reputational opportunity. As a consequence, businesses must demonstrate a pattern and established track-record for giving to maximise the efficacy of philanthropy and neutralise dispositions of scepticism. Moreover, marketers should be careful not to view philanthropy as a panacea to reputational concerns, nor as the cornerstone of an effective CSR strategy. There are a myriad of ambiguous factors in the aftermath of disasters, including the degree of damage and victim needs (Ellen et al., 2000), leading to uncertainty in how giving should be operationalised. Companies should first engage in substantial relief planning and contingency development to wholly take advantage of any reputational opportunities that may arise from disasters, ensuring that internal stakeholders are not reliant on unpredictable circumstances.

For companies directly suffering adverse disaster effects, leading managers should still prioritise community aid to achieve positive consumer perceptions. SMEs are particularly vulnerable to disaster disruption (Sullivan-Taylor \& Branicki, 2011), which means the associations borne of post-disaster donations are critical to overcome threats to reputation (Labadie, 2008). This "reservoir of goodwill” (Jones et al., 2000, p. 21) is particularly helpful for firms that may experience disaster-driven closures and ongoing circumstantial disruptions, which was prolific in the aftermath of the 2016 Kaikōura earthquake (Deloitte, 2017). Rather than concealing the degree of damage experienced in a disaster, it is valuable for companies to help when hurting, remaining transparent with customer stakeholders to access strengthened associations of altruism and foster moral capital. 
The impact of consumer in-group preferences is minimal for cross-national disaster relief decisions; therefore, managers do not need to explicitly consider ethnocentrism before electing benefactors. Instead, marketers should assess the perceived need and magnitude of disasters when determining philanthropic response across geographic contexts, to maximise the value of giving (Schons et al., 2017). Further, situating disaster relief locally is more meaningful for businesses operating in collectivist countries, whereas companies in individualist societies should carefully assess the type of cause to determine geographic aid (Szöcs, 2013).

\subsection{Limitations}

An underlying limitation of this research was the use of samples containing primarily 18-to25-year-old participants, and a majority female presence in responses. As previously acknowledged, young individuals and female consumers are likely to be more liberal, and report lower levels of ethnocentrism (Aziz et al., 2014), which may have skewed the ultimate findings. Further, the research design did not assess whether participants had been previously personally impacted by a disaster, meaning consumers could be influenced by their earlier experiences and exposure to corporate giving.

Some academics argue that the use of a median split can result in a loss of statistical power and persuasive impact by introducing a random error to data, resulting in less reliable results (McClelland, Lynch, Irwin, Spiller \& Fitzsimons, 2015). Equally, however, this statistical transformation simplifies reporting and interpretation of findings, and is salient for comparing group differences in attitudes (Iacobucci et al., 2015). The widespread use of median splits across CSR research (Arendt \& Brettel, 2010; Mohr \& Webb, 2005; Runté, Basil \& Deshpande, 2009) meant the analytical approach was deemed appropriate, however, may have resulted in a heightened random error value.

The use of fictitious companies also limits external validity. Although, controlling for confounding factors and previous company associations promoted internal consistency to best address the objectives of each study. Further, by applying real-life disaster contexts, respondents were expected to recall the magnitude of each crisis, rather than providing detailed vignettes of a fictitious setting. Situating the experiment across these authentic circumstances 
helped to address the aforementioned concerns of external validity and promote managerial insights, justifying the methodological approach taken.

\subsection{Directions for Future Research}

While addressing its objectives, the conclusions of this research lead to several areas of interest for future interdisciplinary corporate philanthropy study. Given the nascence of this field, it would also be interesting to consider a different disaster context to an earthquake, such as a cyclone or tsunami, and identify any resulting changes to reputation following giving. The physical or temporal closeness of a disaster could have a significant impact on perceptions of philanthropy (Trope \& Liberman 2010), hence assessment of CBR across unique scenarios would be useful to examine. Similarly, manipulating size of the philanthropic company, industry of operation, and country contexts would extend the generalisability of these findings for marketers.

Moreover, as the results were focused on reputation as a dependent measure, future inquiry should analyse a wider breadth of consumer-centred impacts. As CBR can improve relational outcomes, such as trust and purchase intention (Walsh et al., 2009), it would be interesting to directly test these extended effects following a disaster. Signalling theory predicts that customer-based reputation will have a substantial impact on customer loyalty and word of mouth (Walsh et al., 2009), which would be useful to assess in supplementing managerial insights. Longitudinal work would also demonstrate the extent to which giving provides longterm reputation inoculation again crises, and sustained trust. As much of the discussion surrounding Study 1B is borrowed from psychological literature, the implications of altruism born of suffering and the newfound 'helping when hurting' principle advanced here should also be measured concerning enduring consumer behaviours and perceptions.

From the perspective of ethnocentrism, it would be useful to replicate Study 2 with a more representative sample of the population. By including more male consumers, and those aged over 40 years, a higher level of ethnocentrism could provide more explanatory information (Aziz et al., 2014). Research with greater resourcing and scope should introduce samples from different countries to extend comparative findings. Assessing collectivist and individualist 
countries, or perceptions of giving in rural and urban communities, for example, would explicate possible reasons for the unexpected conclusions in Study 2, adding value to ethnocentrism scholarship.

Finally, researchers have previously examined citizen's expectations of disaster response at both a government (Chamlee-Wright \& Storr, 2010) and charity level (Fremont-Smith, Boris $\&$ Steuerle, 2006). However, to the author's knowledge, disaster relief expectations of forprofit businesses have not been developed, integrating an antecedent through which reputation is created. Qualitative findings could fill this research gap to identify specific expectation typologies of consumers, such as monetary value or duration of giving. As previously discussed, the expectation confirmation paradigm could be integrated into the philanthropyreputation relationship to develop more fruitful insights into the disconfirmation of consumer philanthropic expectations. Measuring other antecedents to $\mathrm{CBR}$, such as attitudes to $\mathrm{CP}$, similar to Szöcs (2013), would enrichen contributions. Findings could then be anchored in balance theory to delineate attitudinal imbalance across giving scenarios (Szöcs et al., 2016). Determining the extent to which consumers hold consistency in their thoughts, feelings and behaviours when evaluating philanthropy may help to explain the unexpected results surrounding ethnocentrism, and extend purchase-based, behavioural implications. Similarly, it remains unclear why consumers perceive giving from impacted companies more positively, such as risk absorption or feelings of altruism. Qualitative inquiry could develop these conclusions for managers to be better equipped with greater detail in post-disaster philanthropic decision-making. 


\section{Reference List}

Adkins, S. (1999). Cause related marketing: Who cares wins. Oxford, England: ButterworthHeinemann.

Allen, P., Bennett, K., \& Heritage, B. (2014). SPSS statistics version 22: A practical guide. South Melbourne: Cengage Learning.

Andreoni, J. (1990). Impure altruism and donations to public-goods: A theory of warm-glow giving. Economic Journal, 100(401), 464-477.

Arendt, S., \& Brettel, M. (2010). Understanding the influence of corporate social responsibility on corporate identity, image, and firm performance. Management Decision, 48(1), 1469-1492.

Armstrong, J. (2013). Improving international capacity development: Bright spots. London, England: Palgrave Macmillan.

Armstrong, J.S., \& Overton, T.S. (1977). Estimating nonresponse bias in mail surveys. Journal of Marketing Research, 14(3), 396-402.

Ashford, B.E., \& Gibbs, B.W. (1990). The double-edge of organizational legitimation. Organization Science, 1(2), 177-194.

Auger, P., Devinney, T.M., Louviere, J.J., \& Burke, P.F. (2010). The importance of social product attributes in consumer purchasing decisions: A multi-country comparative study. International Business Review, 19(2), 140-159.

Australian Government. (2018). Employment conditions during natural disasters and emergencies. Retrieved from https://www.fairwork.gov.au/how-we-willhelp/templates-and-guides/fact-sheets/rights-and-obligations/employmentconditions-during-natural-disasters-and-emergencies.

Avina, J. (2013). The evolution of corporate social responsibility in the Arab Spring. Middle East Journal, 67(1), 77-92.

Aziz, S., Bahadur, W., Sarwar, B., Farooq, R., \& Arshad, M. (2014). Investigating the role of demographic characteristics on consumer ethnocentrism and buying behaviour. International Review of Management and Business Research, 3(2), 885-893.

Bae, J., \& Cameron, G.T. (2006). Conditioning effect of prior reputation on perception of corporate giving. Public Relations Review, 32(2), 144-150.

Baghramian, M., \& Adam, C.J. (2018). Relativism. In E. Zalta (Ed.), Stanford Encyclopaedia of Philosophy. Retrieved from https://plato.stanford.edu/archives/win2018/entries/relativism/.

Baker, S.M. (2009). Vulnerability and resilience in natural disaters: A marketing and public policy perspective. Journal of Public Policy \& Marketing, 28(1), 114-123. 
Balmer, J.M., \& Greyser, S.A. (2006). Corporate marketing: Integrating corporate identity, corporate branding, corporate communications, corporate image and corporate reputation. European Journal of Marketing, 40(7/8), 730-741.

Baltar, F., \& Brunet, I. (2012). Social research 2.0: Virtual snowball sampling method using Facebook. Internet Research, 22(1), 57-74.

Becker-Olsen, K.L., Cudmore, B.A., \& Hill, R.P. (2006). The impact of perceived corporate social responsibility on consumer behaviour. Journal of Business Research, 59(1), 46-53.

Berkes, F., \& Ross, H. (2013). Community resilience: Toward an integrated approach. Society \& Natural Resources: An International Journal, 26(1), 5-20.

Bernstein, D. (1984). Company image and reality: A critique of corporate communications. Austin, Texas: Holt, Rinehart \& Winston Ltd

Beurden, P., \& Gossling, T. (2008). The worth of values: A literature review on the relation between corporate social and financial performance. Journal of Business Ethics, 82(2), 407-424.

Bhattacharyna, C.B. \& Sankar, S. (2004). Doing better at doing good: When, why, and how consumers respond to corporate social initiatives. California Management Review, 47(1), 9-24.

Bin, O., \& Edwards, B. (2009). Social capital and business giving to charity following a natural disaster: An empirical assessment. Journal of Socio-Economics, 38(4), 601607.

Bizumic, B. (2014). Who coined the concept of ethnocentrism? A brief report. Journal of Social and Political Psychology, 2(1), 3-10.

Block, E.S., Glavas, A., Mannor, M.J., \& Erskine, L. (2017). Business for good? An investigation into the strategies firms use to maximize the impact of financial corporate philanthropy on employee attitudes. Journal of Business Ethics, 146(1), 167-183.

Booth, K. (1979). Strategy and Ethnocentrism. London, England: Croom-Helm.

Bosch-Badia, M.T., Montllor-Serrats, J., \& Tarrazon, M.A. (2013). Corporate social responsibility from Friedman to Porter and Kramer. Theoretical Economics Letters, $3(3 \mathrm{~A}), 11-15$.

Bracha, A., \& Vesterlund, L. (2017). Mixed signals: Charity reporting when donations signal generosity and income. Games and Economic Behaviour, 104(C), 24-42.

Brammer, S.J., \& Millington, A. (2005). Corporate reputation and philanthropy: An empirical analysis. Journal of Business Ethics, 61(1), 29-44. 
Brammer, S.J., \& Millington, A. (2006). Firm size, organizational visibility and corporate philanthropy: An empirical analysis. Business Ethics: A European Review, 15(1), 618.

Brammer, S.J., \& Millington, A. (2008). Does it pay to be different? An analysis of the relationship between corporate social and financial performance. Strategic Management Journal, 29(12), 1325-1343.

Brammer, S.J., Pavelin, S., \& Porter, L.A. (2009). Corporate charitable giving, multinational companies and countries of concern. Journal of Management Studies, 46(4), 575596.

Brand, D., \& Nicholson, H. (2016). Public space and recovery: Learning from postearthquake Christchurch. Journal of Urban Design, 21(2), 159-176.

Brewer, M.B. (1999). The psychology of prejudice: In-group love and out-group hate? Journal of Social Issues, 55(3), 429-444.

Brønn, P.S., \& Vrioni, A.B. (2000). Measuring skepticism to cause related marketing: Preliminary Norwegian results (Discussion Paper 1/2000). Oslo, Norway: BI Norwegian School of Management.

Brooks, J. (2017). Why giving cash, not clothing, is usually best after disasters. Retrieved from https://theconversation.com/why-giving-cash-not-clothing-is-usually-bestafter-disasters-83405.

Carroll, A.B. (1979). A three-dimensional conceptual model of corporate social performance. Academy of Management Review, 4(4), 497-505.

Chalmeta, R., \& Viiinikka, H. (2017). Corporate philanthropy communication on donor websites. Journal of Information, Communication and Ethics in Society, 15(1), 5373.

Chamlee-Wright, E., \& Storr, V.H. (2010). Expectations of government's response to disaster. Public Choice, 144(1/2), 253-274.

Charities Aid Foundation. (2017). CAF world giving index 2017: A global view of giving trends. Retrieved from https://www.cafonline.org/docs/default-source/about-uspublications/cafworldgivingindex2017_2167a_web_210917.pdf.

Charity Navigator. (2019). American Red Cross. Retrieved from https://www.charitynavigator.org/index.cfm?bay=search.summary\&orgid=3277.

Charness, G., Gneezy, U., \& Kuhn, M. (2012). Experimental methods: Between-subject and within-subject design. Journal of Economic Behavior \& Organization, 81(1), 1-8.

Chen, Y-R., Cheng, Y., Hung-Baesecke, C-J., \& Jin, Y. (2019). Engaging international publics via mobile-enhanced CSR (mCSR): A cross-national study on stakeholder reactions to corporate disaster relief efforts. American Behavioural Scientist, 1-21. Advanced online publication. doi: $\underline{10.1177 / 0002764219835258}$ 
Chomvilailuk, R., \& Butcher, K. (2010). Enhancing brand preference through corporate social responsibility initiatives in the Thai banking sector. Asia Pacific Journal of Marketing and Logistics, 22(3), 397-418.

Cohen, J. (1988). Statistical power analysis for the behavioral sciences ( $2^{\text {nd }}$ ed.). Hillsdale, NJ: Lawrence Erlbaum Associates, Publishers.

Collins, M. (1993). Global philanthropy - Marketing beyond the call of duty? European Journal of Marketing, 27(2), 46-58.

Commission of the European Communities. (2001). Promoting a European framework for corporate social responsibilities. COM (2001) 366 final: Brussels, Belgium.

Committee Encouraging Corporate Philanthropy. (2018). Giving in numbers: 2018 edition. Retrieved from http://cecp.co/home/resources/giving-in-numbers/.

Cone Communications. (2015). 2015 Cone Communications Milennial CSR Study. Retrieved from http://www.conecomm.com/2015-cone-communications-millennial-csr-studypdf/.

Coombs, W.T. (2007). Protecting organization reputations during a crisis: The development and application of situational crisis communication theory. Corporate Reputation Review, 10(3), 163-176.

Crampton, W., \& Patten, D. (2008). Social responsiveness, profitability and catastrophic events: Evidence on the corporate philanthropic response to 9/11. Journal of Business Ethics, 81(4), 863-873.

Creswell, J.W. (2014). Research design: Qualitative, quantitative, and mixed methods approaches $\left(4^{\text {th }} \mathrm{ed}\right.$.). Thousand Oaks, CA: SAGE Publications.

Cui, Y., Trent, E.S., Sullivan, P.M., \& Matiru, G.N. (2003). Cause-related marketing: How generation Y responds. International Journal of Retail \& Distribution Management, $31(6 / 7), 310-320$.

Dahlsrud, A (2008). How corporate social responsibility is defined: An analysis of 37 definitions. Cororate Social Responsibility and Environmental Management, 15(1), $1-13$.

Day, J.M., Melnyk, S.A., Larson, P.D., Davis, E.W., \& Whybark, D.C. (2012). Humanitarian and disaster relief supply chains: A matter of life and death. Journal of Supply Chain Management, 48(2), 21-36.

Dean, D.H. (2003). Consumer perception of corporate donations: Effects of company reputation for social responsibility and type of donation. Journal of Advertising, 32(4), 91-102.

Dees, J. G. (2012). A tale of two cultures: Charity, problem solving, and the future of social entrepreneurship. Journal of Business Ethics, 111(3), 321-334. 
Deloitte. (2017). The forgotten impact. Kaikoura earthquake: Wellington still paying the price. Retrieved from

https://www2.deloitte.com/content/dam/Deloitte/nz/Documents/about-deloitte/nzen-Kaikoura-earthquake-Wellington-impact-report.pdf.

Denk, N., Kaufmann, L., \& Roesch, J-F. (2012). Liabilities of foreignness revisited: A review of contemporary studies and recommendations for future research. Journal of International Management, 18(4), 322-334.

Deshpande, R. (1983). "Paradigms lost": On theory and method in research in marketing. Journal of Marketing, 47(4), 101-110.

Diekmann, K.A. (1997). Implicit justifications and self-serving group allocations. Journal of Organizational Behaviour, 18(1), 3-16.

DiNitto, E. (1989). Marketing with a conscience. Marketing Communications, 14(5), 42-46.

Donnelly, J. (1984). Cultural relativism and universal human rights. Human Rights Quarterly, 6(4), 400-419.

Doorley, J., \& Garcia, H.F. (2015). Reputation management: The key to successful public relations and corporate communication. New York, NY: Routledge.

Double the Donation. (2019). Google matching gifts. Retrieved from https://doublethedonation.com/matching-gifts/google-inc.

Easley, R.W., Madden, C.S., \& Dunn, M.G. (2000). Conducting marketing science: The role of replication in the research process. Journal of Business Research, 48(1), 83-92.

Elkington, J. (1998). Partnerships from cannibals with forks: The triple bottom line of $21^{\text {st }}$ century business. Environmental Quality Management, 8(1), 37-51.

Ellen, P.S., Mohr, L.A., \& Webb, D.J. (2000). Charitable programs and the retailer: Do they mix? Journal of Retailing, 76(3), 393-406.

Elving, W.J. (2013). Scepticism and corporate social responsibility communications: The influence of fit and reputation. Journal of Marketing Communications, 19(4), 277292.

Evans, J.R., \& Mathur, A. (2005). The value of online surveys. Internet Research, 15(2), 195219.

Evans, J.R., \& Mathur, A. (2018). The value of online surveys: A look back and a look ahead. Internet Research, 28(4), 854-887.

Eveland, V.B., Crutchfield, T.N., \& Rynarzewska, A.I. (2018). Developing a consumer relationship model of corporate social performance. Journal of Consumer Marketing, 35(5), 543-554.

File, KM., \& Prince, RA. (1998). Cause-related marketing and corporate philanthropy in the privately held enterprise. Journal of Business Ethics, 17(14), 1529-1539. 
Financial Accounting Standards Board. (1993). Accounting for contributions received and contributions made. Norwalk, CT: Financial Accounting Standards Board.

Fombrun, C.J. (1996). Reputation: Realising value from the corporate image. Boston, MA: Harvard Business School Press.

Fombrun, C.J., Gardberg, N.A., \& Sever, J.W. (2000). The reputation quotient: A multistakeholder measure of corporate reputation. The Journal of Brand Management, 7(4), 241-255.

Foster, K.R., Wenseleers, T., \& Ratnieks, F.L. (2006). Kin selection is the key to altruism. Trends in Ecology \& Evolution, 21(2), 57-60.

Fournier, S., \& Mick, D.G. (1999). Rediscovering satisfaction. Journal of Marketing, 63(4), $5-23$.

Fremont-Smith, M., Boris, E.T., \& Steuerle, C.E. (2006). Charities response to disasters: Expectations and realities. In E.T. Boris, \& C.E. Steuerle (Eds.), After Katrina: Public expectation and charities' response (pp. 1-4). Cambridge MA: The Hauser Centre for Nonprofit Organizations.

Friedman, M. (1970). The social responsibility of business is to increase profits. The New York Times Magazine, 32(1), 122-126.

Galaskiewicz, J. (1989). Corporate contributions to charity: Nothing more than a marketing strategy? In R. Magat (Ed.), Philanthropic giving: Studies in varieties and goals (pp. 246-260). NY, New York: Oxford University Press.

Galbreath, J. (2010). Drivers of corporate social responsibility: The role of formal strategic planning and firm culture. British Journal of Management, 21(2), 511-525.

Gao. F., Faff, R., \& Navissi, F. (2012). Corporate philanthropy: Insights from the 2008 Wenchuan Earthquake in China. Pacific-Basin Finance Journal, 20(3), 363-377.

Gao, Y., Hafsi, T. (2015). Competition in corporate philanthropic disaster giving: Balancing between giving timing and amount. Chinese Management Studies, 9(3), 311-332.

Gardberg, N.A., Zyglidopoulos, S.C., Symeou, P.C., \& Schepers, D.H. (2017). The impact of corporate philanthropy on reputation for corporate social performance. Business \& Society, 58(6), 1177-1208.

Gautier, A., \& Pache, A-C. (2015). Research on corporate philanthropy: A review and assessment. Journal of Business Ethics, 126(3), 343-369.

Geuens, M., \& De Pelsmacker. (2017). Planning and conducting experimental advertising research and questionnaire design. Journal of Advertising, 46(1), 83-100.

Gipp, N., Kalafatis, S.P., \& Ledden, L. (2008). Perceived value of corporate donations: An empirical investigation. International Journal of Nonprofit and Voluntary Sector Marketing, 13(4), 327-346. 
Giving USA. (2018). Giving USA 2018: The annual report on philanthropy for the year 2017. Retrieved from https://www.uschamberfoundation.org/blog/post/corporategiving-through-lens-disaster-response.

Godfrey, P.C. (2005). The relationship between corporate philanthropy and shareholder wealth: A risk management perspective. Academy of Management, 30(4), 777-798.

Gotsi, M., \& Wilson, A.M. (2001). Corporate reputation: Seeking a definition. Corporate Communications: An International Journal, 6(1), 24-30.

Greater Christchurch Group. (2017). Lessons from the Canterbury earthquake sequence. Retrieved from https://www.dpmc.govt.nz/sites/default/files/2017-07/wholeofgovernment-report-lessons-from-the-canterbury-earthquake-sequence.pdf.

Grewal, D., Levy, M., \& Lehmann, D.R. (2004). Retail branding and customer loyalty: An overview. Journal of Retailing, 80(4), ix-xii.

Gumplowicz, L. (1879). The right of nationality and language in Austria-Hungary. Innsbruck, Austria: Wagner'sche Universitäts-Buchhandlung.

Hair, J.F., Jr., Black, W.C., Babin, B.J., \& Anderson, R.E. (2010). Multivariate data analysis ( $7^{\text {th }}$ Ed.). Upper Saddle River, NJ.: Pearson Prentice Hall.

Ham, C-D., \& Kim, J. (2017). The role of CSR in crises: Integration of situational crisis communication theory and the persuasion knowledge model. Journal of Business Ethics, 1-20.

Helm, S. (2007). The role of corporate reputation in determining investor satisfaction and loyalty. Corporate Reputation Review, 10(1), 22-37.

Herche, J. (1994). Ethnocentric tendencies, marketing strategy and import purchase behaviour. International Marketing Review, 11(3), 4-16.

Hessling, R.M., Schmidt, T.J., \& Traxel, N.M. (2011). Floor effect. In M.S. Lewis-Beck, A. Bryman \& T.F. Liao (Eds.), The SAGE Encyclopedia of Social Science Research Methods (p. 391). Thousand Oaks, CA: SAGE Publications.

Hildebrand, D., DeMotta, Y., Sen, S., \& Valenzuela, A. (2017). Consumer responses to corporate social responsibility (CSR) contribution type. Journal of Consumer Research, 44(4), 738-758.

Hoffman, M.L. (1978). Psychological and biological perspectives on altruism. International Journal of Behavioural Development, 1(4), 323-339.

Hofstede Insights. (2019). What about New Zealand? Retrieved from https://www.hofstedeinsights.com/country/new-zealand/.

Hudson, L.A., \& Ozanne, J.L. (1988). Alternative ways of seeking knowledge in consumer research. Journal of Consumer Research, 14(4), 508-521. 
Hur, W-M., Kim, H., \& Woo, J. (2014). How CSR leads to corporate brand equity: Mediating mechanisms of corporate brand credibility and reputation. Journal of Business Ethics, 125(1), 75-86.

Hutton, J.G., Goodman, M.B., Alexander, J.B., \& Genest, C.M. (2001). Reputation management: The new face of corporate public relations? Public Relations Review, 27(3), 247-271.

Iacobucci, D., Posavac, S.S., Kardes, F.R., Schneider, M.J., \& Popovich, D.L. (2015). Toward a more nuanced understanding of the statistical properties of a median split. Journal of Consumer Psychology, 25(4), 652-665.

Insurance Council of New Zealand. (2018). 90\% of Kaikoura claims done. Retrieved from https://www.insurancebusinessmag.com/nz/news/breaking-news/90-of-kaikouraclaims-done-90456.aspx.

Irani, A.S. (2018). Positive altruism: Helping that benefits both the recipient and giver. Master of Applied Positive Psychology (MAPP) Capstone Projects 152.

Jamali, D. (2007). The case for strategic corporate social responsibility in developing countries. Business and Society Review, 112(1), 1-27.

Jones, G.H., Jones, B.H., \& Little, P. (2000). Reputation as a reservoir: Buffering against loss in times of economic crisis. Corporate Reputation Review, 3(1), 21-29.

Kaiser, H, F. (1974). An index of factorial simplicity. Psychometrika, 39(1), 31-36.

Kaynak, E., \& Kara, A. (2002). Consumer perceptions of foreign products: An analysis of product-country images and ethnocentrism. European Journal of Marketing, 36(7/8), 928-949.

Kim, Y. (2014). Strategic communication of corporate social responsibility: Effects of stated motives and corporate reputation on stakeholder responses. Public Relations Review, $40(5), 838-840$.

Kim, Y.J., \& Lee, W-N. (2009). Overcoming consumer skepticism in cause-related marketing: The effects of corporate social responsibility and donation size claim objectivity. Journal of Promotion Management, 15(4), 465-483.

Kotler, P. (1972). What consumerism means for marketers. Harvard Business Review, 50(3), 48-57.

Kotler, P., \& Levy, S. (1969). Broadening the concept of marketing. Journal of Marketing, $33(1), 10-15$.

KPMG. (2017). The road ahead: The KPMG survey of corporate responsibility reporting 2017. Retrieved from https://home.kpmg/xx/en/home/insights/2017/10/the-kpmgsurvey-of-corporate-responsibility-reporting-2017.html.

La Cour, A., \& Kromann, J. (2011). Euphemisms and hypocrisy in corporate philanthropy. Business Ethics: A European Review, 20(3), 267-279. 
Labadie, J.R. (2008). Auditing of post-disaster recovery and reconstruction activities. Disaster Prevention and Management: An International Journal, 17(5), 575-586.

Lantz, G., \& Loeb, S. (1998). An examination of the community identity and purchase preferences using the social identity approach. Advances in Consumer Research, $25(1), 486-491$.

LaRose, R., \& Tsai, H.Y.S. (2014). Completion rates and non-response error in online surveys: Comparing sweepstakes and pre-paid cash incentives in studies of online behaviour. Computers in Human Behaviour, 34(1), 110-119.

Lather, P. (1986). Research as praxis. Harvard Educational Review, 56(3), 257-278.

LeVine, R.A., \& Campbell, D.T. (1972). Ethnocentrism: Theories of conflict, ethnic attitudes, and group behaviour. New York, NY: Wiley.

Lieber, R. (2015). Giving more globally, and less locally. Retrieved from https://www.nytimes.com/2015/06/20/your-money/giving-more-globally-and-lesslocally.html.

Lii, Y., \& Lee, M. (2012). Doing right leads to doing well: When the type of CSR and reputation interact to affect consumer evaluations of the firm. Journal of Business Ethics, 105(1), 69-81.

Liket, K., \& Simaens, A. (2015). Battling the devolution in the research on corporate philanthropy. Journal of Business Ethics, 126(2), 285-308.

Lincoln, Y.S., Lynham, S.A., \& Guba, E.G. (2011). Paradigmatic controversies, contradictions, and emerging confluences, revisited. In N.K. Denzin, \& Y.S. Lincoln (Eds.), The SAGE Handbook of Qualitative Research (4 ${ }^{\text {th }}$ ed., pp. 97-128). Thousand Oaks, CA: SAGE Publications.

Liu, W., \& Aaker, J. (2008). The happiness of giving: The time-ask effect. Journal of Consumer Research, 35(3), 543-557.

Ma, L., \& Zhan, M. (2016). Effects of attributed responsibility and response strategies on organizational reputation: A meta-analysis of situational crisis communication theory research. Journal of Public Relations Research, 28(2), 102-119.

Mahon, J.F. (2002). Corporate reputation: A research agenda using strategy and stakeholder literature. Business \& Society, 41(4), 415-445.

Martin, O. (1962). On the social psychology of the psychological experiment: With particular reference to demand characteristics and their implications. American Psychologist, 17(11), 776-783.

Maruyama, M., \& Wu, L. (2015). Overcoming the liability of foreignness in international retailing: A consumer perspective. Journal of International Management, 21(3), 200-210. 
Masulis, R.W., \& Reza, S.W. (2015). Agency problems of corporate philanthropy. The Review of Financial Studies, 28(2), 592-636.

Mayner, L., \& Arbon, P. (2015). Defining disaster: The need for harmonisation of terminology. Australasian Journal of Disaster and Trauma Studies, 19, 21-26.

McClelland, G.H., Lynch Jr, J.G., Irwin, J.R., Spiller. S.A., \& Fitzsimons, G.J. (2015). Median splits, Type II errors, and false-positive consumer psychology: Don't fight the power. Journal of Consumer Psychology, 25(4), 679-689.

McKnight, B., \& Linnenluecke, M.K. (2016). How firm responses to natural disasters strengthen community resilience: A stakeholder-based perspective. Organization \& Environment, 29(3), 290-307.

McLeod, J. (2017). The New Zealand cause report: Shape of the charity sector. Retrieved from https://www.jbwere.co.nz/assets/Uploads/JBWereNZ-CauseReportMarch2017-DigitalVersion.pdf.

Mescon, T.S., \& Tilson, D.J. (1987). Corporate philanthropy: A strategic approach to the bottom-line. California Management Review, 29(2), 49-61.

Ministry of Foreign Affairs \& Trade. (2018). Annual report 2017-18. Retrieved from https://www.mfat.govt.nz/assets/MFAT-Corporate-publications/MFAT-annualreport-2018/MFAT-Annual-Report-2017-18.pdf.

Mithani, M.A. (2017). Liability of foreignness, natural disasters, and corporate philanthropy. Journal of International Business Studies, 48(8), 941-963.

Mohr, L.A., Eroglu, D., \& Ellen, P.S. (1998). The development and testing of a measure of skepticism toward environmental claims in marketers' communications. The Journal of Consumer Affairs, 32(1), 30-55.

Mohr, L.A., \& Webb, D.J. (2005). The effects of corporate social responsibility and price on consumer responses. The Journal of Consumer Affairs, 39(1), 121-147.

Morris, D. (2018). When disasters strike: Pay, leave and related issues. Retrieved from https://www.shrm.org/resourcesandtools/hrtopics/compensation/pages/disasters.aspx.

Morris, S.A., Bartkus, B.R., Glassman, M., \& Rhiel, S.G. (2013). Philanthropy and corporate reputation: an empirical investigation. Corporate Reputation Review, 16(4), 285299.

Muller, A.R., \& Kräussl, R. (2011a). Doing good deeds in times of needs: a strategic perspective on corporate disaster donations. Strategic Management Journal, 32(9), 911-929.

Muller, A.R., \& Kräussl, R. (2011b). The value of corporate philanthropy during times of crisis: The sensegiving effect of employee involvement. Journal of Business Ethics, 103(2), 203-220. 
Muller, A.R., Pfarrer, M.D., \& Little, L.M. (2014). A theory of collective empathy in corporate philanthropy decisions. Academy of Management Review, 39(1), 1-21.

Muller, A., \& Whiteman, G. (2009). Exploring the geography of corporate philanthropic disaster response: A study of fortune global 500 firms. Journal of Business Ethics, 84(4), 589-603.

Muller, A., \& Whiteman, G. (2016). Corporate philanthropic responses to emergent human needs: The role of organizational attention focus. Journal of Business Ethics, 137(2), 299-314.

Murray, K. (2004). Reputation: Managing the single greatest risk facing business today. Journal of Communication Management, 8(2), 142-149.

Nan, X., \& Heo, K. (2007). Consumer responses to corporate social responsibility (CSR) initiatives; examining the role of brand-cause fit in cause-related marketing. Journal of Advertising, 36(2), 63-74.

National Business Review. (2018). Spark offers free wi-fi, Vodafone free mobile data as Gita hits. Retrieved from https://www.nbr.co.nz/article/spark-offers-free-wi-fi-vodafonefree-mobile-data-gita-hits-ck-212872.

Negy, C., Shreve, T.L., Jensen, B.J., \& Uddin, N. (2003). Ethnic identity, self-esteem, and ethnocentrism: A study of social identity versus multicultural theory of development. Cultural Diversity and Ethnic Minority Psychology, 9(4), 333-344.

Neuliep, J.W., \& McCroskey, J.C. (1997). The development of a U.S. and generalized ethnocentrism scale. Communication Research Reports, 14(4), 385-398.

Neuliep, J.W., \& McCroskey, J.C. (2013). Ethnocentrism Scale. Retrieved from http://www.midss.org/sites/default/files/ethnocentrism_scale.pdf.

Netemeyer, R.G., Durvasula, S., \& Lichtenstein, D.R. (1991). A cross-national assessment of the reliability and validity of the CETSCALE. Journal of Marketing Research, 28(3), 320-327.

Nguyen, T.D., Nguyen, T.T., \& Barrett, N.J. (2008). Consumer ethnocentrism, cultural sensitivity, and intention to purchase local products - evidence from Vietnam. Journal of Consumer Behaviour, 7(1), 88-100.

O'Hare, B.C. (1991). Good deeds are good business. American Demographics, 13(9), 38-42.

Obermiller, C., \& Spangenberg, E.R. (1998). Development of a scale to measure consumer skepticism toward advertising. Journal of Consumer Psychology, 7(2), 159-186.

OECD. (2019). OECD broadband statistics update. Retrieved from https://www.oecd.org/sti/broadband/broadband-statistics-update.htm.

Oliver, R.L. (1977). Effect of expectation and disconfirmation on postexposure product evaluations: An alternative interpretation. Journal of Applied Psychology, 62(4), 480-486. 
Orlitzky, M., Siegel, D.S., \& Waldman, D.A. (2011). Strategic corporate social responsibility and environmental sustainability. Business \& Society, 50(1), 6-27.

Park, J., Lee, H., \& Kim, C. (2014). Corporate social responsibilities, consumer trust and corporate reputation: South Korean consumers' perspectives. Journal of Business Research, 67(3), 295-302.

Parker, M., \& Steenkamp, D. (2012). The economic impact of the Canterbury earthquakes. Reserve Bank of New Zealand: Bulletin, 75(3), 13-25.

Patten, D.M. (2008). Does the market value corporate philanthropy? Evidence from the response to the 2004 tsunami relief effort. Journal of Business Ethics, 81(3), 599607.

Patton, M.Q. (2001). Qualitative evaluation and research methods ( $3^{\text {rd }}$ ed.). Thousand Oak, CA: Sage Publications.

Peloza, J., \& Shang, J. (2011). How can corporate social responsibility activities create value for stakeholders? A systematic review. Journal of the Academy of Marketing Science, 39(1), 117-135.

Perry, N. (2018). Magnitude 7.5 earthquake strikes in pacific near New Caledonia. Retrieved from https://www.bloomberg.com/news/articles/2018-12-05/urgent-magnitude-7-5quake-strikes-in-pacific-near-new-caledonia.

Peterson, D.K. (2018). Enhancing corporate reputation through corporate philanthropy. Journal of Strategy and Management, 11(1), 18-32.

Philanthropy New Zealand. (2014). Giving New Zealand: Philanthropic Funding 2014. Retrieved from https://philanthropy.org.nz/wp-content/uploads/2016/03/GivingNew-Zealand-2014-1.pdf.

Porter, M.E., \& Kramer. M.R. (2002). The competitive advantage of corporate philanthropy. Retrieved from https://hbr.org/2002/12/the-competitive-advantage-of-corporatephilanthropy.

Prasad, A., \& Holzinger, I. (2013). Seeing through smoke and mirrors: A critical analysis of marketing CSR. Journal of Business Research, 66(10), 1915-1921.

Ramirez, R., Mukherjee, M., Vezzoli, S., \& Kramer, A.M. (2015). Scenarios as a scholarly methodology to produce "interesting research". Futures, 71(1), 70-87.

Rampal, M., \& Bawa, M. (2008). Corporate philanthropy: A study of consumer perceptions. Vision: The Journal of Business Perspective, 12(2), 23-33.

Reddit. (2019). r/newzealand. Retrieved from https://www.reddit.com/r/newzealand/.

Rindova, V.P. (1997). Part VII: Managing reputation: Pursuing everyday excellence: The image cascade and the formation of corporate reputations. Corporate Reputation Review, 1(2), 188-194. 
Roberts, P.W., \& Dowling, G.R. (2002). Corporate reputation and sustained superior financial performance. Strategic Management Journal, 23(1), 1077-1093.

Rovai, A.P., Baker, J.D., \& Ponton, M.K. (2014). Social science research design and statistics. Chesapeake, VA: Watertree Press LLC.

Runté, M., Basil, D.Z., \& Deshpande, S. (2009). Cause-related marketing from the nonprofit's perspective: Classifying goals and experienced outcomes. Journal of Nonprofit \& Public Sector Marketing, 21(3), 255-270.

Russell, D.W., \& Russell, C.A. (2010). Here or there? Consumer reactions to corporate social responsibility initiatives: Egocentric tendencies and their moderators. Marketing Letters, 21(1), 65-81.

Salvador, J.T. (2016). Revisiting the philosophical underpinnings of qualitative research. International Education \& Research Journal, 2(6), 4-6.

Satherley, D. (2017). New Zealand 'high-risk' for almost every natural disaster possible. Retrieved from https://www.newshub.co.nz/home/new-zealand/2017/11/newzealand-high-risk-for-almost-every-natural-disaster-possible.html.

Sawilowsky, S.S. (2009). New effect size rules of thumb. Journal of Modern Applied Statistical Methods, 8(2), 597-599.

Schons, L.M., Cadogan, J., \& Tsakona, R. (2017). Should charity begin at home? An empirical investigation of consumers' responses to companies' varying geographic allocations of donation budgets. Journal of Business Ethics, 144(3), 559-576.

Schwaiger, M., Raithel, S., Rinkenburger, R., \& Schloderer, M. (2011). Measuring the impact of corporate reputation on stakeholder behaviour. In R.J. Burke, G. Martin, \& C.L. Cooper (Eds.), Corporate reputation: Managing threats and opportunities (pp. 4671). Farnham, England: Ashgate Publishing Limited.

Schwaiger, M. (2004). Components and parameters of corporate reputation - An empirical study. Schmalenbach Business Review, 56(1), 46-71.

Schwartz, D. (2012). Michaëlle Jean: 'You cannot build a sustainable economy on charity'. Retrieved from https://www.cbc.ca/news/world/micha\%C3\%ABlle-jean-youcannot-build-a-sustainable-economy-on-charity-1.1136138.

Schwartz, M.S., \& Saiia. D. (2012). Should firms go "beyond profits"? Milton Friedman versus broad CSR. Business and Society Review, 117(1), 1-31.

Seifert, B., Morris, S.A., \& Bartkus, B.R. (2004). Having, giving, and getting: Slack resources, corporate philanthropy, and firm financial performance. Business \& Society, 43(2), 135-161.

Sen, S., \& Bhattacharya, C.B. (2001). Does doing good always lead to doing better? Consumer reactions to corporate social responsibility. Journal of Marketing Research, 38(2), 225-243. 
Shamma, H.M., \& Hassan, S.S. (2009). Customer and non-customer perspectives for examining corporate reputation. Journal of Product \& Brand Management, 18(5), 326-337.

Shank, T., Manullang, D., \& Hill, R. (2005). Doing well while doing good revisited, a study of socially responsible firms' short-term versus long-term performance. Managerial Finance, 31(8), 33-46.

Shankarmahesh, M.N. (2006). Consumer ethnocentrism: An integrative review of its antecedents and consequences. International Marketing Review, 23(2), 146-172.

Sharma, S., Shimp, T.A., \& Shin, J. (1995). Consumer ethnocentrism: A test of antecedents and moderators. Journal of the Academy of Marketing Science, 23(1), 26-37.

Sheikh, SR., \& Beise-Zee, R. (2011). Corporate social responsibility or cause-related marketing? The role of cause specificity of CSR. Journal of Consumer Marketing, 28(1), 27-39.

Sheth, J.N., \& Uslay, C. (2007). Implications of the revised definition of marketing: From exchange to value creation. Journal of Public Policy \& Marketing, 26(2), 302-307.

Shim, K., \& Yang, S-U. (2016). The effect of bad reputation: The occurrence of crisis, corporate social responsibility, and perceptions of hypocrisy and attitudes toward a company. Public Relations Review, 42(1), 68-78.

Shimp, T.A., \& Sharma, S. (1987). Consumer ethnocentrism: Construction and validation of the CETSCALE. Journal of Marketing Research, 24(3), 280-289.

Simon, F.L. (1995). Global corporate philanthropy: A strategic framework. International Marketing Review, 12(4), 20-37.

Singer, A. (2013). Giving practices in Islamic societies. Social Research: An International Quarterly, 80(2), 341-358.

Skarmeas, D., \& Leonidou, C.N. (2013). When consumers doubt, watch out! The role of CSR skepticism. Journal of Business Research, 66(10), 1831-1838.

Solinger, D. (2017). Wrapping up a year of impact with holiday giving. Retrieved from https://blog.google/outreach-initiatives/google-org/wrapping-year-impact-holidaygiving/

Spence, C., \& Thomson, I. (2009). Resonance tropes in corporate philanthropy discourse. Business Ethics: A European Review, 18(4), 372-388.

Starship. (2019). Cause related marketing. Retrieved from https://www.starship.org.nz/foundation/how-your-business-can-help/how-you-canpartner-with-us/cause-related-marketing/.

Statista. (2019a). Active internet users as a percentage of the total population in New Zealand from 2015 to 2018. Retrieved from https://www.statista.com/statistics/680688/newzealand-internet-penetration/. 
Statista. (2019b). Breakdown of Facebook users in New Zealand as of January 2018, by age group. Retrieved from https://www.statista.com/statistics/681512/new-zealandfacebook-users-by-age/.

Statistics New Zealand. (2019). Statistics about a place. Retrieved from https://www.stats.govt.nz/tools/statistics-about-a-place.

Staub, E., \& Vollhardt, J. (2008). Altruism born of suffering: The roots of caring and helping after victimisation and other trauma. American Journal of Orthopsychiatry, 78(3), 267-280.

Strauss, K. (2017). The 10 companies with the best CSR reputations in 2017. Retrieved from https://www.forbes.com/sites/karstenstrauss/2017/09/13/the-10-companies-with-thebest-csr-reputations-in-2017/\#2428eb0d546b.

Stockmeyer, J. (1996). Brands in crisis: Consumer help for deserving victims. In K.P. Corfman \& J.G. Lynch Jr (Eds.), NA - Advances in Consumer Research, 23 (pp. 429-435). Provo, UT: Association for Consumer Research.

Su, J., \& He, J. (2010). Does giving lead to getting? Evidence from Chinese private enterprises. Journal of Business Ethics, 93(1), 73-90.

Sullivan-Taylor, B., \& Branicki, L. (2011). Creating resilient SMEs: Why one size might not fit all. International Journal of Production Research, 49(18), 5565-5579.

Sumner, W.G. (1906). Folkways: A study of the sociological importance of usages, manners, customs, mores, and morals. Boston, MA: Ginn and Company.

Szöcs, I. (2013). The relationship between corporate philanthropy and corporate reputation: Examining the consumer-company-cause triad ( $\mathrm{PhD}$ thesis, Vienna University of Economics and Business, Vienna, Austria).

Szöcs, I., Schlegelmilch, B.B., Rusch, T., \& Shamma, H.M. (2016). Linking cause assessment, corporate philanthropy, and corporate reputation. Journal of the Academy of Marketing Science, 44(3), 376-396.

Tajfel, H. (1982). Social psychology of intergroup relations. Annual Review of Psychology, 33(1), 1-39.

The Coca-Cola Company. (2016). 2016 sustainability report. Retrieved from https://www.cocacolacompany.com/content/dam/journey/us/en/private/fileassets/pdf/2017/2016sustainability-update/2016-Sustainability-Report-The-Coca-Cola-Company.pdf.

The Coca-Cola Company. (2018). Bottled water relieffor Tonga. Retrieved from https://www.coca-colajourney.co.nz/stories/bottled-water-relief-for-tonga.

Thomas, A., \& Mizushima, M. (2005). Logistics training: Necessity or luxury? Forced Migration Review, 22(1), 60-61. 
Tilcsik, A., \& Marquis, C. (2013). Punctuated generosity: How mega-events and natural disasters affect corporate philanthropy in U.S. communities. Administrative Science Quarterly, 58(1), 111-148.

Tornhill, S. (2016). "A bulletin board of dreams": Corporate empowerment promotion and feminist implications. International Feminist Journal of Politics, 18(4), 528-543.

Trochim, W., Donnelly, J., \& Arora, K. (2016). Research methods: The essential knowledge base ( $2^{\text {nd }}$ ed.). Boston, MA: Cengage Learning.

Trope, Y., \& Liberman, N. (2010). Construal-level theory of psychological distance.

Psychological Review, 117(2), 440-463.

Tsai, W.S., Yoo, J.J., \& Lee, W-N. (2013). For love of country? Consumer ethnocentrism in China, South Korea, and the United States. Journal of Global Marketing, 26(2), 98114.

Tseng, T-H., Balabanis, G., \& Liu, M.T. (2018). Explaining inconsistencies in implicit and explicit attitudes towards domestic and foreign products. International Marketing Review, 35(1), 72-92.

Twigg, J. (2001). Corporate social responsibility and disaster reduction: A global overview. London, England: Benfield Greig Hazard Research Centre, University College London.

United Nations General Assembly. (2016). Report of the open-ended intergovernmental expert working group on indicators and terminology relating to disaster risk reduction (A/RES/71/644). Retrieved from https://www.preventionweb.net/files/50683_oiewgreportenglish.pdf.

United Nations Global Compact. (2018). United Nations Global Compact progress report. Retrieved from https://www.unglobalcompact.org/docs/publications/UN-GlobalCompact-Progress-Report-2018.pdf.

Van der Vegt, G., Essens, P., Wahlstrom, M., \& George, G. (2015). Managing risk and resilience. Academy of Management Journal, 58(4), 971-980.

Van Selm, M., \& Jankowski, N.W. (2006). Conducting online surveys. Quality \& Quantity, 40(3), 435-456.

Van Teijlingen, E.R., \& Hundley, V. (2001). The importance of pilot studies. Social Research Update, 35, 1-4.

Vanhamme, J., \& Grobben, B. (2009). “Too good to be true!” The effectiveness of CSR history in countering negative publicity. Journal of Business Ethics, 85(S2), 273283.

Varadarajan, P.R., \& Menon, A. (1988). Cause-related marketing: A coalignment of marketing strategy and corporate philanthropy. Journal of Marketing, 52(3), 58-74. 
Vargas, P.T., Duff, B.R., \& Faber, R.J. (2017). A practical guide to experimental advertising research. Journal of Advertising, 46(1), 101-114.

Visser, W. (2011). The age of responsibility: CSR 2.0 and the new DNA of business. New York, NY: John Wiley.

Vohs, K.D., Mead, N.L., \& Goode, M.R. (2006). The psychological consequences of money. Science, 314(5802), 1154-1156.

Vveinhardt, J., \& Zygmantaite, R. (2015). Impact of social context on strategic philanthropy: Theoretical insight. Procedia - Social and Behavioural Sciences, 214, 1165-1173.

Walker, K. (2010). A systematic review of the corporate reputation literature: Definition, measurement, and theory. Corporate Reputation Review, 12(4), 357-387.

Walker, P., \& Maxwell, D. (2009). Shaping the humanitarian world. Abingdon, England: Routledge.

Walsh, G., \& Beatty, S.E. (2007). Measuring customer-based corporate reputation: scale development, validation, and application. Journal of the Academy of Marketing Science, 35(1), 127-143.

Walsh, G., Beatty, S.E., \& Shiu, E.M. (2009). The customer-based corporate reputation scale: Replication and short-form. Journal of Business Research, 62(10), 924-930.

Wang, H., Choi, J., \& Li, J. (2008). Too little or too much? Untangling the relationship between corporate philanthropy and firm financial performance. Organization Science, 19(1), 143-159.

Wang, H., \& Qian, C. (2011). Corporate philanthropy and corporate financial performance: The roles of stakeholder response and political access. Academy of Management Journal, 54(6), 1159-1181.

Wang, H., Tong, L., Takeuchi, R., \& George, G. (2016). Corporate social responsibility: An overview and new research directions. Academy of Management Journal, 59(2), 534-544.

Wartick, S. (2002). Measuring corporate reputation: Definition and data. Business \& Society, 41(4), 371-392.

Webb, D.J., \& Mohr, L.A. (1998). A typology of consume responses to cause-related marketing: From skeptics to socially concerned. Journal of Public Policy and Marketing, 17(2), 226-238.

Wepener, M., \& Boshoff, C. (2015). An instrument to measure the customer-based corporate reputation of large service organizations. Journal of Services Marketing, 29(3), 163172.

Whetten, D.A. (1997). Part II: Where do reputations come from? Theory development and the study of corporate reputation. Corporate Reputation Review, 1(1), 26-34. 
Whittaker, J., McLennan, B., \& Handmer, J. (2015). A review of informal volunteerism in emergencies and disasters: Definition, opportunities and challenges. International Journal of Disaster Risk Reduction, 13, 358-368.

Williams, R.J., \& Barrett, J.D. (2000). Corporate philanthropy, criminal activity, and firm reputation: Is there a link? Journal of Business Ethics, 26(4), 341-350.

Wulfson, M. (2001). The ethics of corporate social responsibility and philanthropic ventures. Journal of Business Ethics, 29(1/2), 135-145.

Yoon, Y., Gürhan-Canli, Z., \& Schwarz, N. (2006). The effect of corporate social responsibility (CSR) activities on companies with bad reputations. Journal of Consumer Psychology, 16(4), 377-390.

Zagefka, H., Noor, M., Brown, R., de Moura, G.R., \& Hopthrow, T. (2011). Donating to disaster victims: Responses to natural and humanly caused events. European Journal of Social Psychology, 41(3), 353-363.

Zikmund, W.G., Babin, B.J., Carr, J.C., \& Griffin, M. (2013). Business research methods $\left(9^{\text {th }}\right.$ ed.). Mason, $\mathrm{OH}$ : Cengage Learning.

Zizek, S. (1989). The sublime object of ideology. New York, NY: Verso Books. 


\section{Appendices}

\section{Appendix A: Study 1A Questionnaire}

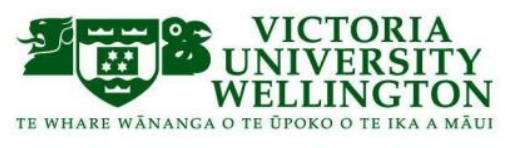

This study is being undertaken as part of my Masters degree in Marketing, to investigate and better understand perceptions of consumers. The survey is completely voluntary and it is not possible for any respondent to be identified personally in conjunction with this survey. The survey should take around 5 minutes to complete. Instructions on how to answer the survey are on the following page.

Please only complete the survey once.

Results from the study will be compiled into a written report for MARK592: Thesis in Marketing. Ethics approval (ID 26872) has been obtained for this research from the Pipitea Human Ethics Committee.

This is a secure website and all responses collected will remain anonymous. All of the material related to survey responses will only be viewed by the researcher and the supervisor. All printed information will be kept in a locked file with access restricted to the researcher.

All electronic data will be kept in a password protected file only accessible by the researcher. Data collected in this survey will be destroyed after 5 years.

It is possible that summary results from this survey may appear in academic or professional journals and may also be presented at academic or professional conferences.

If you have any concerns, questions or require any further information please feel free to contact:

Student Researcher

\section{Guy Bennett-Longley}

bennetguy1@myvuw.ac.nz

or

Student Supervisor

AProf Dan Laufer

dan.laufer@vuw.ac.nz

Thank you for your interest and help in completing this research.

Sincerely,

Guy Bennett-Longley

\section{Human Ethics Committee information}

If you have any concerns about the ethical conduct of the research you may contact the Victoria University HEC Convenor: Dr Judith Loveridge. Email hec@vuw.ac.nz or telephone +64-4-463 6028. 
What is your age?

Under 18 years

18 to 25 years

26 to 45 years

46 to 64 years

65 years and over

Please indicate your ethnicity

New Zealand European/Pākehā

Māori

Pasifika

Asian

Other

Please indicate your country of residence

Aotearoa New Zealand

Australia

United Kingdom

United States

Other 
Following the 2016 7.8-magnitude Kaikōura earthquake in New Zealand, Wellington experienced significant damage to a number of buildings and disruption to core infrastructure. PowerHouse, a New Zealand electricity provider based in downtown Wellington had its operations adversely impacted, but endeavoured to provide assistance within the local community. The following questions seek to understand your views towards PowerHouse's response following this disaster.

\section{NB: Scenario One (Monetary Donation)}

PowerHouse decided to specifically assist in the city's immediate earthquake response by donating $\$ 100,000$ to the Red Cross to assist in disaster recovery efforts. Please answer the following questions.

On the below scale, please rank how strongly you agree with each statement in relation to PowerHouse's earthquake response.

\begin{tabular}{|c|c|c|c|c|c|c|c|}
\hline & $\begin{array}{l}\text { Strongly } \\
\text { disagree }\end{array}$ & Disagree & $\begin{array}{c}\text { Somewhat } \\
\text { disagree }\end{array}$ & $\begin{array}{l}\text { Neither } \\
\text { agree } \\
\text { nor } \\
\text { disagree }\end{array}$ & $\begin{array}{l}\text { Somewhat } \\
\text { agree }\end{array}$ & Agree & $\begin{array}{c}\text { Strongly } \\
\text { agree }\end{array}$ \\
\hline $\begin{array}{c}\text { I have a } \\
\text { good feeling } \\
\text { about } \\
\text { PowerHouse }\end{array}$ & 0 & 0 & 0 & 0 & 0 & 0 & 0 \\
\hline $\begin{array}{c}\text { I admire } \\
\text { PowerHouse }\end{array}$ & 0 & 0 & 0 & 0 & 0 & 0 & 0 \\
\hline $\begin{array}{c}\text { I trust } \\
\text { PowerHouse }\end{array}$ & 0 & 0 & 0 & 0 & $\bigcirc$ & $\bigcirc$ & 0 \\
\hline $\begin{array}{l}\text { I am proud } \\
\text { to be } \\
\text { associated } \\
\text { with } \\
\text { PowerHouse }\end{array}$ & 0 & 0 & 0 & 0 & $\bigcirc$ & $\bigcirc$ & 0 \\
\hline $\begin{array}{c}\text { I like } \\
\text { PowerHouse }\end{array}$ & $\bigcirc$ & $\bigcirc$ & 0 & 0 & 0 & 0 & 0 \\
\hline
\end{tabular}


On the below scale, please rank how strongly you agree with each statement in relation to PowerHouse's earthquake response.

\begin{tabular}{|c|c|c|c|c|c|c|c|}
\hline & $\begin{array}{l}\text { Strongly } \\
\text { disagree }\end{array}$ & Disagree & $\begin{array}{l}\text { Somewhat } \\
\text { disagree }\end{array}$ & $\begin{array}{l}\text { Neither } \\
\text { agree } \\
\text { nor } \\
\text { disagree }\end{array}$ & $\begin{array}{l}\text { Somewhat } \\
\text { agree }\end{array}$ & Agree & $\begin{array}{l}\text { Strongly } \\
\text { agree }\end{array}$ \\
\hline $\begin{array}{l}\text { PowerHouse } \\
\text { supports good } \\
\text { causes }\end{array}$ & O & & & & $\bigcirc$ & & $\mathrm{O}$ \\
\hline $\begin{array}{l}\text { PowerHouse } \\
\text { is committed } \\
\text { to social } \\
\text { responsibility } \\
\text { (social issues) }\end{array}$ & & & & & C & & ( \\
\hline $\begin{array}{l}\text { PowerHouse } \\
\text { responds to } \\
\text { the needs of } \\
\text { communities }\end{array}$ & & & & & C & & \\
\hline $\begin{array}{l}\text { PowerHouse } \\
\text { reaches out to } \\
\text { its social } \\
\text { environment }\end{array}$ & $\bigcirc$ & & $\cap$ & & 0 & & 0 \\
\hline
\end{tabular}

On the below scale, please rank how strongly you agree with each statement in relation to PowerHouse's earthquake response.

\begin{tabular}{|c|c|c|c|c|c|c|c|}
\hline & $\begin{array}{l}\text { Strongly } \\
\text { disagree }\end{array}$ & Disagree & $\begin{array}{c}\text { Somewhat } \\
\text { disagree }\end{array}$ & $\begin{array}{c}\text { Neither } \\
\text { agree } \\
\text { nor } \\
\text { disagree }\end{array}$ & $\begin{array}{c}\text { Somewhat } \\
\text { agree }\end{array}$ & Agree & $\begin{array}{c}\text { Strongly } \\
\text { agree }\end{array}$ \\
\hline $\begin{array}{l}\text { PowerHouse } \\
\text { appears to } \\
\text { make } \\
\text { financially } \\
\text { sound } \\
\text { decisions }\end{array}$ & & & C & & & & ( \\
\hline $\begin{array}{l}\text { PowerHouse } \\
\text { has good } \\
\text { management in } \\
\text { place }\end{array}$ & O & Л & $\bigcirc$ & 0 & & & 0 \\
\hline $\begin{array}{l}\text { The } \\
\text { management of } \\
\text { PowerHouse is } \\
\text { held in high } \\
\text { regard }\end{array}$ & 0 & $\frown$ & 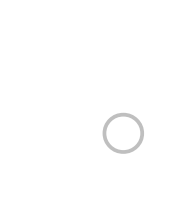 & & $\bigcirc$ & & \\
\hline
\end{tabular}

How is PowerHouse helping the Red Cross following the disaster? 


\section{NB: Scenario Two (Employee Time)}

PowerHouse decided to assist in the city's earthquake response by funding its employees to volunteer for the Red Cross for $\mathbf{4 0}$ hours (equating to roughly $\$ 100,000$ worth of labour). Please answer the following questions.

On the below scale, please rank how strongly you agree with each statement in relation to PowerHouse's earthquake response.

\begin{tabular}{|c|c|c|c|c|c|c|c|}
\hline & $\begin{array}{l}\text { Strongly } \\
\text { disagree }\end{array}$ & Disagree & $\begin{array}{c}\text { Somewhat } \\
\text { disagree }\end{array}$ & $\begin{array}{c}\text { Neither } \\
\text { agree } \\
\text { nor } \\
\text { disagree }\end{array}$ & $\begin{array}{l}\text { Somewhat } \\
\text { agree }\end{array}$ & Agree & $\begin{array}{c}\text { Strongly } \\
\text { agree }\end{array}$ \\
\hline $\begin{array}{c}\text { I have a } \\
\text { good feeling } \\
\text { about } \\
\text { PowerHouse }\end{array}$ & 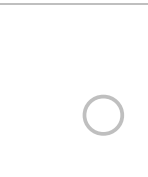 & C & & & & & \\
\hline $\begin{array}{c}\text { I admire } \\
\text { PowerHouse }\end{array}$ & 0 & ( & & & & & \\
\hline $\begin{array}{c}\text { I trust } \\
\text { PowerHouse }\end{array}$ & O & 0 & 0 & 0 & C & 0 & \\
\hline $\begin{array}{l}\text { I am proud } \\
\text { to be } \\
\text { associated } \\
\text { with } \\
\text { PowerHouse }\end{array}$ & O & $\bigcirc$ & 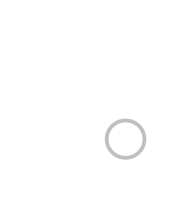 & & & & \\
\hline $\begin{array}{c}\text { I like } \\
\text { PowerHouse }\end{array}$ & O & 0 & 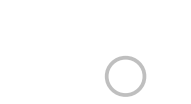 & & & 0 & \\
\hline
\end{tabular}


On the below scale, please rank how strongly you agree with each statement in relation to PowerHouse's earthquake response.

\begin{tabular}{|c|c|c|c|c|c|c|c|}
\hline & $\begin{array}{l}\text { Strongly } \\
\text { disagree }\end{array}$ & Disagree & $\begin{array}{c}\text { Somewhat } \\
\text { disagree }\end{array}$ & $\begin{array}{c}\text { Neither } \\
\text { agree } \\
\text { nor } \\
\text { disagree }\end{array}$ & $\begin{array}{c}\text { Somewhat } \\
\text { agree }\end{array}$ & Agree & $\begin{array}{c}\text { Strongly } \\
\text { agree }\end{array}$ \\
\hline $\begin{array}{l}\text { PowerHouse } \\
\text { supports } \\
\text { good causes }\end{array}$ & C & O & O & 0 & ( & & $C$ \\
\hline $\begin{array}{l}\text { PowerHouse } \\
\text { is committed } \\
\text { to social } \\
\text { responsibility } \\
\text { (social } \\
\text { issues) }\end{array}$ & C & ( & ( & C & & & D \\
\hline $\begin{array}{l}\text { PowerHouse } \\
\text { responds to } \\
\text { the needs of } \\
\text { communities }\end{array}$ & 0 & 0 & 0 & 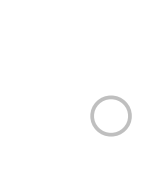 & 0 & 0 & D \\
\hline $\begin{array}{l}\text { PowerHouse } \\
\text { reaches out } \\
\text { to its social } \\
\text { environment }\end{array}$ & 0 & 0 & 0 & O & & & \\
\hline
\end{tabular}

On the below scale, please rank how strongly you agree with each statement in relation to PowerHouse's earthquake response.

\begin{tabular}{|c|c|c|c|c|c|c|c|}
\hline & $\begin{array}{l}\text { Strongly } \\
\text { disagree }\end{array}$ & Disagree & $\begin{array}{c}\text { Somewhat } \\
\text { disagree }\end{array}$ & $\begin{array}{l}\text { Neither } \\
\text { agree nor } \\
\text { disagree }\end{array}$ & $\begin{array}{l}\text { Somewhat } \\
\text { agree }\end{array}$ & Agree & $\begin{array}{c}\text { Strongly } \\
\text { agree }\end{array}$ \\
\hline $\begin{array}{l}\text { PowerHouse } \\
\text { appears to } \\
\text { make } \\
\text { financially } \\
\text { sound } \\
\text { decisions }\end{array}$ & O & 0 & O & & & & \\
\hline $\begin{array}{l}\text { PowerHouse } \\
\text { has good } \\
\text { management } \\
\text { in place }\end{array}$ & 0 & $\bigcirc$ & O & O & & & \\
\hline $\begin{array}{c}\text { The } \\
\text { management } \\
\text { of } \\
\text { PowerHouse } \\
\text { is held in } \\
\text { high regard }\end{array}$ & O & 0 & $\bigcirc$ & O & O & 0 & D \\
\hline
\end{tabular}

How is PowerHouse helping the Red Cross as a result of the Kaikōura earthquake? 
NB: Scenario Three (Focusing Internally)

PowerHouse decided to forgo giving to disaster recovery efforts so it can focus on minimising internal disruptions to its own operations. Please answer the following questions.

On the below scale, please rank how strongly you agree with each statement in relation to PowerHouse's earthquake response.

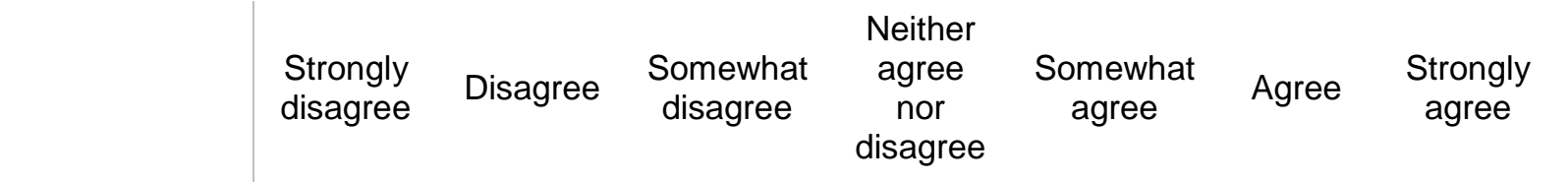

\footnotetext{
I have a good feeling about PowerHouse

I admire PowerHouse

I trust PowerHouse

I am proud to be associated with PowerHouse

I like PowerHouse
} 
On the below scale, please rank how strongly you agree with each statement in relation to PowerHouse's earthquake response.

\begin{tabular}{|c|c|c|c|c|c|c|c|}
\hline & $\begin{array}{l}\text { Strongly } \\
\text { disagree }\end{array}$ & Disagree & $\begin{array}{c}\text { Somewhat } \\
\text { disagree }\end{array}$ & $\begin{array}{c}\text { Neither } \\
\text { agree } \\
\text { nor } \\
\text { disagree }\end{array}$ & $\begin{array}{c}\text { Somewhat } \\
\text { agree }\end{array}$ & Agree & $\begin{array}{c}\text { Strongly } \\
\text { agree }\end{array}$ \\
\hline $\begin{array}{l}\text { PowerHouse } \\
\text { supports } \\
\text { good causes }\end{array}$ & C & O & O & 0 & ( & & $C$ \\
\hline $\begin{array}{l}\text { PowerHouse } \\
\text { is committed } \\
\text { to social } \\
\text { responsibility } \\
\text { (social } \\
\text { issues) }\end{array}$ & C & ( & ( & C & & & D \\
\hline $\begin{array}{l}\text { PowerHouse } \\
\text { responds to } \\
\text { the needs of } \\
\text { communities }\end{array}$ & 0 & 0 & 0 & 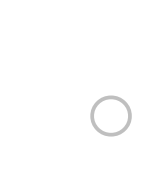 & 0 & 0 & D \\
\hline $\begin{array}{l}\text { PowerHouse } \\
\text { reaches out } \\
\text { to its social } \\
\text { environment }\end{array}$ & 0 & 0 & 0 & O & & & \\
\hline
\end{tabular}

On the below scale, please rank how strongly you agree with each statement in relation to PowerHouse's earthquake response.

\begin{tabular}{|c|c|c|c|c|c|c|c|}
\hline & $\begin{array}{l}\text { Strongly } \\
\text { disagree }\end{array}$ & Disagree & $\begin{array}{c}\text { Somewhat } \\
\text { disagree }\end{array}$ & $\begin{array}{c}\text { Neither } \\
\text { agree } \\
\text { nor } \\
\text { disagree }\end{array}$ & $\begin{array}{l}\text { Somewhat } \\
\text { agree }\end{array}$ & Agree & $\begin{array}{c}\text { Strongly } \\
\text { agree }\end{array}$ \\
\hline $\begin{array}{l}\text { PowerHouse } \\
\text { appears to } \\
\text { make } \\
\text { financially } \\
\text { sound } \\
\text { decisions }\end{array}$ & ( & & & C & & & \\
\hline $\begin{array}{l}\text { PowerHouse } \\
\text { has good } \\
\text { management } \\
\text { in place }\end{array}$ & D & & & C & ) & & 0 \\
\hline $\begin{array}{c}\text { The } \\
\text { management } \\
\text { of } \\
\text { PowerHouse } \\
\text { is held in } \\
\text { high regard }\end{array}$ & $\Omega$ & $\Omega$ & $\cap$ & O & 0 & & \\
\hline
\end{tabular}


The following questions seek to understand your general attitude towards companies engaging in corporate social responsibility (CSR).

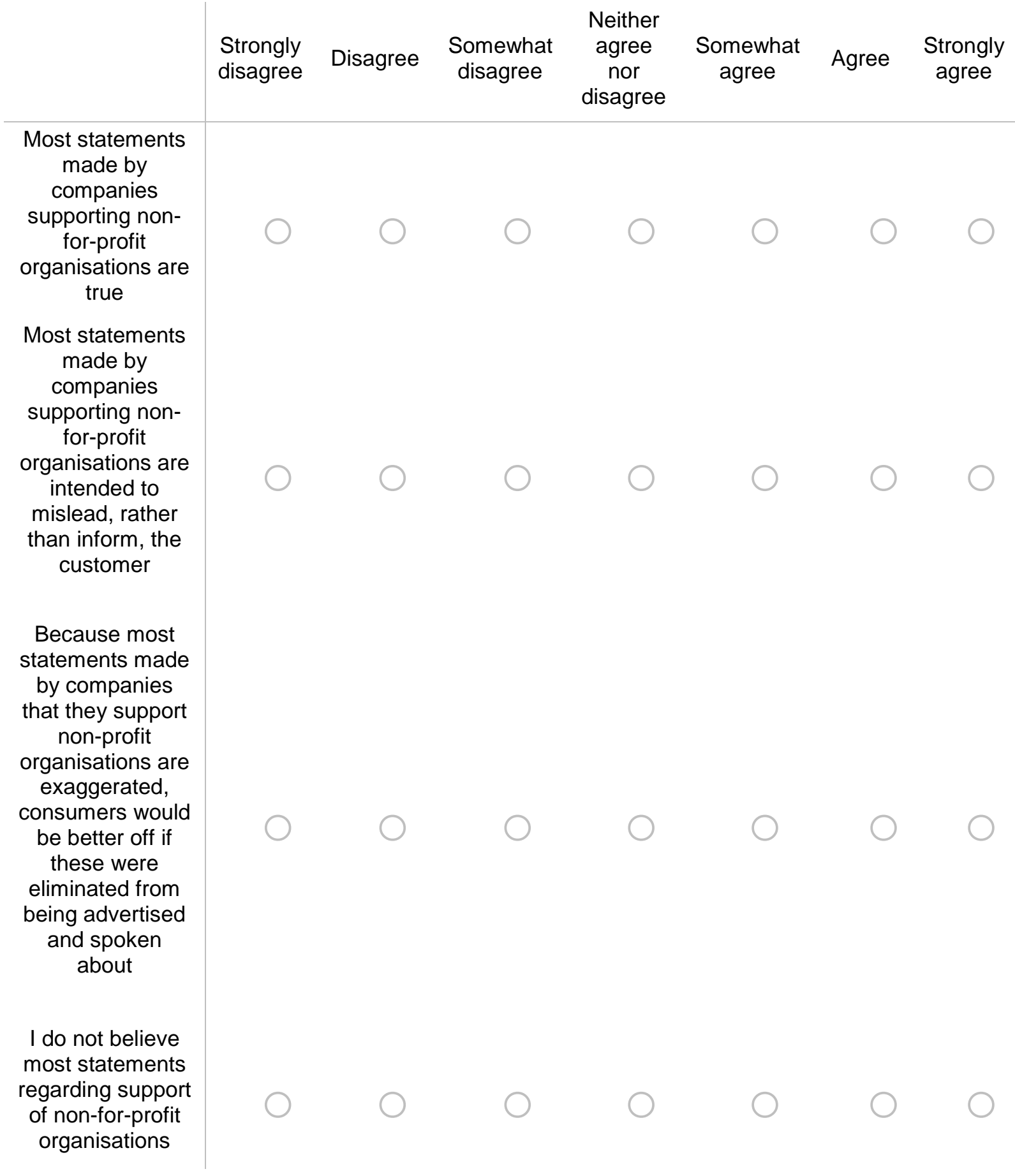


Please indicate the gender with which you most strongly identify.
Male
Female
Other

Are you currently enrolled in part- or full-time study?
Yes
No

What is the highest level of education you have completed? If you are currently enrolled, please select your completed education attainment.

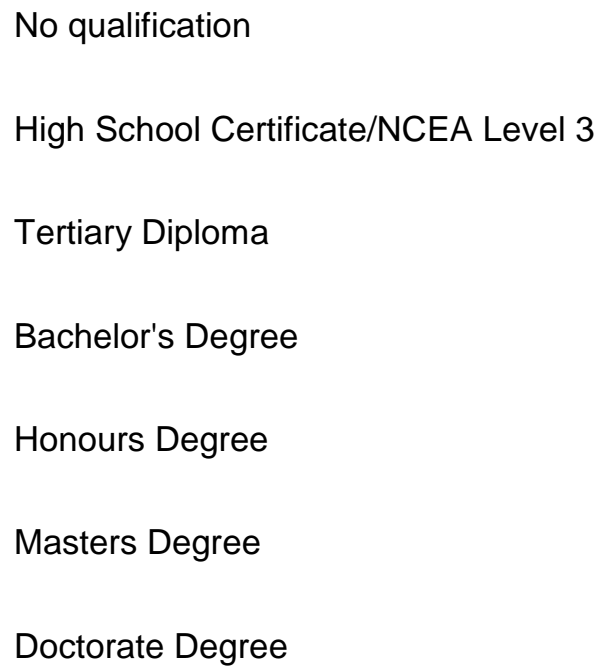

What do you think this survey is about? 


\title{
Appendix B: Study 1B Questionnaire
}

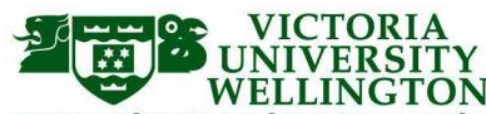 \\ TE WHARE WÃNANGA O TE ÛPOKO O TE IKA A MĀU
}

This study is being undertaken as part of my Masters degree in Marketing, to investigate and better understand perceptions of consumers. The survey is completely voluntary and it is not possible for any respondent to be identified personally in conjunction with this survey. The survey should take around 5 minutes to complete. Instructions on how to answer the survey are on the following page.

Please only complete the survey once.

Results from the study will be compiled into a written report for MARK592: Thesis in Marketing. Ethics approval (ID 26872) has been obtained for this research from the Pipitea Human Ethics Committee.

This is a secure website and all responses collected will remain anonymous. All of the material related to survey responses will only be viewed by the researcher and the supervisor. All printed information will be kept in a locked file with access restricted to the researcher.

All electronic data will be kept in a password protected file only accessible by the researcher. Data collected in this survey will be destroyed after 5 years.

It is possible that summary results from this survey may appear in academic or professional journals and may also be presented at academic or professional conferences.

If you have any concerns, questions or require any further information please feel free to contact:

Student Researcher

Guy Bennett-Longley

bennetguy1@myvuw.ac.nz

or

Student Supervisor

AProf Dan Laufer

dan.laufer@vuw.ac.nz

Thank you for your interest and help in completing this research.

Sincerely,

Guy Bennett-Longley

\section{Human Ethics Committee information}

If you have any concerns about the ethical conduct of the research you may contact the Victoria University HEC Convenor: Dr Judith Loveridge. Email hec@vuw.ac.nz or telephone +64-4-463 6028. 
What is your age?

Under 18 years

18 to 25 years

26 to 45 years

46 to 64 years

65 years and over

Please indicate your ethnicity

New Zealand European/Pākehā

Māori

Pasifika

Asian

Other

Please indicate your country of residence

Aotearoa New Zealand

Australia

United States

United Kingdom

Other 


\section{NB: Scenario One (Operations Adversely Impacted)}

Following the 2016 7.8-magnitude Kaikōura earthquake in New Zealand, Wellington experienced damage to a number of buildings, and the short-term closure of well-known landmarks. PowerHouse, a New Zealand electricity provider based in downtown Wellington, had its operations adversely impacted, but endeavoured to provide assistance within the local community. The following questions seek to understand your views towards PowerHouse's response following this disaster.

The electrical provider decided to assist in the city's immediate earthquake response by funding its employees to volunteer at the Red Cross for $\mathbf{4 0}$ hours (equating to roughly $\$ 100,000$ worth of labour hours). Please answer the following questions.

On the below scale, please rank how strongly you agree with each statement in relation to PowerHouse's earthquake response.

\begin{tabular}{|c|c|c|c|c|c|c|c|}
\hline & $\begin{array}{l}\text { Strongly } \\
\text { disagree }\end{array}$ & Disagree & $\begin{array}{c}\text { Somewhat } \\
\text { disagree }\end{array}$ & $\begin{array}{c}\text { Neither } \\
\text { agree } \\
\text { nor } \\
\text { disagree }\end{array}$ & $\begin{array}{l}\text { Somewhat } \\
\text { agree }\end{array}$ & Agree & $\begin{array}{l}\text { Strongly } \\
\text { agree }\end{array}$ \\
\hline $\begin{array}{c}\text { I have a } \\
\text { good feeling } \\
\text { about } \\
\text { PowerHouse }\end{array}$ & 0 & C & & & & & \\
\hline $\begin{array}{c}\text { I admire } \\
\text { PowerHouse }\end{array}$ & 0 & C & & & & & \\
\hline $\begin{array}{c}\text { I trust } \\
\text { PowerHouse }\end{array}$ & 0 & O & ) & 0 & & & \\
\hline $\begin{array}{l}\text { I am proud } \\
\text { to be }\end{array}$ & & & & & & & \\
\hline $\begin{array}{l}\text { associated } \\
\text { with } \\
\text { PowerHouse }\end{array}$ & 0 & 0 & & & & & \\
\hline $\begin{array}{c}\text { I like } \\
\text { PowerHouse }\end{array}$ & 0 & 0 & $D$ & 0 & & 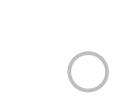 & 0 \\
\hline
\end{tabular}


On the below scale, please rank how strongly you agree with each statement in relation to PowerHouse's earthquake response.

\begin{tabular}{|c|c|c|c|c|c|c|c|}
\hline & $\begin{array}{l}\text { Strongly } \\
\text { disagree }\end{array}$ & Disagree & $\begin{array}{c}\text { Somewhat } \\
\text { disagree }\end{array}$ & $\begin{array}{l}\text { Neither } \\
\text { agree nor } \\
\text { disagree }\end{array}$ & $\begin{array}{l}\text { Somewhat } \\
\text { agree }\end{array}$ & Agree & $\begin{array}{c}\text { Strongly } \\
\text { agree }\end{array}$ \\
\hline $\begin{array}{l}\text { PowerHouse } \\
\text { supports } \\
\text { good causes }\end{array}$ & C & & $\bigcirc$ & 0 & 0 & & \\
\hline $\begin{array}{l}\text { PowerHouse } \\
\text { is committed } \\
\text { to social } \\
\text { responsibility } \\
\text { (social } \\
\text { issues) }\end{array}$ & ( & & 0 & 0 & 0 & & \\
\hline $\begin{array}{l}\text { PowerHouse } \\
\text { responds to } \\
\text { the needs of } \\
\text { communities }\end{array}$ & 0 & $\bigcirc$ & O & 0 & 0 & & \\
\hline $\begin{array}{l}\text { PowerHouse } \\
\text { reaches out } \\
\text { to its social } \\
\text { environment }\end{array}$ & 0 & $\cap$ & 0 & 0 & 0 & ( & \\
\hline
\end{tabular}

On the below scale, please rank how strongly you agree with each statement in relation to PowerHouse's earthquake response.

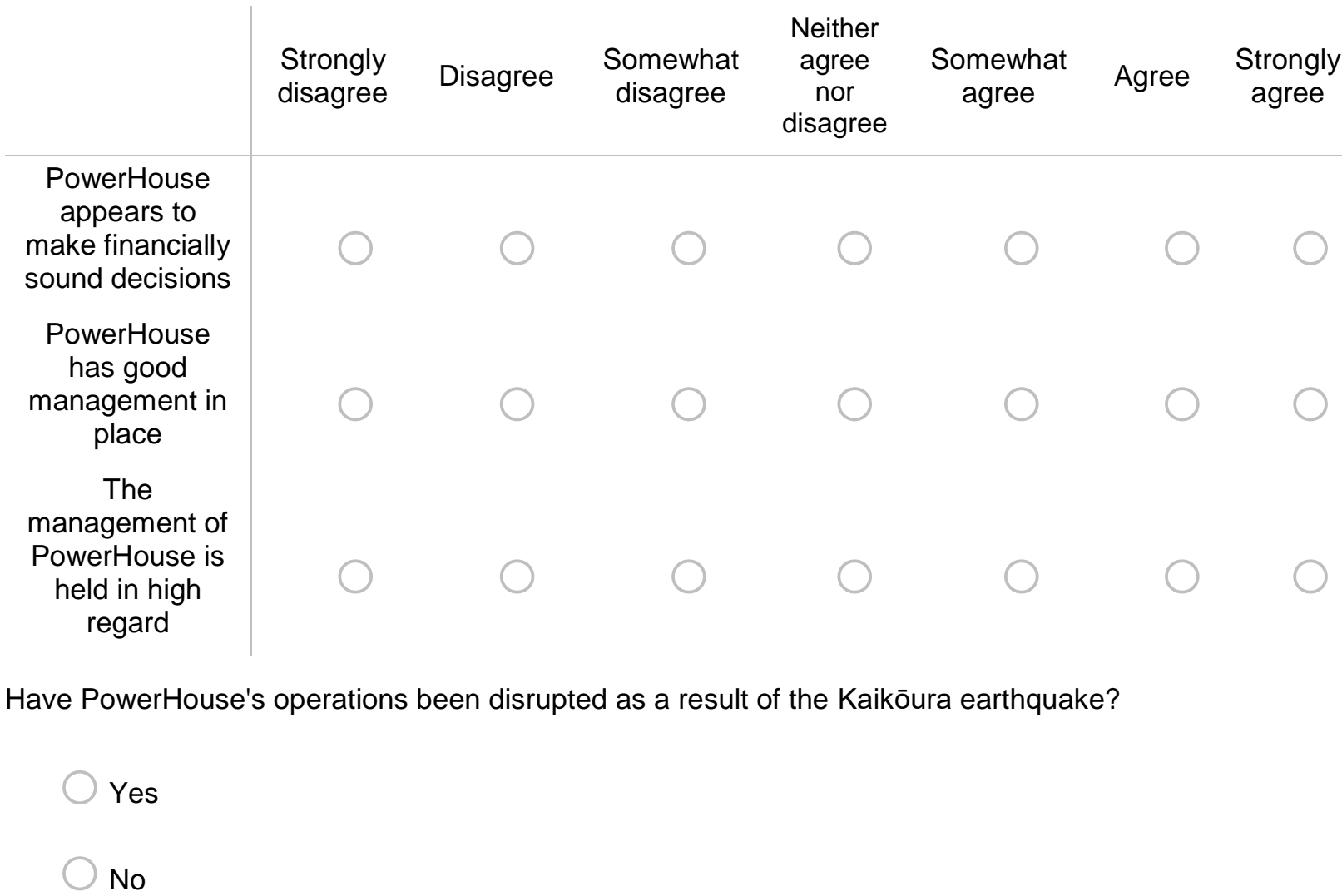




\section{NB: Scenario Two (Operations Not Adversely Impacted)}

Following the 2016 7.8-magnitude Kaikōura earthquake in New Zealand, Wellington experienced damage to a number of buildings, and the short-term closure of well-known landmarks. PowerHouse, a New Zealand electricity provider based in downtown Wellington, did not have its operations adversely impacted, and provided assistance within the local community. The following questions seek to understand your views towards PowerHouse's response following this disaster.

The electrical provider decided to assist in the city's immediate earthquake response by funding its employees to volunteer at the Red Cross for $\mathbf{4 0}$ hours (equating to roughly $\$ 100,000$ worth of labour hours). Please answer the following questions.

On the below scale, please rank how strongly you agree with each statement in relation to PowerHouse's earthquake response.

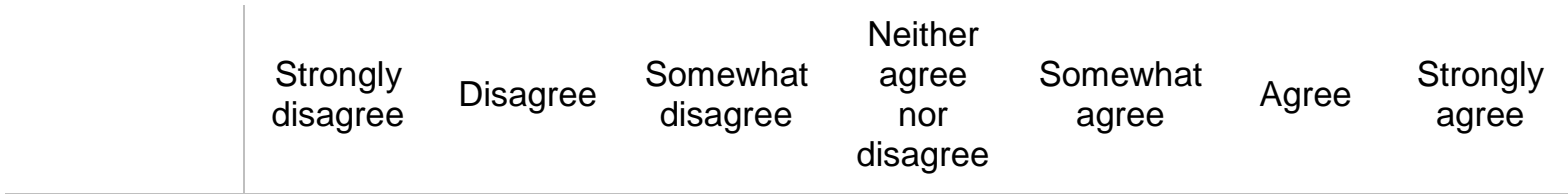

I have a good feeling about

PowerHouse

I admire

PowerHouse

I trust

PowerHouse

I am proud

to be

associated

with

PowerHouse

I like

PowerHouse 
On the below scale, please rank how strongly you agree with each statement in relation to PowerHouse's earthquake response.

\begin{tabular}{|c|c|c|c|c|c|c|c|}
\hline & $\begin{array}{l}\text { Strongly } \\
\text { disagree }\end{array}$ & Disagree & $\begin{array}{c}\text { Somewhat } \\
\text { disagree }\end{array}$ & $\begin{array}{l}\text { Neither } \\
\text { agree } \\
\text { nor } \\
\text { disagree }\end{array}$ & $\begin{array}{l}\text { Somewhat } \\
\text { agree }\end{array}$ & Agree & $\begin{array}{l}\text { Strongly } \\
\text { agree }\end{array}$ \\
\hline $\begin{array}{l}\text { PowerHouse } \\
\text { supports } \\
\text { good causes }\end{array}$ & C & & & $\mathrm{O}$ & ( & & \\
\hline $\begin{array}{l}\text { PowerHouse } \\
\text { is committed } \\
\text { to social } \\
\text { responsibility } \\
\text { (social } \\
\text { issues) }\end{array}$ & C & $C$ & 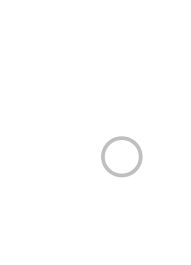 & $C$ & & & J \\
\hline $\begin{array}{l}\text { PowerHouse } \\
\text { responds to } \\
\text { the needs of } \\
\text { communities }\end{array}$ & 0 & 0 & $\cap$ & C & & ) & \\
\hline $\begin{array}{l}\text { PowerHouse } \\
\text { reaches out } \\
\text { to its social } \\
\text { environment }\end{array}$ & 0 & $\cap$ & & $\cap$ & & & \\
\hline
\end{tabular}

On the below scale, please rank how strongly you agree with each statement in relation to PowerHouse's earthquake response.

\begin{tabular}{|c|c|c|c|c|c|c|c|}
\hline & $\begin{array}{l}\text { Strongly } \\
\text { disagree }\end{array}$ & Disagree & $\begin{array}{c}\text { Somewhat } \\
\text { disagree }\end{array}$ & $\begin{array}{l}\text { Neither } \\
\text { agree } \\
\text { nor } \\
\text { disagree }\end{array}$ & $\begin{array}{c}\text { Somewhat } \\
\text { agree }\end{array}$ & Agree & $\begin{array}{c}\text { Strongly } \\
\text { agree }\end{array}$ \\
\hline $\begin{array}{l}\text { PowerHouse } \\
\text { appears to } \\
\text { make financially } \\
\text { sound decisions }\end{array}$ & & & & C & & & \\
\hline $\begin{array}{l}\text { PowerHouse } \\
\text { has good } \\
\text { management in } \\
\text { place }\end{array}$ & & & & ( & & & \\
\hline $\begin{array}{l}\text { The } \\
\text { management of } \\
\text { PowerHouse is } \\
\text { held in high } \\
\text { regard }\end{array}$ & $?$ & $\cap$ & 0 & $\cap$ & & & \\
\hline
\end{tabular}

Have PowerHouse's operations been disrupted as a result of the Kaikōura earthquake?

Yes

No 
Please indicate the gender with which you most strongly identify.

\section{Male \\ Female \\ Other}

Are you currently enrolled in part- or full-time study?
Yes
No

What is the highest level of education you have completed? If you are currently enrolled, please select your completed education attainment.

No qualification

High School Certificate/NCEA Level 3

Tertiary Diploma

Bachelor's Degree

Honours Degree

Masters Degree

Doctorate Degree

What do you think this survey is about? 


\section{Appendix C: Study 2 Questionnaire}

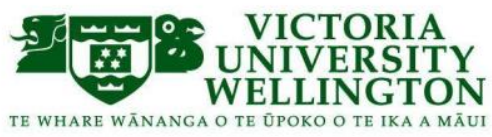

This study is being undertaken as part of my Masters degree in Marketing, to investigate and better understand perceptions of consumers. The survey is completely voluntary and it is not possible for any respondent to be identified personally in conjunction with this survey. The survey should take around 5 minutes to complete. Instructions on how to answer the survey are on the following page.

Please only complete the survey once.

Results from the study will be compiled into a written report for MARK592: Thesis in Marketing. Ethics approval (ID 26872) has been obtained for this research from the Pipitea Human Ethics Committee.

This is a secure website and all responses collected will remain anonymous. All of the material related to survey responses will only be viewed by the researcher and the supervisor. All printed information will be kept in a locked file with access restricted to the researcher.

All electronic data will be kept in a password protected file only accessible by the researcher. Data collected in this survey will be destroyed after 5 years.

It is possible that summary results from this survey may appear in academic or professional journals and may also be presented at academic or professional conferences.

If you have any concerns, questions or require any further information please feel free to contact:

Student Researcher

Guy Bennett-Longley

bennetguy1@myvuw.ac.nz

or

Student Supervisor

AProf Dan Laufer

dan.laufer@vuw.ac.nz

Thank you for your interest and help in completing this research.

Sincerely,

Guy Bennett-Longley

\section{Human Ethics Committee information}

If you have any concerns about the ethical conduct of the research you may contact the Victoria University HEC Convenor: Dr Judith Loveridge. Email hec@vuw.ac.nz or telephone +64-4-463 6028. 
What is your age?

Under 18 years

18 to 25 years

26 to 45 years

46 to 64 years

65 years and over

Please indicate your ethnicity

New Zealand European/Pākehā

Māori

Pasifika

Asian

Other

Please indicate your country of residence

Aotearoa New Zealand

Australia

United States

United Kingdom

Other 


\section{NB: Scenario One (Global Giving)}

Following a 2018 7.5-magnitude earthquake and tsunami in New Caledonia, an Auckland-based communications company, Teletech, decided to donate $\$ 100,000$ to the Red Cross to help with disaster recovery efforts. Please answer the following questions.

On the below scale, please rank how strongly you agree with each statement in relation to the telecommunication company's disaster response.

\begin{tabular}{|c|c|c|c|c|c|c|c|}
\hline & $\begin{array}{l}\text { Strongly } \\
\text { disagree }\end{array}$ & Disagree & $\begin{array}{c}\text { Somewhat } \\
\text { disagree }\end{array}$ & $\begin{array}{l}\text { Neither } \\
\text { agree nor } \\
\text { disagree }\end{array}$ & $\begin{array}{l}\text { Somewhat } \\
\text { agree }\end{array}$ & Agree & $\begin{array}{c}\text { Strongly } \\
\text { agree }\end{array}$ \\
\hline $\begin{array}{l}\text { I have a } \\
\text { good } \\
\text { feeling } \\
\text { about } \\
\text { Teletech }\end{array}$ & C & & O & & & & $\bigcirc$ \\
\hline $\begin{array}{l}\text { I admire } \\
\text { Teletech }\end{array}$ & O & 0 & 0 & $\checkmark$ & 0 & & $\mathrm{C}$ \\
\hline $\begin{array}{l}\text { I trust } \\
\text { Teletech }\end{array}$ & O & 0 & 0 & $U$ & 0 & & \\
\hline $\begin{array}{l}\text { I am proud } \\
\text { to be } \\
\text { associated } \\
\text { with } \\
\text { Teletech }\end{array}$ & O & ( & $\bigcirc$ & & 0 & & \\
\hline $\begin{array}{c}\text { I like } \\
\text { Teletech }\end{array}$ & O & ) & O & & D & & \\
\hline
\end{tabular}


On the below scale, please rank how strongly you agree with each statement in relation to the telecommunication company's disaster response.

\begin{tabular}{|c|c|c|c|c|c|c|c|}
\hline & $\begin{array}{l}\text { Strongly } \\
\text { disagree }\end{array}$ & Disagree & $\begin{array}{c}\text { Somewhat } \\
\text { disagree }\end{array}$ & $\begin{array}{l}\text { Neither } \\
\text { agree } \\
\text { nor } \\
\text { disagree }\end{array}$ & $\begin{array}{l}\text { Somewhat } \\
\text { agree }\end{array}$ & Agree & $\begin{array}{c}\text { Strongly } \\
\text { agree }\end{array}$ \\
\hline $\begin{array}{l}\text { Teletech } \\
\text { supports } \\
\text { good causes }\end{array}$ & & & & C & O & & C \\
\hline $\begin{array}{l}\text { Teletech is } \\
\text { committed to } \\
\text { social } \\
\text { responsibility } \\
\text { (social } \\
\text { issues) }\end{array}$ & $\bigcirc$ & & ( & ( & $\bigcirc$ & & \\
\hline $\begin{array}{l}\text { Teletech } \\
\text { responds to } \\
\text { the needs of } \\
\text { communities }\end{array}$ & O & O & ( & $\bigcirc$ & 0 & & \\
\hline $\begin{array}{l}\text { Teletech } \\
\text { reaches out } \\
\text { to its social } \\
\text { environment }\end{array}$ & 0 & & & $\cap$ & $\cap$ & & \\
\hline
\end{tabular}

On the below scale, please rank how strongly you agree with each statement in relation to the telecommunication company's disaster response.

\begin{tabular}{|c|c|c|c|c|c|c|c|}
\hline & $\begin{array}{l}\text { Strongly } \\
\text { disagree }\end{array}$ & Disagree & $\begin{array}{c}\text { Somewhat } \\
\text { disagree }\end{array}$ & $\begin{array}{c}\text { Neither } \\
\text { agree } \\
\text { nor } \\
\text { disagree }\end{array}$ & $\begin{array}{c}\text { Somewhat } \\
\text { agree }\end{array}$ & Agree & $\begin{array}{c}\text { Strongly } \\
\text { agree }\end{array}$ \\
\hline $\begin{array}{l}\text { Teletech } \\
\text { appears to } \\
\text { make } \\
\text { financially } \\
\text { sound } \\
\text { decision }\end{array}$ & ( & $\bigcirc$ & O & $\bigcirc$ & & & \\
\hline $\begin{array}{l}\text { Teletech has } \\
\text { good } \\
\text { management } \\
\text { in place }\end{array}$ & ) & 0 & 0 & $\bigcirc$ & 0 & & 0 \\
\hline $\begin{array}{l}\text { The } \\
\text { management } \\
\text { of Teletech } \\
\text { is held in } \\
\text { high regard }\end{array}$ & 2 & $\bigcirc$ & $\Omega$ & O & $\curvearrowright$ & & 0 \\
\hline
\end{tabular}

Where did this natural disaster take place? 


\section{NB: Scenario Two (Domestic Giving)}

Following the destructive 2016 7.8-magnitude Kaikōura earthquake in New Zealand, an Aucklandbased telecommunications company, Teletech, decided to donate $\$ 100,000$ to the Red Cross to help with the disaster recovery efforts. Please answer the following questions.

On the below scale, please rank how strongly you agree with each statement in relation to the telecommunication company's disaster response.

\begin{tabular}{|c|c|c|c|c|c|c|c|}
\hline & $\begin{array}{l}\text { Strongly } \\
\text { disagree }\end{array}$ & Disagree & $\begin{array}{c}\text { Somewhat } \\
\text { disagree }\end{array}$ & $\begin{array}{l}\text { Neither } \\
\text { agree nor } \\
\text { disagree }\end{array}$ & $\begin{array}{c}\text { Somewhat } \\
\text { agree }\end{array}$ & Agree & $\begin{array}{c}\text { Strongly } \\
\text { agree }\end{array}$ \\
\hline $\begin{array}{l}\text { I have a } \\
\text { good } \\
\text { feeling } \\
\text { about } \\
\text { Teletech }\end{array}$ & & 0 & & & O & & ( \\
\hline $\begin{array}{l}\text { I admire } \\
\text { Teletech }\end{array}$ & & 0 & & $\checkmark$ & $\bigcirc$ & & 0 \\
\hline $\begin{array}{c}\text { I trust } \\
\text { Teletech }\end{array}$ & 0 & 0 & 0 & 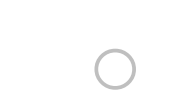 & 0 & & \\
\hline $\begin{array}{l}\text { I am proud } \\
\text { to be } \\
\text { associated } \\
\text { with } \\
\text { Teletech }\end{array}$ & $\bigcirc$ & 0 & 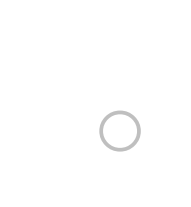 & & & & \\
\hline $\begin{array}{c}\text { I like } \\
\text { Teletech }\end{array}$ & $\bigcirc$ & $\bigcirc$ & D & 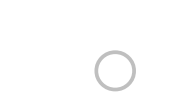 & 0 & 0 & \\
\hline
\end{tabular}


On the below scale, please rank how strongly you agree with each statement in relation to the telecommunication company's disaster response.

\begin{tabular}{|c|c|c|c|c|c|c|c|}
\hline & $\begin{array}{l}\text { Strongly } \\
\text { disagree }\end{array}$ & Disagree & $\begin{array}{c}\text { Somewhat } \\
\text { disagree }\end{array}$ & $\begin{array}{c}\text { Neither } \\
\text { agree } \\
\text { nor } \\
\text { disagree }\end{array}$ & $\begin{array}{l}\text { Somewhat } \\
\text { agree }\end{array}$ & Agree & $\begin{array}{c}\text { Strongly } \\
\text { agree }\end{array}$ \\
\hline $\begin{array}{l}\text { Teletech } \\
\text { supports } \\
\text { good causes }\end{array}$ & C & C & & $\mathrm{O}$ & & & $\mathcal{U}$ \\
\hline $\begin{array}{l}\text { Teletech is } \\
\text { committed to } \\
\text { social } \\
\text { responsibility } \\
\text { (social } \\
\text { issues) }\end{array}$ & $\bigcirc$ & 0 & ( & C & ( & & D \\
\hline $\begin{array}{l}\text { Teletech } \\
\text { responds to } \\
\text { the needs of } \\
\text { communities }\end{array}$ & 0 & 0 & 0 & C & & & \\
\hline $\begin{array}{l}\text { Teletech } \\
\text { reaches out } \\
\text { to its social } \\
\text { environment }\end{array}$ & 0 & $\bigcirc$ & & $\bigcirc$ & & & \\
\hline
\end{tabular}

On the below scale, please rank how strongly you agree with each statement in relation to the telecommunication company's disaster response.

\begin{tabular}{|c|c|c|c|c|c|c|c|}
\hline & $\begin{array}{l}\text { Strongly } \\
\text { disagree }\end{array}$ & Disagree & $\begin{array}{c}\text { Somewhat } \\
\text { disagree }\end{array}$ & $\begin{array}{c}\text { Neither } \\
\text { agree } \\
\text { nor } \\
\text { disagree }\end{array}$ & $\begin{array}{l}\text { Somewhat } \\
\text { agree }\end{array}$ & Agree & $\begin{array}{c}\text { Strongly } \\
\text { agree }\end{array}$ \\
\hline $\begin{array}{l}\text { Teletech } \\
\text { appears to } \\
\text { make } \\
\text { financially } \\
\text { sound } \\
\text { decisions }\end{array}$ & $\bigcirc$ & & ( & ( & & & ( \\
\hline $\begin{array}{l}\text { Teletech has } \\
\text { good } \\
\text { management } \\
\text { in place }\end{array}$ & 0 & ) & ( & C & ( & & 0 \\
\hline $\begin{array}{l}\text { The } \\
\text { management } \\
\text { of Teletech } \\
\text { is held in } \\
\text { high regard }\end{array}$ & $\Omega$ & ) & $\cap$ & $\cap$ & $\cap$ & & 0 \\
\hline
\end{tabular}

Where did this natural disaster take place? 
The following questions seek to understand your general attitude towards other social groups and cultures.

\begin{tabular}{|c|c|c|c|c|c|c|c|}
\hline & $\begin{array}{l}\text { Strongly } \\
\text { disagree }\end{array}$ & Disagree & $\begin{array}{c}\text { Somewhat } \\
\text { disagree }\end{array}$ & $\begin{array}{c}\text { Neither } \\
\text { agree } \\
\text { nor } \\
\text { disagree }\end{array}$ & $\begin{array}{l}\text { Somewhat } \\
\text { agree }\end{array}$ & Agree & $\begin{array}{c}\text { Strongly } \\
\text { agree }\end{array}$ \\
\hline $\begin{array}{l}\text { Most other } \\
\text { cultures are } \\
\text { backward } \\
\text { compared to } \\
\text { my culture }\end{array}$ & & $\bigcirc$ & & $\mathrm{O}$ & & & C \\
\hline $\begin{array}{l}\text { My culture } \\
\text { should be the } \\
\text { role model } \\
\text { for other } \\
\text { cultures }\end{array}$ & & 0 & & & & & \\
\hline $\begin{array}{l}\text { Lifestyles in } \\
\text { other cultures } \\
\text { are just as } \\
\text { valid as } \\
\text { those in my } \\
\text { culture }\end{array}$ & & 0 & & C & & & \\
\hline $\begin{array}{c}\text { Other } \\
\text { cultures } \\
\text { should try to } \\
\text { be more like } \\
\text { my culture }\end{array}$ & $\bigcirc$ & 0 & 0 & C & ( & & \\
\hline $\begin{array}{l}\text { People from } \\
\text { my culture } \\
\text { could learn a } \\
\text { lot from } \\
\text { people in } \\
\text { other cultures }\end{array}$ & 0 & $\Omega$ & $\cap$ & $\bigcirc$ & $\cap$ & & \\
\hline
\end{tabular}


The following questions seek to understand your general attitude towards other social groups and cultures.

\begin{tabular}{|c|c|c|c|c|c|c|c|}
\hline & $\begin{array}{l}\text { Strongly } \\
\text { disagree }\end{array}$ & Disagree & $\begin{array}{l}\text { Somewhat } \\
\text { disagree }\end{array}$ & $\begin{array}{l}\text { Neither } \\
\text { agree } \\
\text { nor } \\
\text { disagree }\end{array}$ & $\begin{array}{l}\text { Somewhat } \\
\text { agree }\end{array}$ & Agree & $\begin{array}{c}\text { Strongly } \\
\text { agree }\end{array}$ \\
\hline $\begin{array}{l}\text { Most people } \\
\text { from other } \\
\text { cultures just } \\
\text { don't know } \\
\text { what's good } \\
\text { for them }\end{array}$ & $\mathrm{C}$ & & & ( & & & 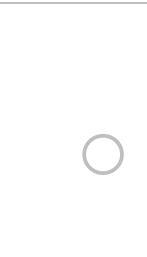 \\
\hline $\begin{array}{l}\text { I respect the } \\
\text { values and } \\
\text { customs from } \\
\text { other cultures }\end{array}$ & $\bigcirc$ & & & 0 & & & \\
\hline $\begin{array}{l}\text { Other cultures } \\
\text { are smart to } \\
\text { look up to our } \\
\text { culture }\end{array}$ & $\mathrm{O}$ & & $C$ & ( & & & \\
\hline $\begin{array}{l}\text { Most people } \\
\text { would be } \\
\text { happier if they } \\
\text { lived like } \\
\text { people in my } \\
\text { culture }\end{array}$ & 0 & $\bigcirc$ & 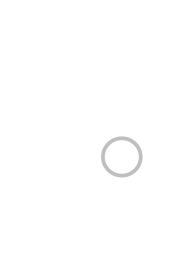 & $\bigcirc$ & & & \\
\hline $\begin{array}{l}\text { People in my } \\
\text { culture have } \\
\text { just about the } \\
\text { best lifestyles } \\
\text { of anywhere }\end{array}$ & 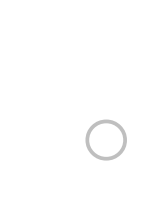 & $\bigcirc$ & & $\bigcirc$ & & & \\
\hline
\end{tabular}


The following questions seek to understand your general attitude towards other social groups and cultures.

\begin{tabular}{c|ccccc} 
Strongly & Disagree & $\begin{array}{c}\text { Somewhat } \\
\text { disagree }\end{array}$ & $\begin{array}{c}\text { Neither } \\
\text { agree } \\
\text { nor } \\
\text { disagree }\end{array}$ & $\begin{array}{c}\text { Somewhat } \\
\text { agree }\end{array}$ & $\begin{array}{c}\text { Agree } \\
\text { Strongly } \\
\text { agree }\end{array}$ \\
\hline $\begin{array}{c}\text { Lifestyles in } \\
\text { other cultures } \\
\text { are not as valid } \\
\text { as those in my } \\
\text { culture }\end{array}$ \\
$\begin{array}{c}\text { I do not } \\
\text { cooperate with } \\
\text { people who } \\
\text { are different } \\
\text { I do not trust } \\
\text { people who } \\
\text { are different } \\
\text { I dislike } \\
\text { interacting with } \\
\text { people from } \\
\text { other cultures } \\
\text { I have little } \\
\text { respect for the } \\
\text { values and } \\
\text { customs of } \\
\text { other cultures }\end{array}$
\end{tabular}


Please indicate the gender with which you most strongly identify.
Male
Female
Other

Are you currently enrolled in part- or full-time study?
Yes
No

What is the highest level of education you have completed? If you are currently enrolled, please select your completed education attainment.

No qualification

High School Certificate/NCEA Level 3

Tertiary Diploma

Bachelor's Degree

Honours Degree

Masters Degree

Doctorate Degree

What do you think this survey is about? 
Appendix D: Pre-Test Reliability Results

Variance Explained

Cronbach's

KMO

Alpha

Customer-based

Corporate

$62.19 \%$

.839

.846

Reputation

$\mathrm{p}<.001$

Consumer Scepticism

$73.06 \%$

.872

.802

$\mathrm{p}<.001$

Ethnocentrism

$63.87 \%$

.773

.763

$\mathrm{p}<.001$ 


\section{Appendix E: Pre-Test Amendments to Survey Design}

Imagine that Wellington has recently experienced a severe earthquake (similar to the 2011 Christchurch series of earthquakes).

This has resulted in significant damage to buildings and well-known landmarks, including the partial collapse of the building housing David Jones. Core infrastructure, including electricity and water supply, have been significantly reduced.

The following questions seek to understand your view of Victoria University's strategic philanthropic decisions following the earthquake.
Following the 2016 7.8-

magnitude Kaikōura earthquake in New Zealand, Wellington experienced significant damage to a number of buildings and disruption to core infrastructure.

PowerHouse, a New Zealand electricity provider based in downtown Wellington had its operations adversely impacted, but endeavoured to provide assistance within the local community.

The following questions seek to understand your views towards PowerHouse's response following this disaster.
General philanthropic aid

(Undisclosed)

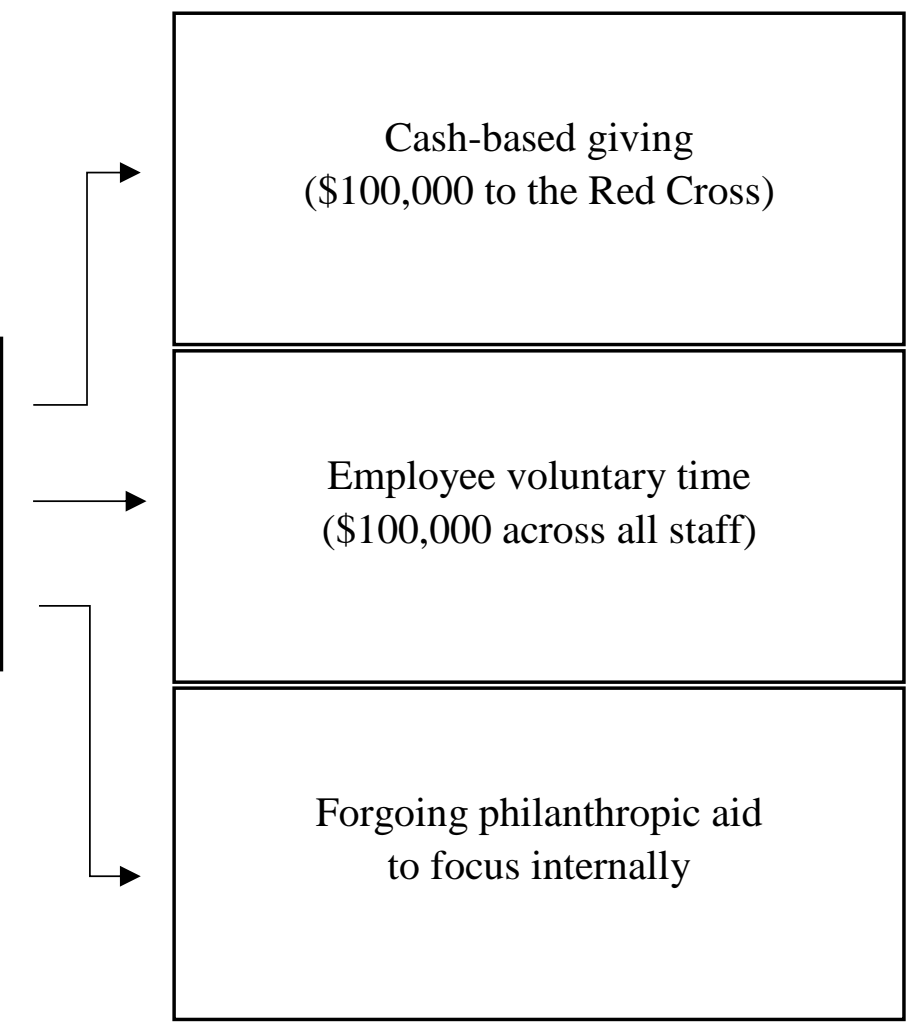




\section{Appendix F: Abbreviated Item Labels}

\section{Customer-based Corporate Reputation}

\begin{tabular}{cr}
\hline CBR_1 & I have a good feeling about PowerHouse (Teletech) \\
\hline CBR_2 & I admire PowerHouse (Teletech) \\
\hline CBR_3 & I trust PowerHouse (Teletech) \\
\hline CBR_4 & I am proud to be associated with PowerHouse (Teletech) \\
\hline CBR_5 & I like PowerHouse (Teletech) \\
\hline CBR_7 & PowerHouse (Teletech) is committed to social responsibility \\
\hline CBR_8 & PowerHouse (Teletech) responds to the needs of communities \\
\hline CBR_9 & PowerHouse (Teletech) reaches out to its social environment \\
\hline CBR_10 & PowerHouse (Teletech) appears to make financially sound decisions \\
\hline
\end{tabular}

\section{Consumer Scepticism}

Scept_1 Most statements made by companies in advertising or product labels about supporting non-profit organisations are true

Scept_2 Most statements made by companies supporting non-profit organisations are intended to mislead, rather than inform, the customer

Scept_3 exaggerated, consumers would be better off if such statements were eliminated from being advertised or spoken about

Scept_4 I do not believe most statements regarding support of non-profit organisations

\section{Ethnocentrism}

Ethno_1 Most other cultures are backward compared to my culture

Ethno_2 My culture should be the role model for other cultures

Ethno_3 Lifestyles in other cultures are just as valid as those in my culture

Ethno_4 Other cultures should try to be more like my culture 
Ethno_5

People in my culture could learn a lot from other cultures

Ethno_6

Most people from other cultures just don't know what's good for them

Ethno_7

I respect the values and customs of other cultures

Ethno_8

Other cultures are smart to look up to our culture

Ethno_9

Most people would be happier if they lived like people in my culture

Ethno_10

People in my culture have just about the best lifestyles of anywhere

Ethno_11

Lifestyles in other cultures are not as valid as those in my culture

Ethno_12

I do not cooperate with people who are different

Ethno 13

I do not trust people who are different

Ethno_14

I dislike interacting with people from other cultures

Ethno_15

I have little respect for the value and customs of other cultures 


\section{Appendix G: Full Factor Analysis Results}

\begin{tabular}{|c|c|c|c|c|c|c|c|}
\hline & Items & Loadings & Communalities & $\begin{array}{c}\% \text { of } \\
\text { Variance }\end{array}$ & $\begin{array}{c}\text { Cronbach's } \\
\text { Alpha }\end{array}$ & KMO & $\begin{array}{c}\text { Bartlett's } \\
\text { Test }\end{array}$ \\
\hline \multirow{9}{*}{$\begin{array}{l}\$ 100,000 \\
\text { donation to } \\
\text { Red Cross }\end{array}$} & CBR_1 & .758 & .629 & \multirow{9}{*}{$72.6 \%$} & \multirow{9}{*}{931} & \multirow{9}{*}{.876} & \multirow{9}{*}{.000} \\
\hline & CBR_2 & .788 & .713 & & & & \\
\hline & CBR_6 & .803 & .684 & & & & \\
\hline & CBR_7 & .830 & .705 & & & & \\
\hline & CBR_8 & .862 & .798 & & & & \\
\hline & CBR_9 & .891 & .806 & & & & \\
\hline & CBR_10 & .722 & .583 & & & & \\
\hline & CBR_11 & .769 & .756 & & & & \\
\hline & CBR_12 & .917 & .910 & & & & \\
\hline \multirow{7}{*}{$\begin{array}{l}\text { Employee } \\
\text { voluntary } \\
\text { time valued } \\
\text { at } \$ 100,000\end{array}$} & CBR_1 & .752 & .813 & \multirow{7}{*}{$69.7 \%$} & \multirow{7}{*}{.868} & \multirow{7}{*}{.803} & \multirow{7}{*}{.000} \\
\hline & CBR_2 & .724 & .662 & & & & \\
\hline & CBR_3 & .791 & .652 & & & & \\
\hline & CBR_5 & .770 & .668 & & & & \\
\hline & CBR_10 & .739 & .816 & & & & \\
\hline & CBR_11 & .705 & .744 & & & & \\
\hline & CBR_12 & .703 & .593 & & & & \\
\hline \multirow{10}{*}{$\begin{array}{l}\text { Minimise } \\
\text { internal } \\
\text { disruptions }\end{array}$} & CBR_1 & .865 & .750 & \multirow{10}{*}{$78.0 \%$} & \multirow{10}{*}{.947} & \multirow{10}{*}{.891} & \multirow{10}{*}{.000} \\
\hline & CBR_2 & .897 & .805 & & & & \\
\hline & CBR_3 & .804 & .652 & & & & \\
\hline & CBR_5 & .840 & .706 & & & & \\
\hline & CBR_6 & .808 & .702 & & & & \\
\hline & CBR_7 & .877 & .850 & & & & \\
\hline & CBR_8 & .891 & .817 & & & & \\
\hline & CBR_9 & .905 & .884 & & & & \\
\hline & CBR_10 & .728 & .663 & & & & \\
\hline & CBR_11 & .733 & .806 & & & & \\
\hline \multirow{3}{*}{$\begin{array}{l}\text { Consumer } \\
\text { Scepticism }\end{array}$} & Scept_1 & .730 & .688 & \multirow{3}{*}{$64.6 \%$} & \multirow{3}{*}{.726} & \multirow{3}{*}{.668} & \multirow{3}{*}{.000} \\
\hline & Scept_2 & .749 & .639 & & & & \\
\hline & Scept_4 & .739 & .758 & & & & \\
\hline
\end{tabular}




\begin{tabular}{|c|c|c|c|c|c|c|c|}
\hline & Items & Loadings & Communalities & $\begin{array}{c}\% \text { of } \\
\text { Variance }\end{array}$ & $\begin{array}{c}\text { Cronbach's } \\
\text { Alpha }\end{array}$ & $\mathrm{KMO}$ & $\begin{array}{c}\text { Bartlett's } \\
\text { Test }\end{array}$ \\
\hline \multirow{11}{*}{$\begin{array}{l}\text { Operations } \\
\text { impacted }\end{array}$} & CBR_1 & .758 & .626 & \multirow{11}{*}{$67.2 \%$} & \multirow{11}{*}{.930} & \multirow{11}{*}{.896} & \multirow{11}{*}{.000} \\
\hline & CBR_2 & .712 & .558 & & & & \\
\hline & CBR_3 & .840 & .836 & & & & \\
\hline & CBR_4 & .709 & .662 & & & & \\
\hline & CBR_5 & .824 & .841 & & & & \\
\hline & CBR_6 & .831 & .700 & & & & \\
\hline & CBR_7 & .773 & .783 & & & & \\
\hline & CBR_8 & .801 & .894 & & & & \\
\hline & CBR_9 & .811 & .814 & & & & \\
\hline & CBR_11 & .762 & .692 & & & & \\
\hline & CBR_12 & .706 & .581 & & & & \\
\hline \multirow{11}{*}{$\begin{array}{c}\text { Operations } \\
\text { not } \\
\text { impacted }\end{array}$} & CBR_1 & .872 & .819 & \multirow{11}{*}{$70.2 \%$} & \multirow{11}{*}{.945} & \multirow{11}{*}{.902} & \multirow{11}{*}{.000} \\
\hline & CBR_2 & .799 & .648 & & & & \\
\hline & CBR_3 & .774 & .610 & & & & \\
\hline & CBR_4 & .772 & .621 & & & & \\
\hline & CBR_5 & .862 & .742 & & & & \\
\hline & CBR_6 & .884 & .807 & & & & \\
\hline & CBR_7 & .809 & .701 & & & & \\
\hline & CBR_8 & .861 & .749 & & & & \\
\hline & CBR_9 & .831 & .691 & & & & \\
\hline & CBR_11 & .717 & .879 & & & & \\
\hline & CBR_12 & .715 & .912 & & & & \\
\hline
\end{tabular}




\begin{tabular}{|c|c|c|c|c|c|c|c|}
\hline & Items & Loadings & Communalities & $\begin{array}{c}\% \text { of } \\
\text { Variance }\end{array}$ & $\begin{array}{c}\text { Cronbach's } \\
\text { Alpha }\end{array}$ & KMO & $\begin{array}{c}\text { Bartlett's } \\
\text { Test }\end{array}$ \\
\hline \multirow{6}{*}{ Global Giving } & CBR_1 & .786 & .729 & \multirow{6}{*}{$65.9 \%$} & \multirow{6}{*}{.832} & \multirow{6}{*}{.764} & \multirow{6}{*}{.000} \\
\hline & CBR_2 & .743 & .650 & & & & \\
\hline & CBR_4 & .786 & .696 & & & & \\
\hline & CBR_5 & .851 & .754 & & & & \\
\hline & CBR_11 & .718 & .891 & & & & \\
\hline & CBR_12 & .727 & .856 & & & & \\
\hline \multirow{6}{*}{$\begin{array}{l}\text { Domestic } \\
\text { Giving }\end{array}$} & CBR_1 & .785 & .617 & \multirow{6}{*}{$66.0 \%$} & \multirow{6}{*}{.773} & \multirow{6}{*}{.838} & \multirow{6}{*}{.000} \\
\hline & CBR_2 & .834 & .695 & & & & \\
\hline & CBR_6 & .811 & .658 & & & & \\
\hline & CBR_7 & .914 & .835 & & & & \\
\hline & CBR_8 & .868 & .753 & & & & \\
\hline & CBR_9 & .852 & .726 & & & & \\
\hline \multirow{7}{*}{ Ethnocentrism } & Ethno_2 & .722 & .742 & \multirow{7}{*}{$62.7 \%$} & \multirow{7}{*}{.841} & \multirow{7}{*}{.832} & \multirow{7}{*}{.000} \\
\hline & Ethno_4 & .712 & .782 & & & & \\
\hline & Ethno_9 & .703 & .780 & & & & \\
\hline & Ethno_12 & .674 & .693 & & & & \\
\hline & Ethno_13 & .812 & .770 & & & & \\
\hline & Ethno_14 & .760 & .708 & & & & \\
\hline & Ethno_15 & .778 & .753 & & & & \\
\hline
\end{tabular}

